\title{
Visible Light-Driven Decarboxylative Alkylation of Aldehydes via Electron Donor-Acceptor Complexes of Active Esters
}

\author{
Fang-Yuan Nie, Yi-Ping Cai and Qin-Hua Song* \\ Department of Chemistry, University of Science and Technology of China, Hefei 230026, P. R. China. \\ E-mail: qhsong@ustc.edu.cn
}

\section{Contents}

1. The luminescence spectrum of the light resource.

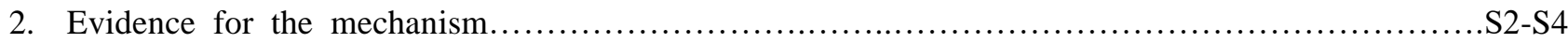

3. The Influence of irradiation time on reaction yield.......................................................

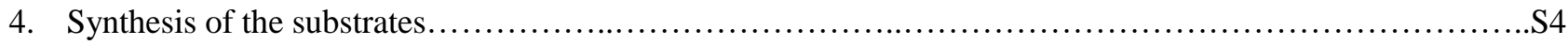

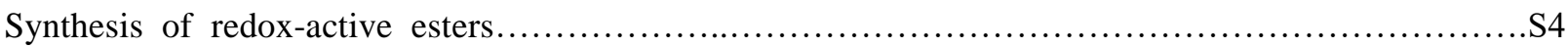

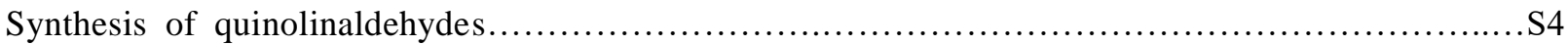

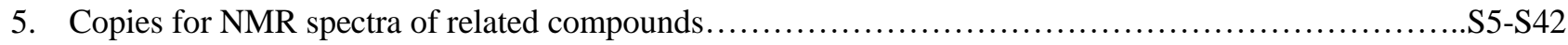




\section{The luminescence spectrum of the light resource}
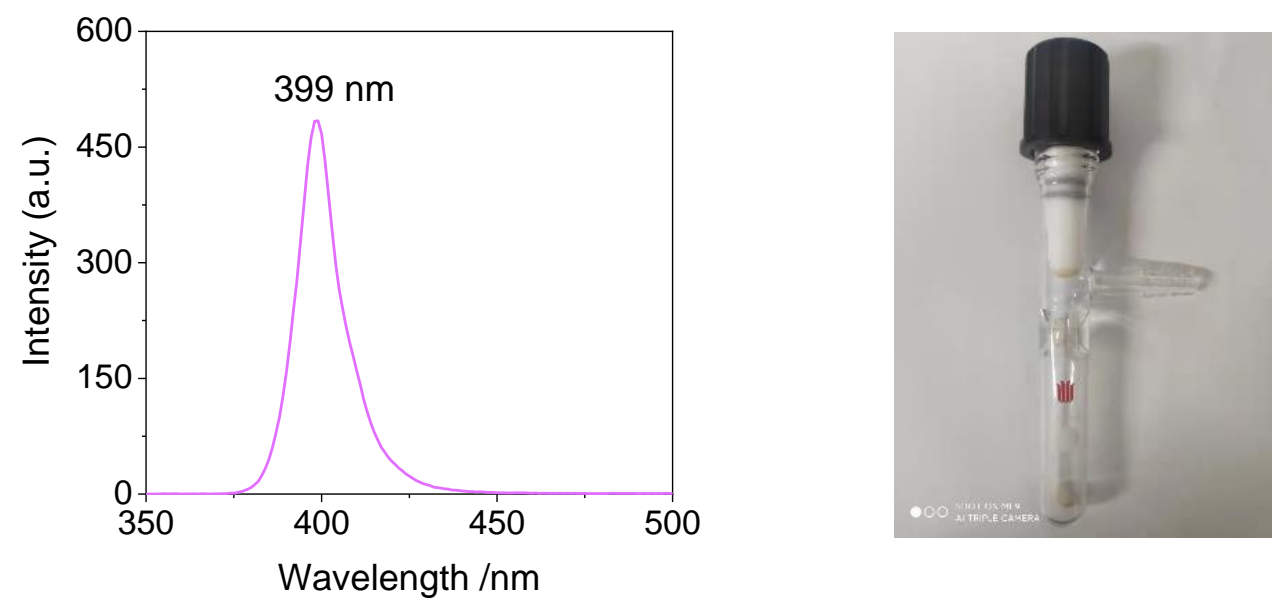

Figure S1. Left: The luminescence spectrum of the LED lamp in this work; Right: Photo of the Sclenk vessel for the photochemical reactions.

\section{Mechanistic studies}

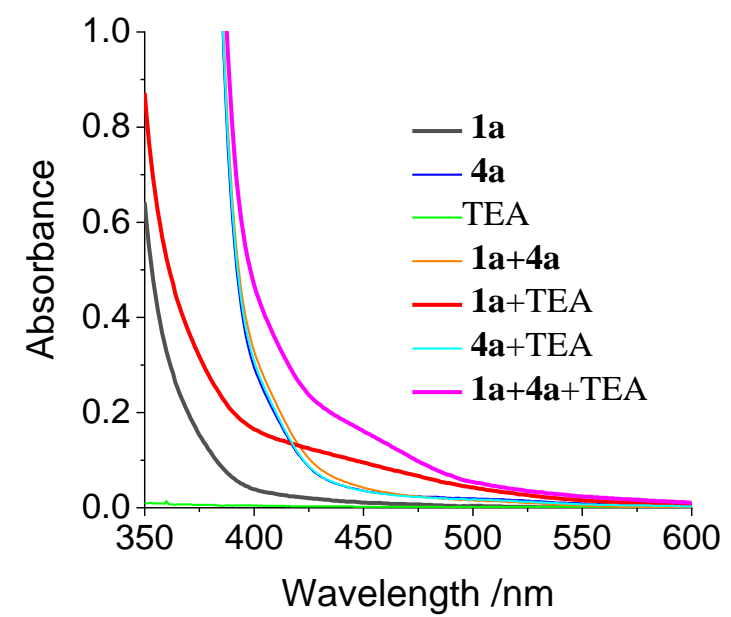

Figure S2. UV/vis absorption of DMSO solutions spectra of 1a $(0.1 \mathrm{M}), \mathbf{4 a}(0.15 \mathrm{M})$ and TEA $(0.06 \mathrm{M})$.

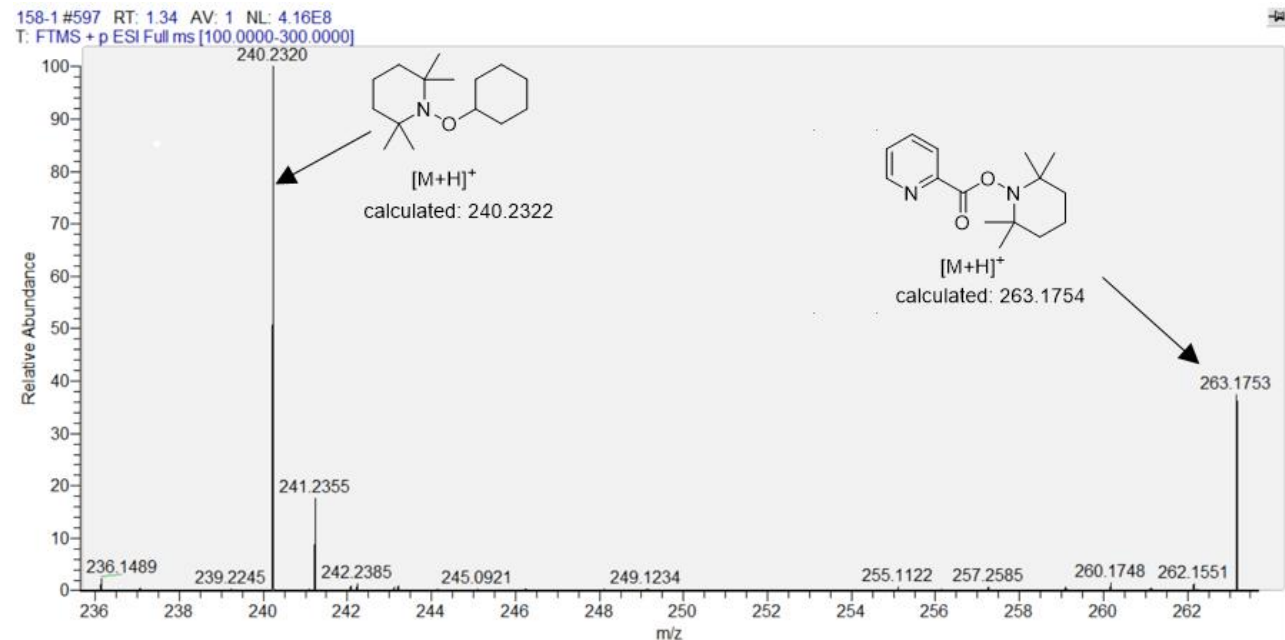


Figure S3. The evidence for the formation of 3af (an adduct of TEMPO and cyclohexyl radical) and 3ag (an adduct of TEMPO and 2-pyridinyl acyl radical).

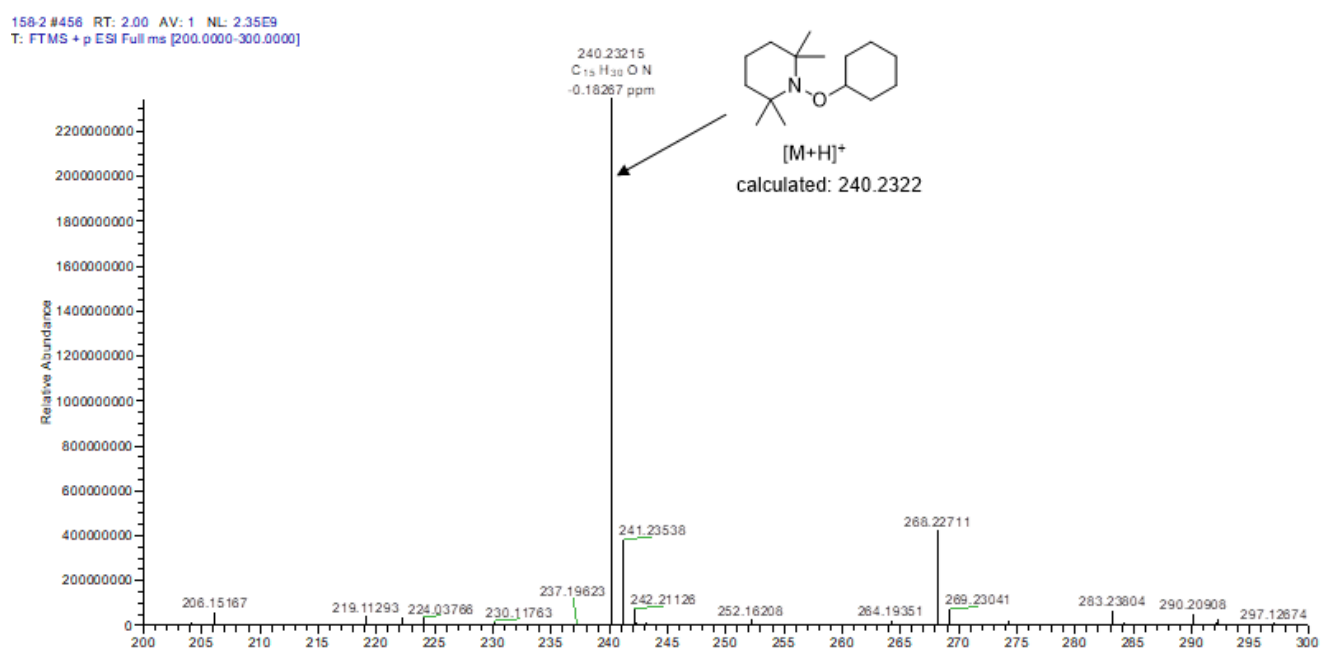

Figure S4. The evidence for the formation of 3af (an adduct of TEMPO and cyclohexyl radical).

\section{The Influence of irradiation time on reaction yield}
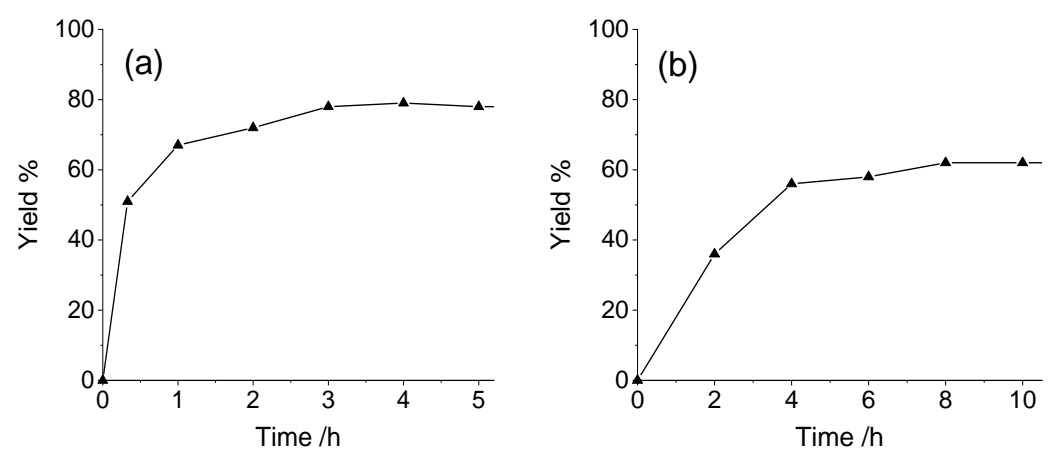

Figure S5. The yields of the reaction of 1a with $\mathbf{2 a}$ (left) or $\mathbf{4 a}$ (right) at different irradiation times.

\section{Synthesis of the substrates}

3.1 Synthesis of Redox-Active Esters (1a-1l)
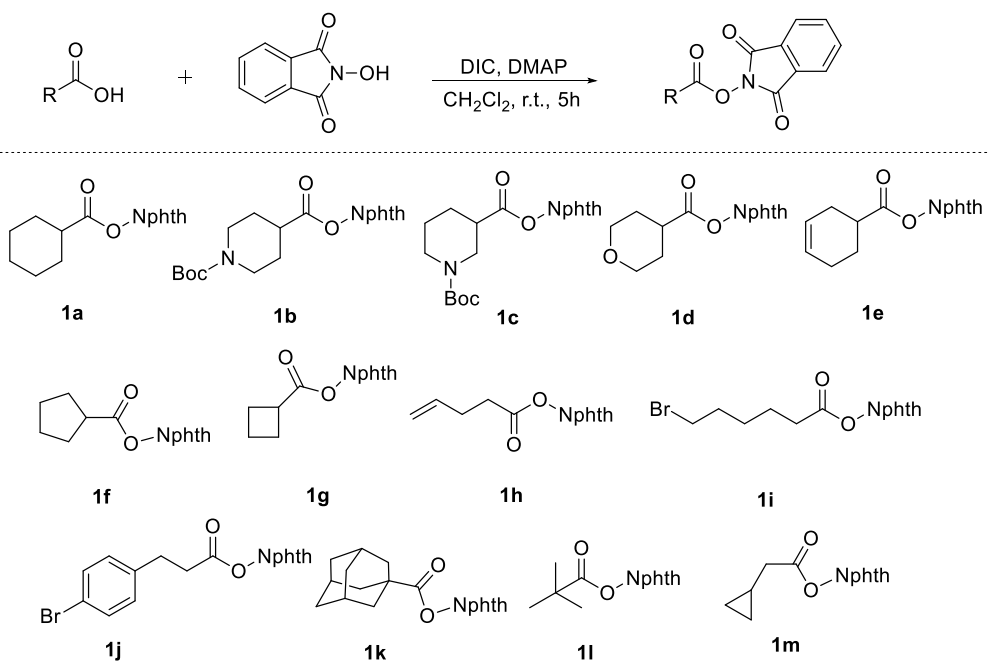
Chart S1. Synthesis route of the active esters and their structures

3.2 Synthesis of quinolinaldehyde $(\mathbf{4 a}-\mathbf{4 d})$

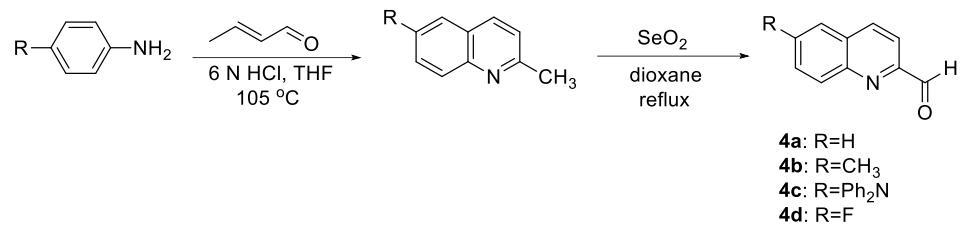

Scheme S1. Synthesis route of 2-quolinaldehydes and their structures 
5. Copies for NMR spectra of related compounds

${ }^{1} \mathrm{H}$ NMR of compound 3aa $\left(500 \mathrm{MHz}, \mathrm{CDCl}_{3}\right)$

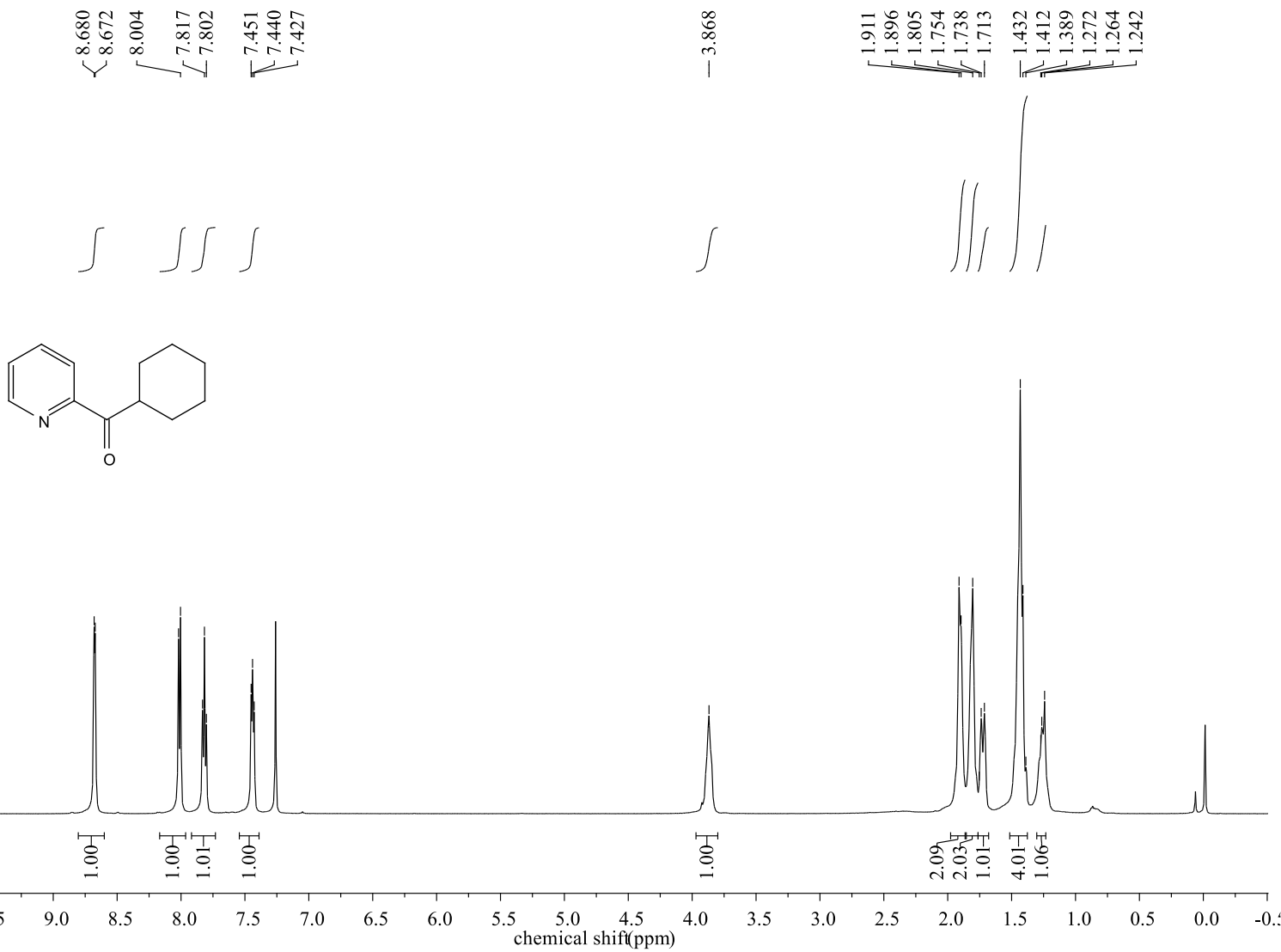

${ }^{13} \mathrm{C}\left\{{ }^{1} \mathrm{H}\right\}$ NMR of compound 3aa $\left(125 \mathrm{MHz}, \mathrm{CDCl}_{3}\right)$

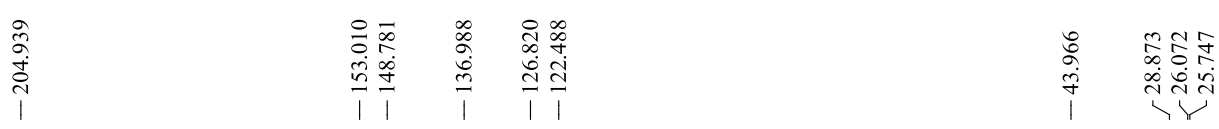<smiles>O=C(c1ccccn1)C1CCCCC1</smiles>

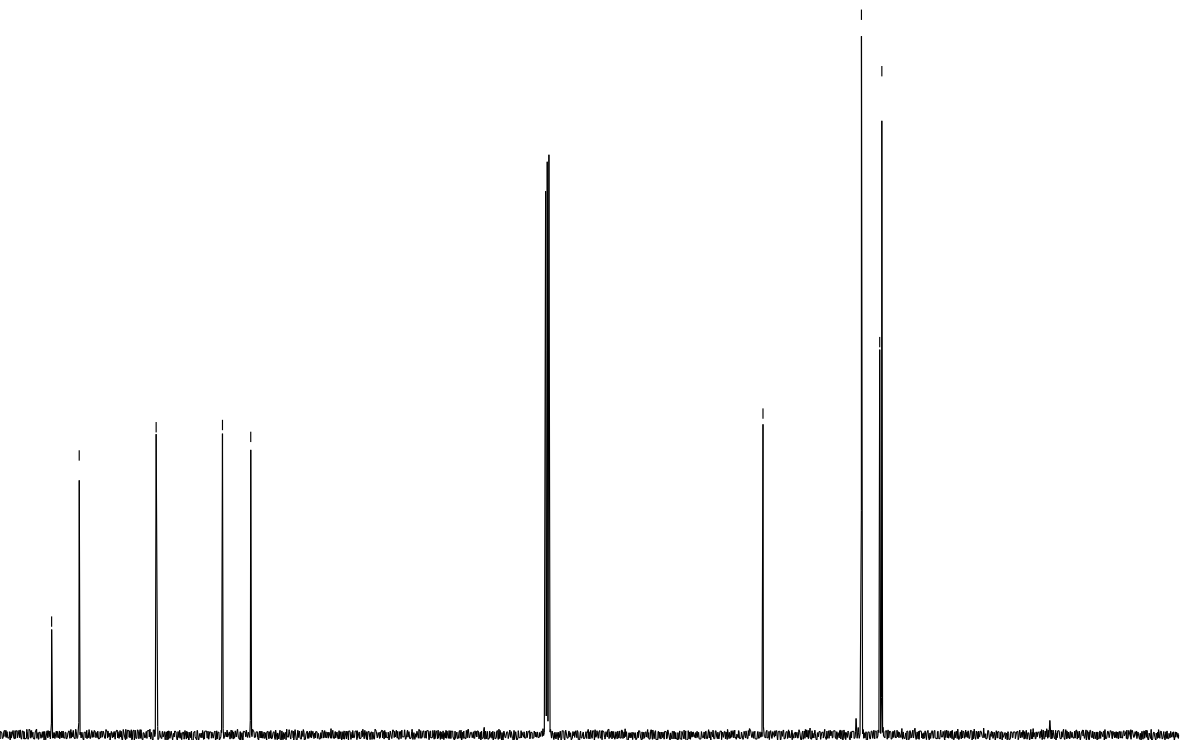

$\begin{array}{llllllllllllllllllllll}210 & 200 & 190 & 180 & 170 & 160 & 150 & 140 & 130 & 120 & \begin{array}{c}110 \\ \text { chemical shift(ppm) }\end{array} & \begin{array}{l}100 \\ \text { che }\end{array} & 70 & 60 & 50 & 40 & 30 & 20 & 10 & 0 & -10\end{array}$ 
${ }^{1} \mathrm{H}$ NMR of compound $3 \mathbf{a b}\left(500 \mathrm{MHz}, \mathrm{CDCl}_{3}\right)$

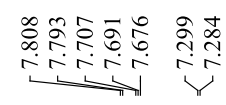

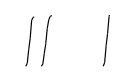

(l)
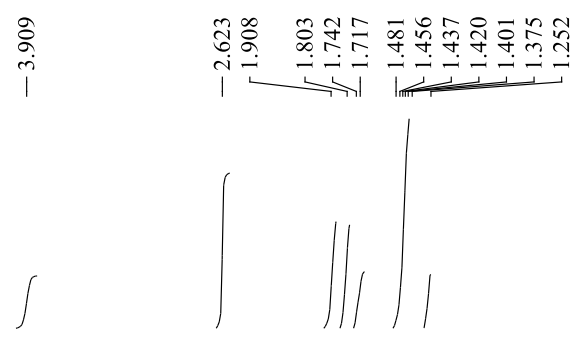

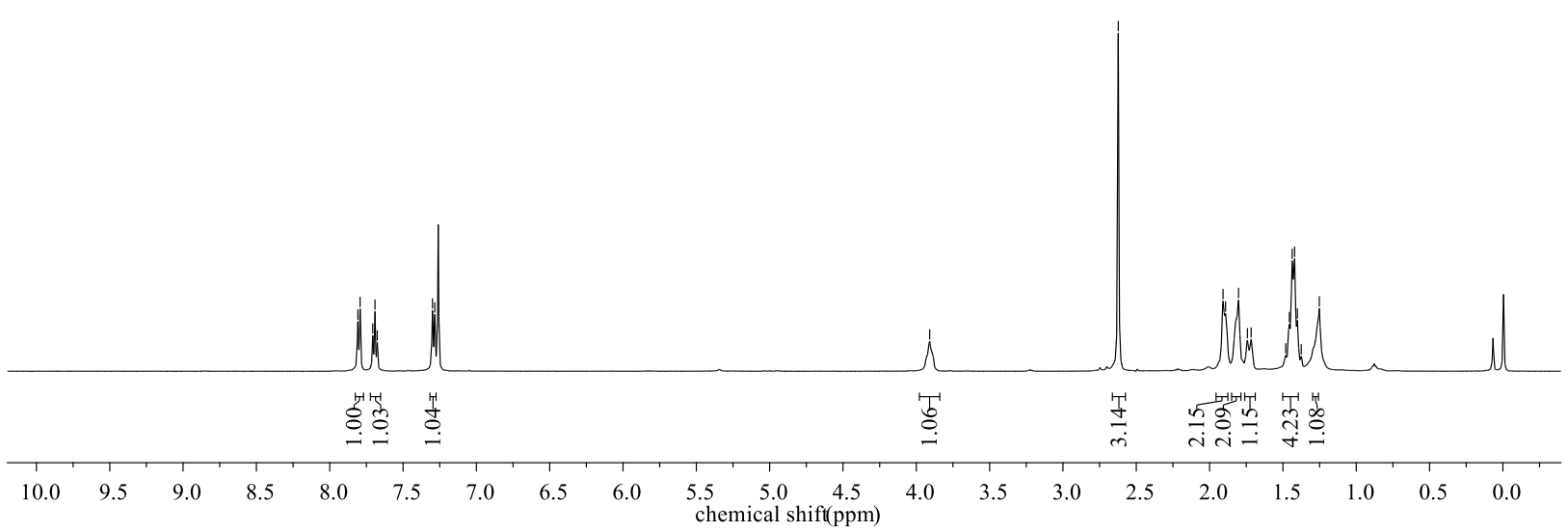

${ }^{13} \mathrm{C}\left\{{ }^{1} \mathrm{H}\right\}$ NMR of compound $3 \mathbf{a b}\left(125 \mathrm{MHz}, \mathrm{CDCl}_{3}\right)$

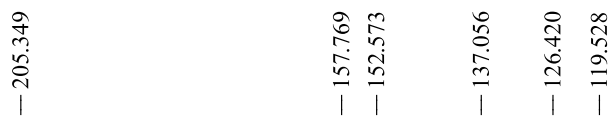

m.

।<smiles>Cc1cccc(C(=O)C2CCCCC2)n1</smiles>

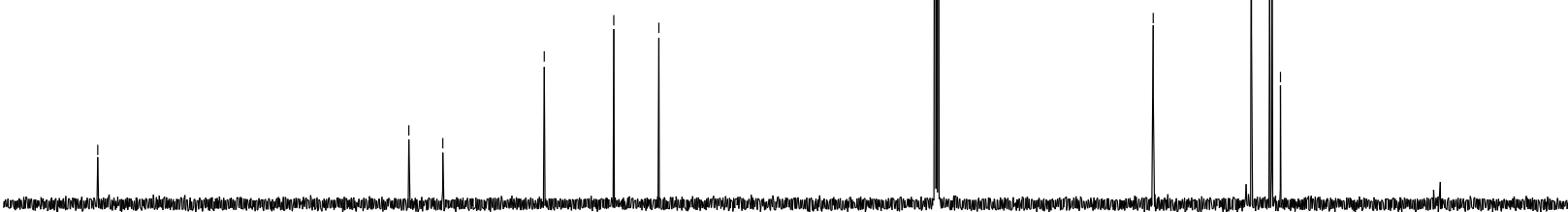

$\begin{array}{llllllllllllllllllllllll}210 & 200 & 190 & 180 & 170 & 160 & 150 & 140 & 130 & 120 & 110 & 100 & 90 & 80 & 70 & 60 & 50 & 40 & 30 & 20 & 10 & 0 & -10 & \end{array}$ 
${ }^{1} \mathrm{H}$ NMR of compound $3 \mathrm{ac}\left(500 \mathrm{MHz}, \mathrm{CDCl}_{3}\right)$
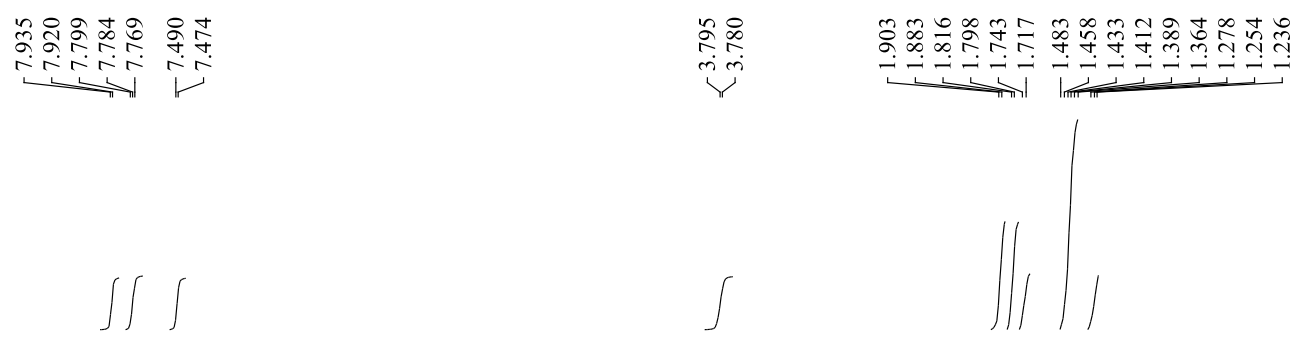<smiles>O=C(c1cccc(Cl)n1)C1CCCCC1</smiles>

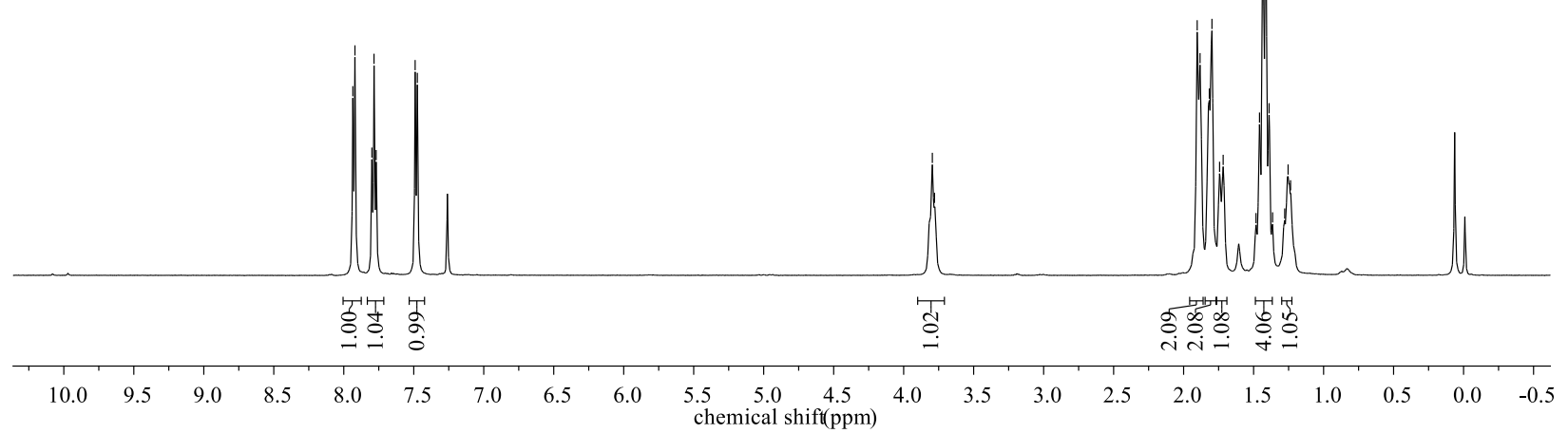

${ }^{13} \mathrm{C}\left\{{ }^{1} \mathrm{H}\right\}$ NMR of compound 3ac $\left(125 \mathrm{MHz}, \mathrm{CDCl}_{3}\right)$

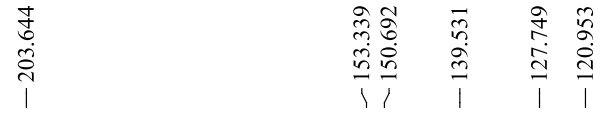<smiles>O=C(c1cccc(Cl)n1)C1CCCCC1</smiles> 
${ }^{1} \mathrm{H}$ NMR of compound $3 \mathbf{a d}\left(500 \mathrm{MHz}, \mathrm{CDCl}_{3}\right.$ )

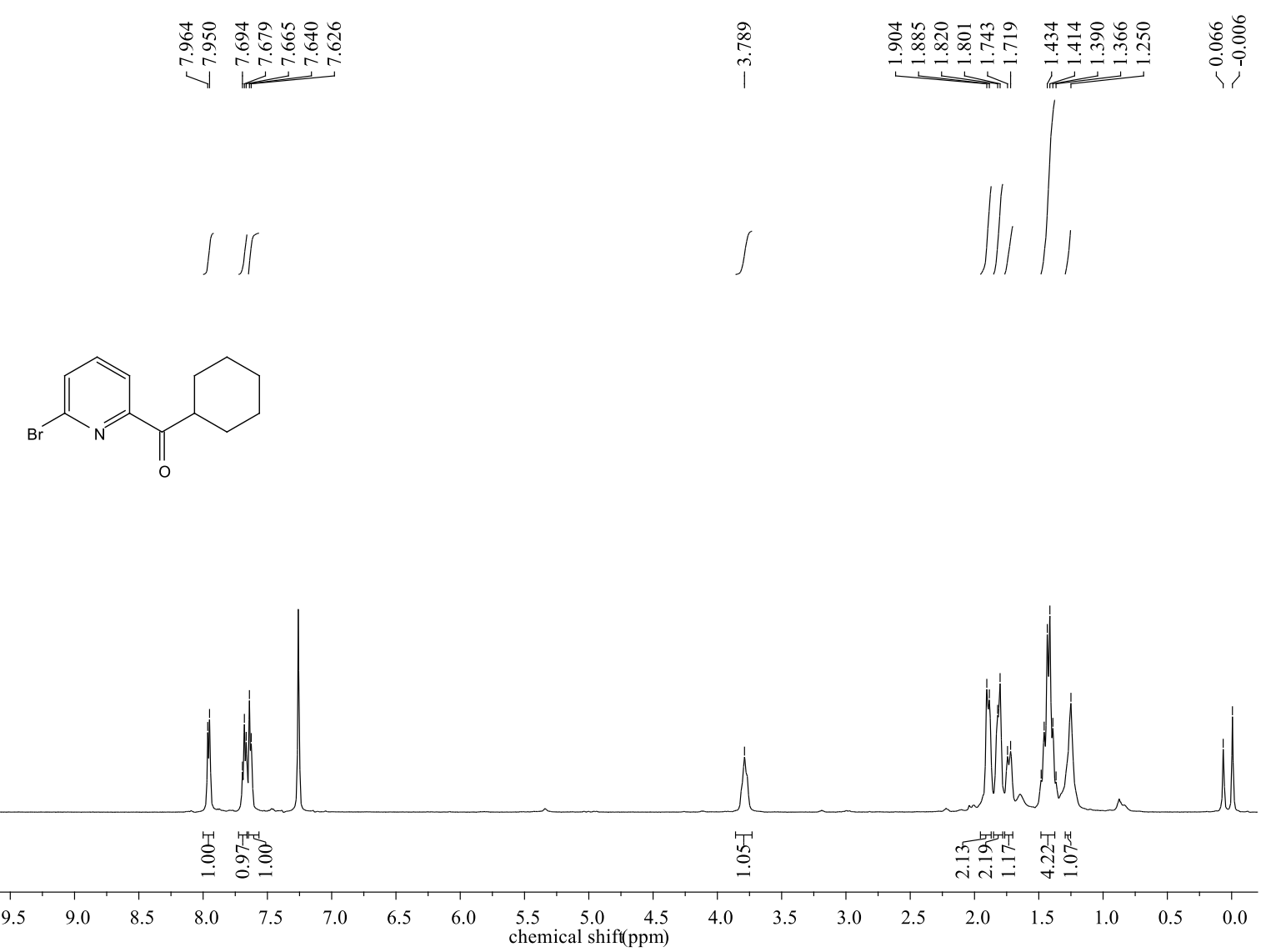

${ }^{13} \mathrm{C}\left\{{ }^{1} \mathrm{H}\right\}$ NMR of compound $\mathbf{3 a d}\left(125 \mathrm{MHz}, \mathrm{CDCl}_{3}\right)$

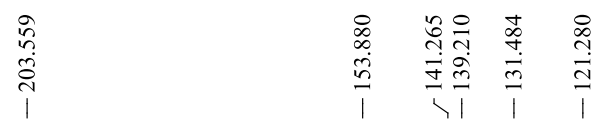

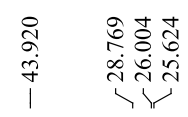<smiles>O=C(c1cccc(Br)n1)C1CCCCC1</smiles> 
${ }^{1} \mathrm{H}$ NMR of compound 3ae $\left(500 \mathrm{MHz}, \mathrm{CDCl}_{3}\right)$
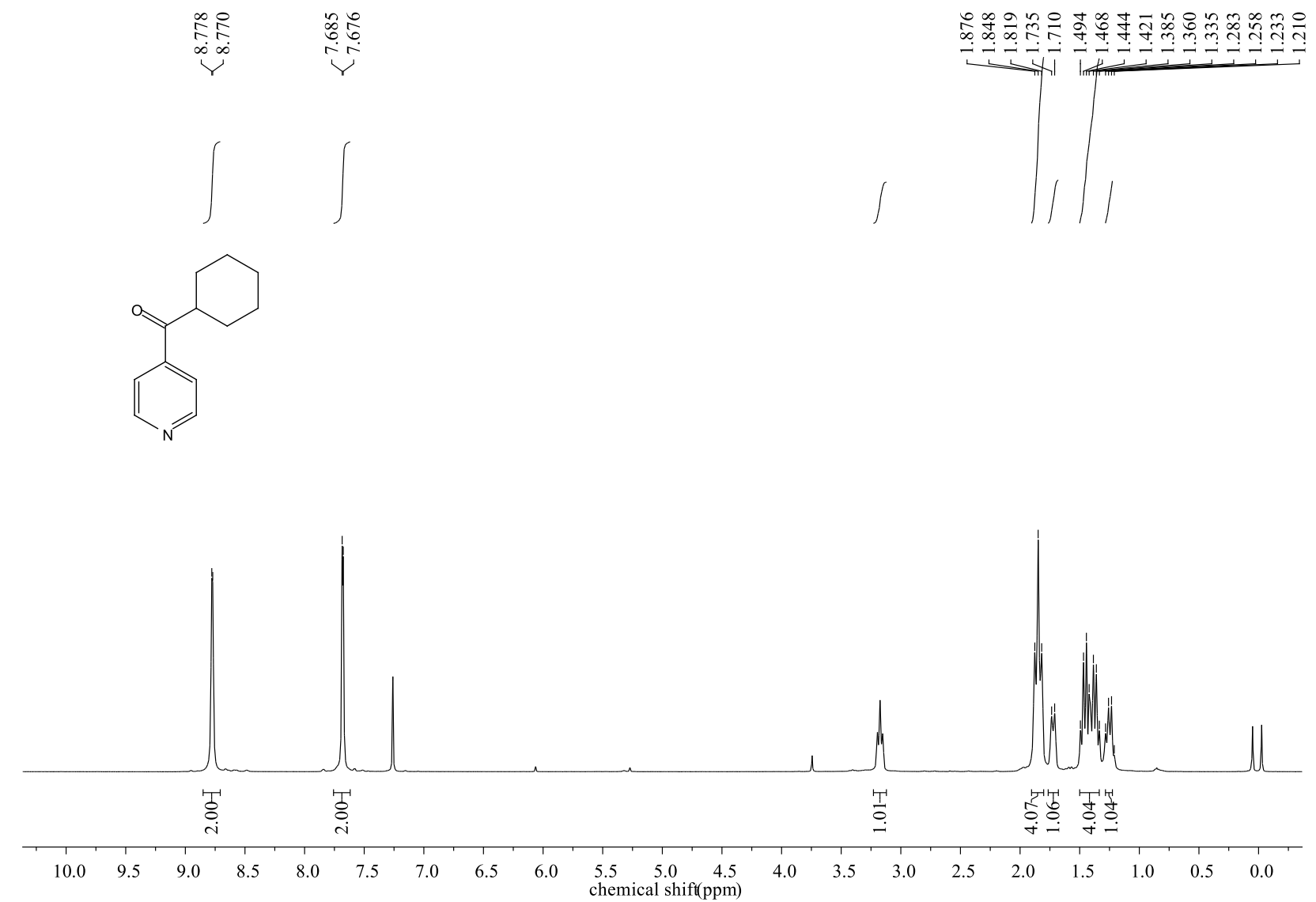

${ }^{13} \mathrm{C}\left\{{ }^{1} \mathrm{H}\right\}$ NMR of compound 3ae $\left(125 \mathrm{MHz}, \mathrm{CDCl}_{3}\right)$

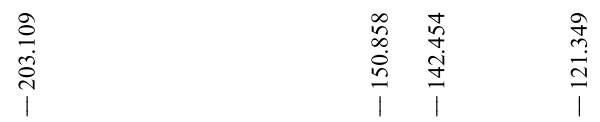<smiles>O=C(c1ccncc1)C1CCCCC1</smiles>

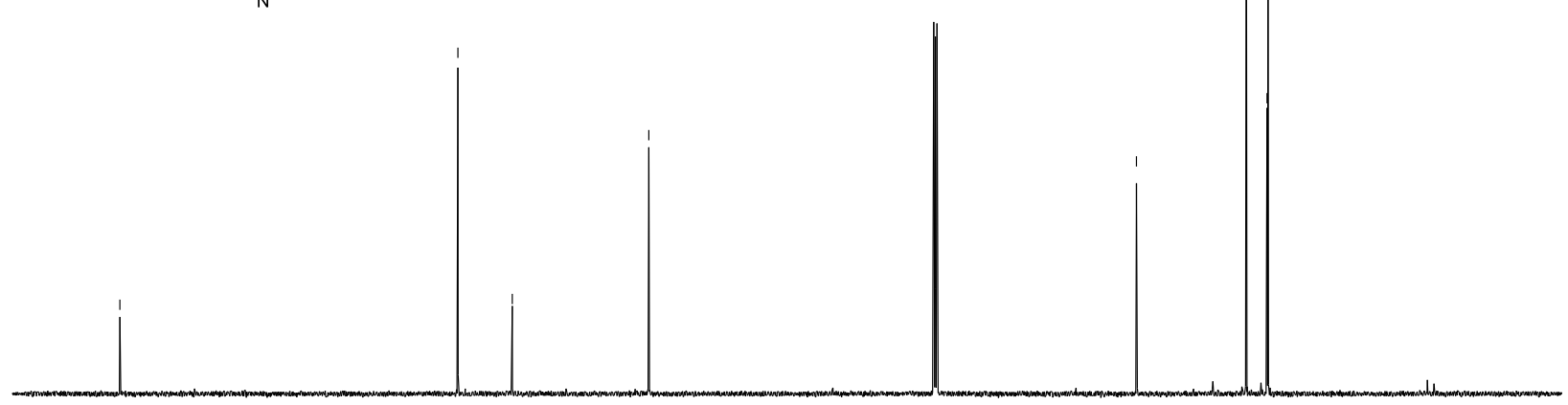

$\begin{array}{lllllllllllllllllllll}210 & 200 & 190 & 180 & 170 & 160 & 150 & 140 & 130 & 120 & \begin{array}{c}110 \\ \text { chemical shift(ppm) }\end{array} & 80 & 70 & 60 & 50 & 40 & 30 & 20 & 10 & 0 & -10\end{array}$ 
${ }^{1} \mathrm{H}$ NMR of compound $\mathbf{3 b a}\left(500 \mathrm{MHz}, \mathrm{CDCl}_{3}\right)$

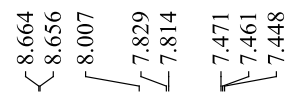

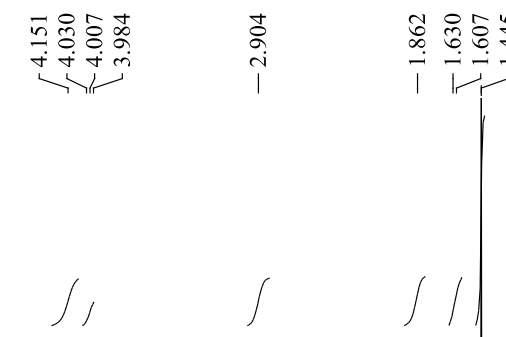

$\overbrace{0}^{(}$

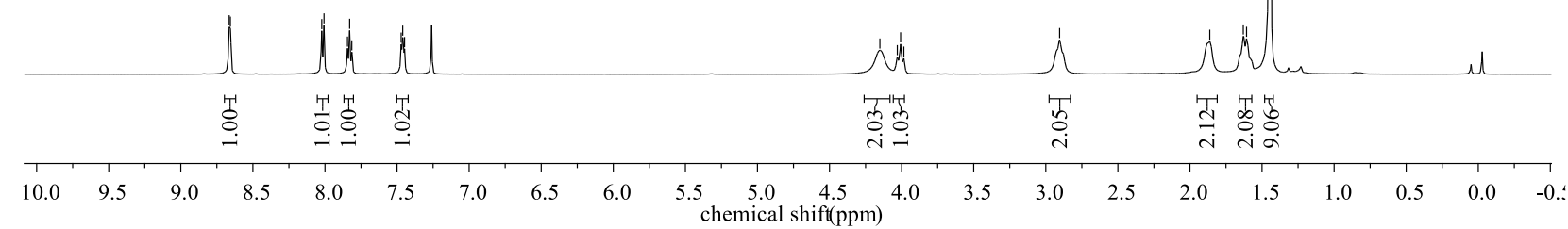

${ }^{13} \mathrm{C}\left\{{ }^{1} \mathrm{H}\right\}$ NMR of compound $\mathbf{3 b a}\left(125 \mathrm{MHz}, \mathrm{CDCl}_{3}\right)$

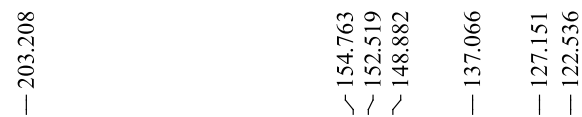<smiles>CC(C)(C)OC(=O)N1CCC(C(=O)c2ccccn2)CC1</smiles>

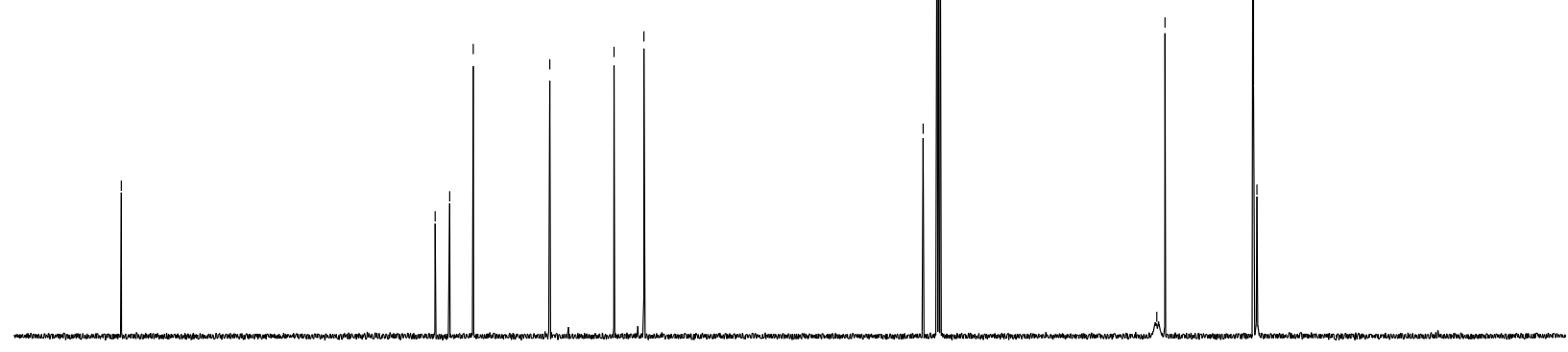

$\begin{array}{llllllllllllllllllllll}210 & 200 & 190 & 180 & 170 & 160 & 150 & 140 & 130 & 120 & \begin{array}{c}110 \\ \text { chemical shift(ppm) }\end{array} & \begin{array}{l}100 \\ \text { chem }\end{array} & 70 & 60 & 50 & 40 & 30 & 20 & 10 & 0 & -10 & \end{array}$ 
${ }^{1} \mathrm{H}$ NMR of compound $\mathbf{3 b f}\left(500 \mathrm{MHz}, \mathrm{CDCl}_{3}\right)$

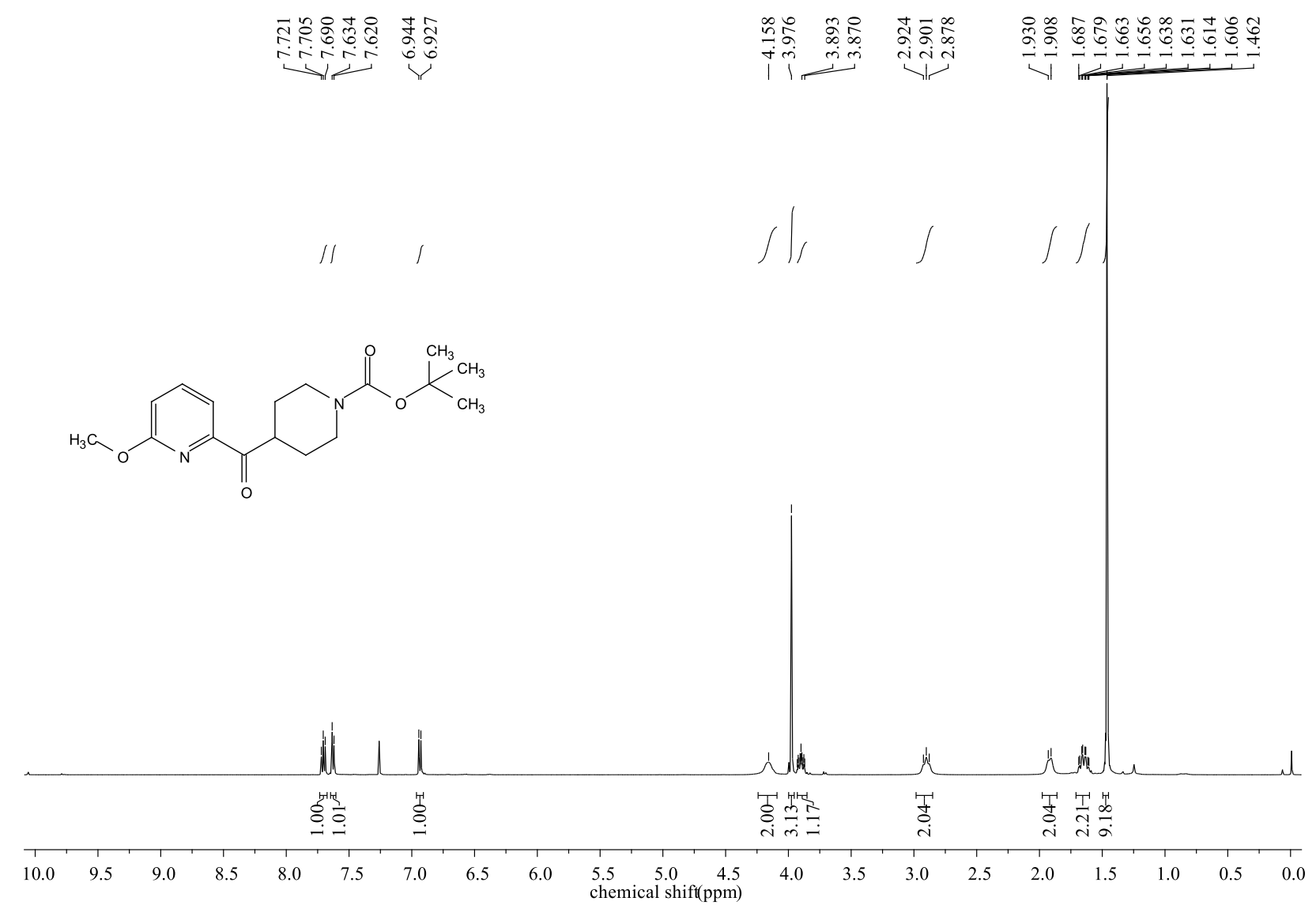

${ }^{13} \mathrm{C}\left\{{ }^{1} \mathrm{H}\right\}$ NMR of compound $\mathbf{3 b f}\left(125 \mathrm{MHz}, \mathrm{CDCl}_{3}\right)$

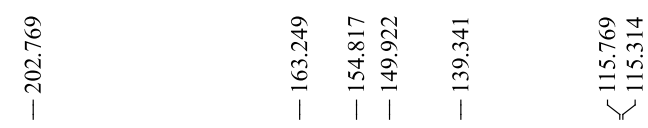<smiles>COc1cccc(C(=O)C2CCN(C(=O)OC(C)(C)C)CC2)n1</smiles>

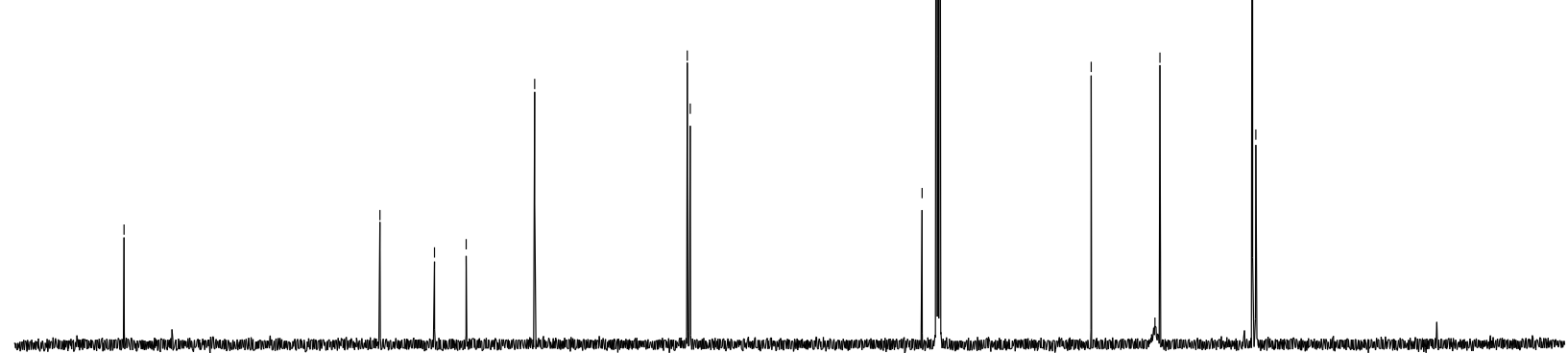

$\begin{array}{lllllllllllllllllllllll}210 & 200 & 190 & 180 & 170 & 160 & 150 & 140 & 130 & 120 & \begin{array}{c}110 \\ \text { chemical shift(ppm) }\end{array} & 80 & 70 & 60 & 50 & 40 & 30 & 20 & 10 & 0 & -10\end{array}$ 
${ }^{1} \mathrm{H}$ NMR of compound 3ca $\left(500 \mathrm{MHz}, \mathrm{CDCl}_{3}\right)$

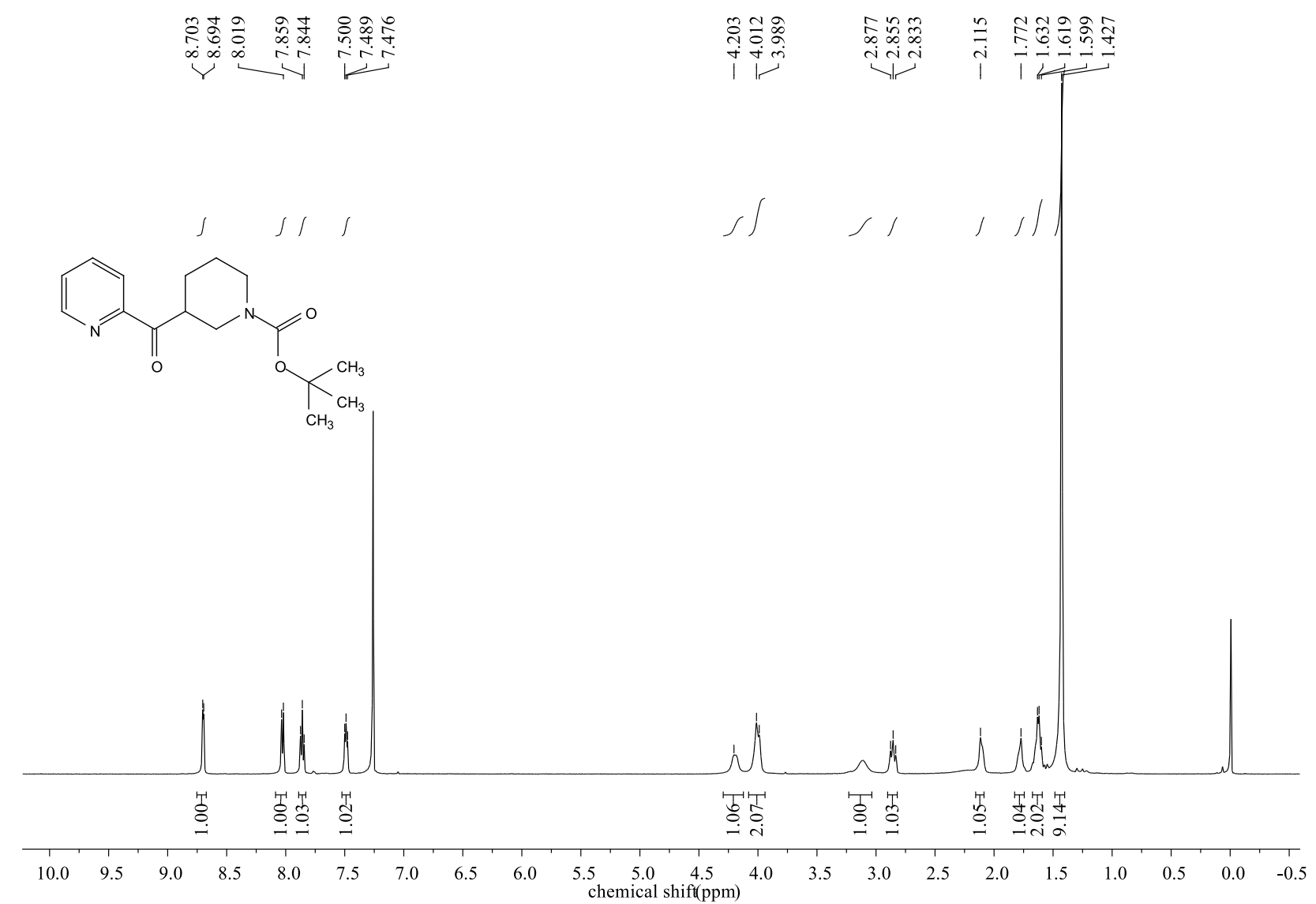

${ }^{13} \mathrm{C}\left\{{ }^{1} \mathrm{H}\right\}$ NMR of compound $3 \mathbf{c a}\left(125 \mathrm{MHz}, \mathrm{CDCl}_{3}\right)$

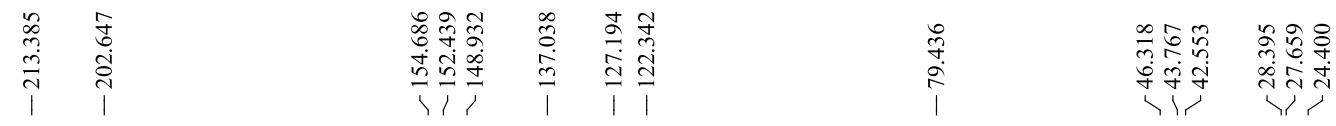<smiles>CC(C)(C)OC(=O)N1CCCC(C(=O)c2ccccn2)C1</smiles>

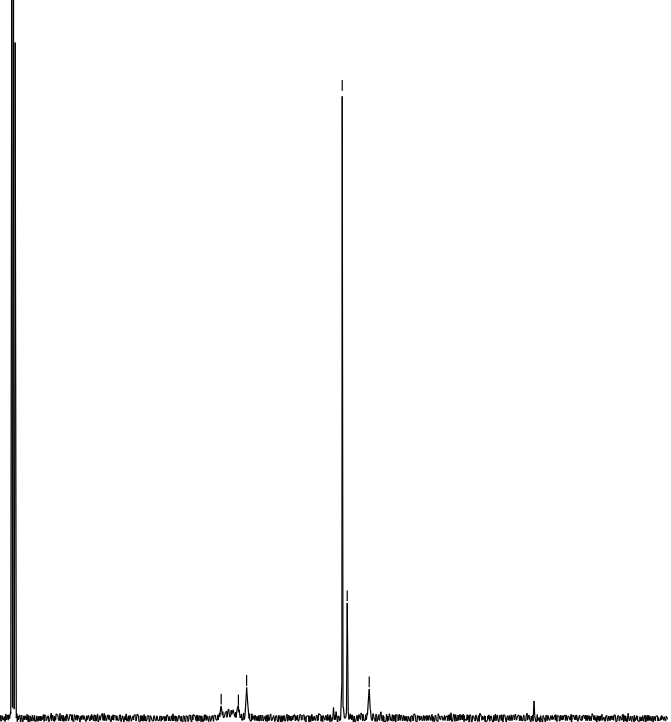

$\begin{array}{llllllllllllllllllllllll}210 & 200 & 190 & 180 & 170 & 160 & 150 & 140 & 130 & 120 & \begin{array}{c}110 \\ \text { chemical shift(ppm) }\end{array} & 80 & 70 & 60 & 50 & 40 & 30 & 20 & 10 & 0 & -10 & \end{array}$ 
${ }^{1} \mathrm{H}$ NMR of compound 3da $\left(500 \mathrm{MHz}, \mathrm{CDCl}_{3}\right)$

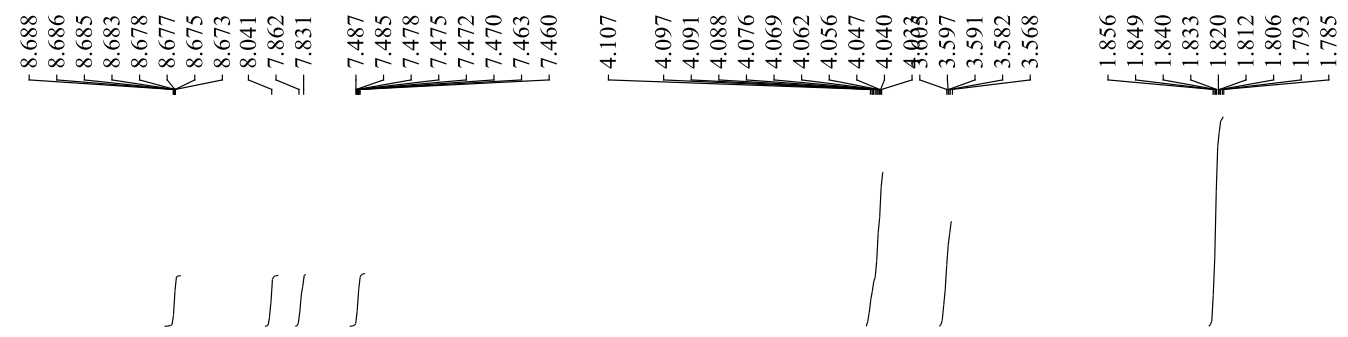<smiles>O=C(c1ccccn1)C1CCOCC1</smiles>

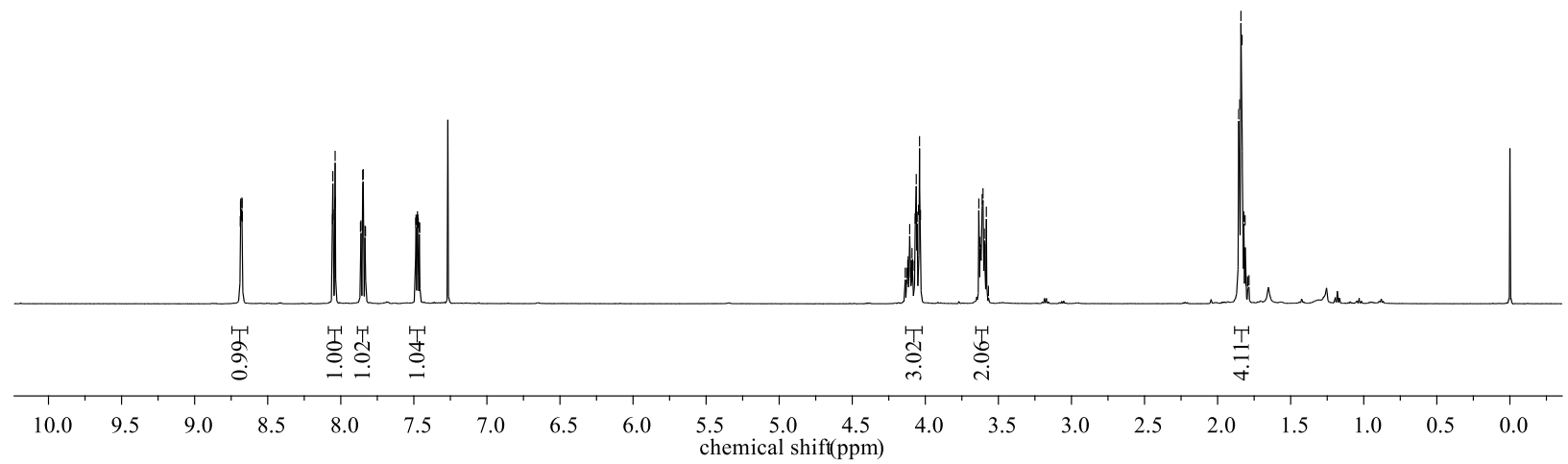

${ }^{13} \mathrm{C}\left\{{ }^{1} \mathrm{H}\right\}$ NMR of compound $\mathbf{3 d a}\left(125 \mathrm{MHz}, \mathrm{CDCl}_{3}\right)$
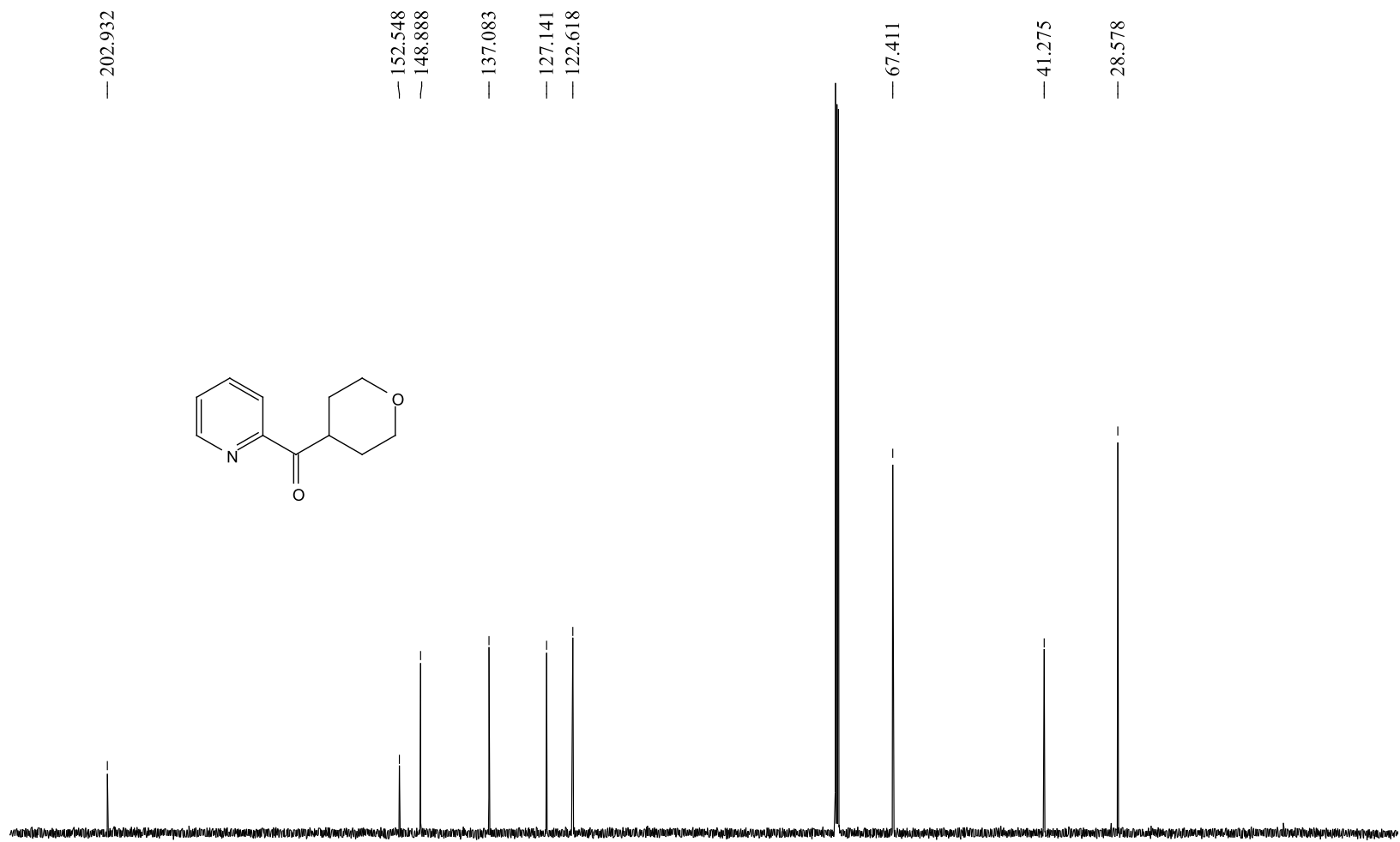

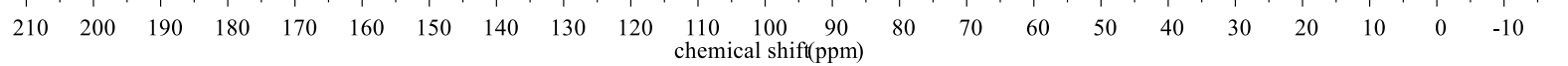


${ }^{1} \mathrm{H}$ NMR of compound 3ea $\left(400 \mathrm{MHz}, \mathrm{CDCl}_{3}\right)$

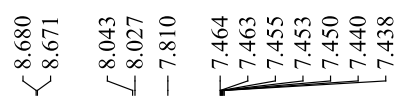

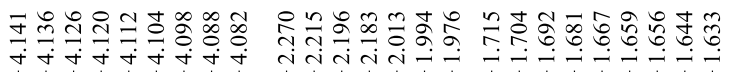
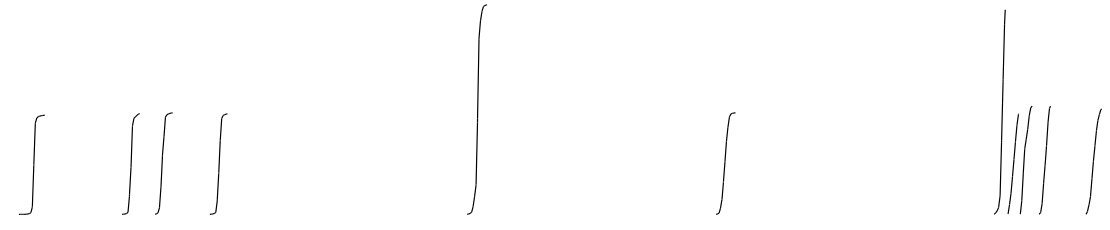<smiles>O=C(c1ccccn1)C1CC=CCC1</smiles>

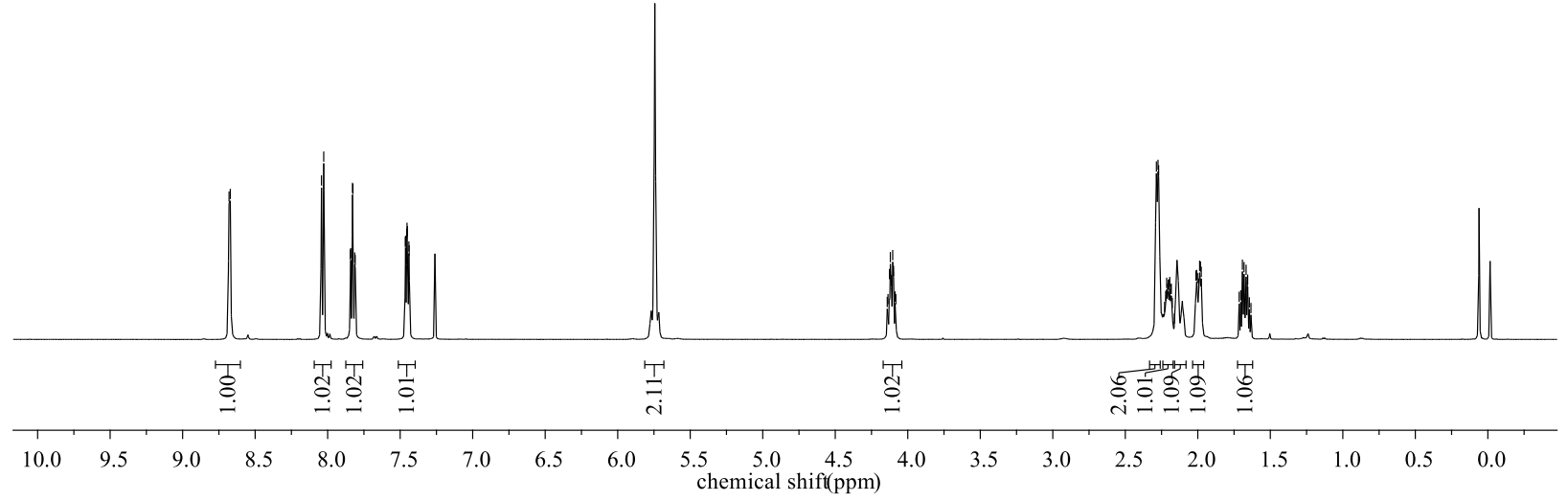

${ }^{13} \mathrm{C}\left\{{ }^{1} \mathrm{H}\right\}$ NMR of compound 3ea $\left(125 \mathrm{MHz}, \mathrm{CDCl}_{3}\right)$

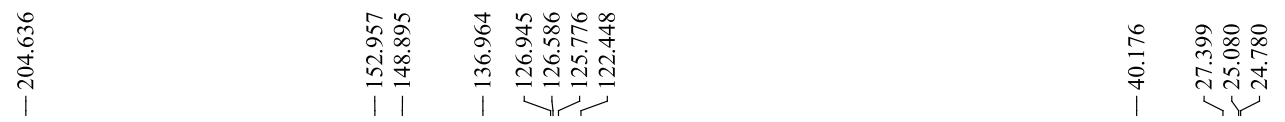<smiles>O=C(c1ccccn1)C1CC=CCC1</smiles>

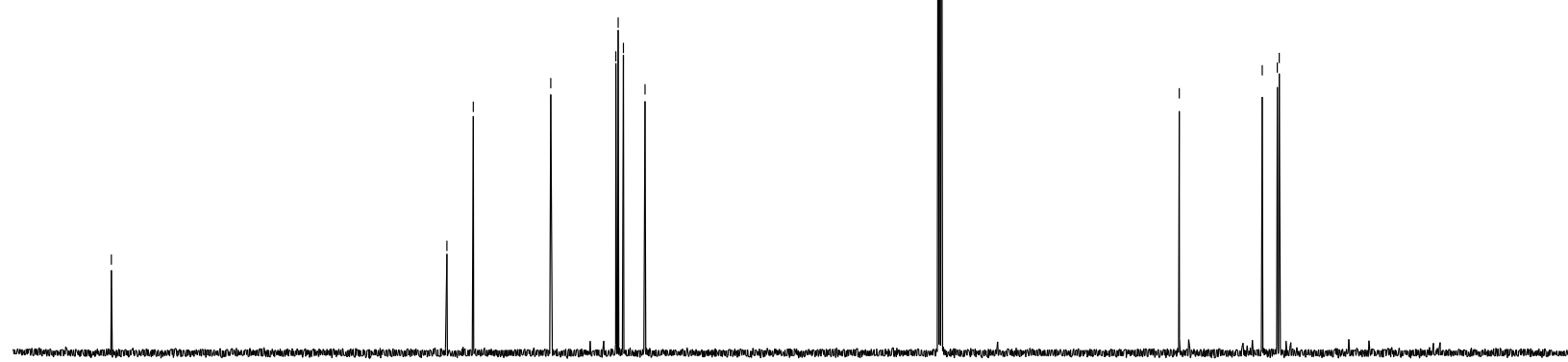

$\begin{array}{llllllllllllllllllllll}210 & 200 & 190 & 180 & 170 & 160 & 150 & 140 & 130 & 120 & \begin{array}{c}110 \\ \text { chemical shift(ppm) }\end{array} & 80 & 70 & 60 & 50 & 40 & 30 & 20 & 10 & 0 & -10 & \end{array}$ 
${ }^{1} \mathrm{H}$ NMR of compound $\mathbf{3 f a}\left(500 \mathrm{MHz}, \mathrm{CDCl}_{3}\right)$

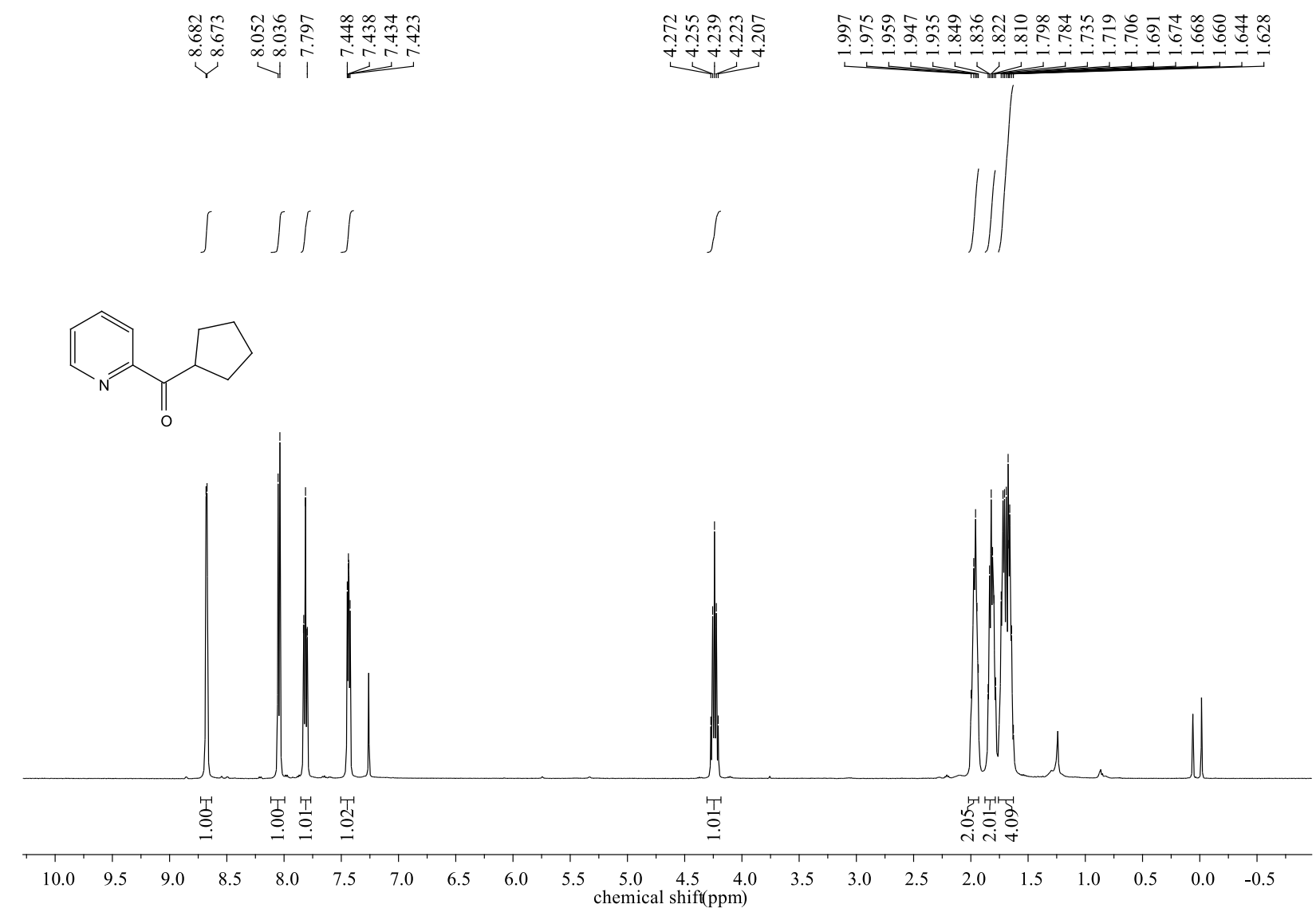

${ }^{13} \mathrm{C}\left\{{ }^{1} \mathrm{H}\right\}$ NMR of compound $3 \mathbf{f a}\left(125 \mathrm{MHz}, \mathrm{CDCl}_{3}\right)$

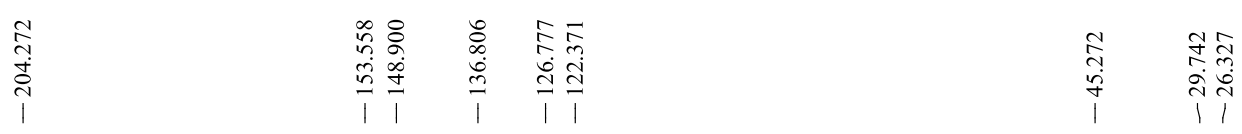<smiles>O=C(c1ccccn1)C1CCCC1</smiles>

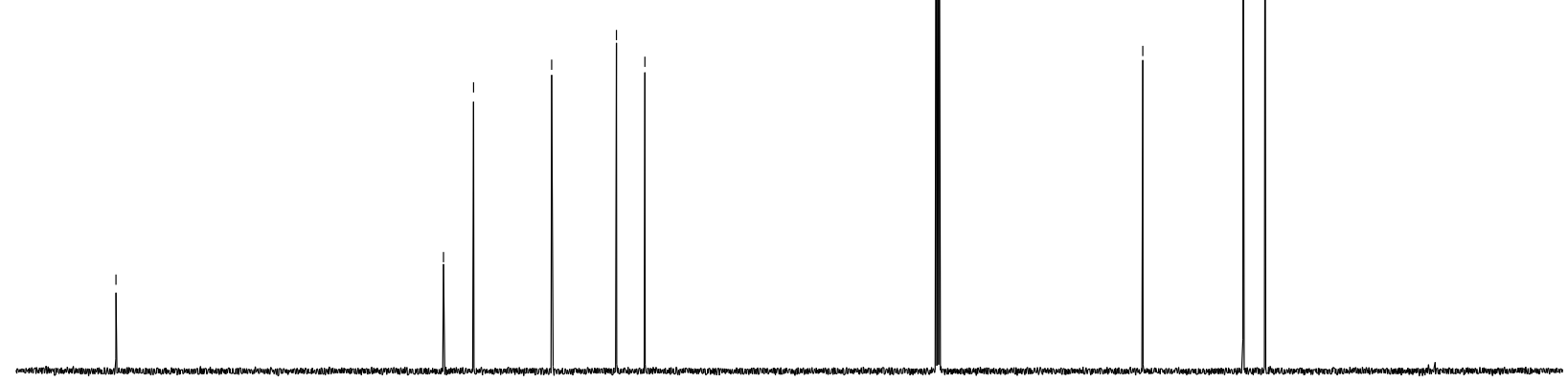

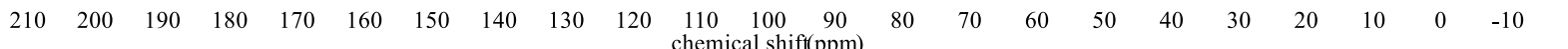


${ }^{1} \mathrm{H}$ NMR of compound 3ga $\left(500 \mathrm{MHz}, \mathrm{CDCl}_{3}\right)$

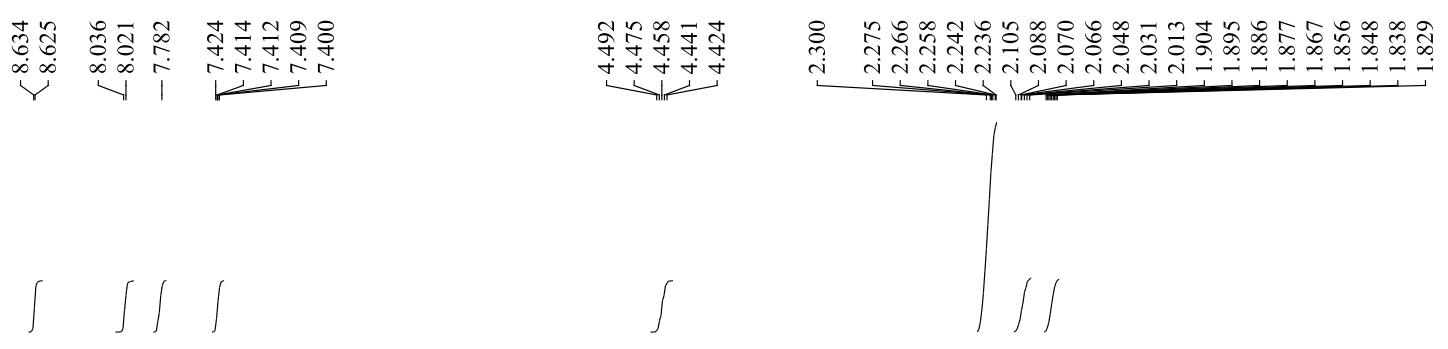<smiles>O=C(c1ccccn1)C1CCC1</smiles>

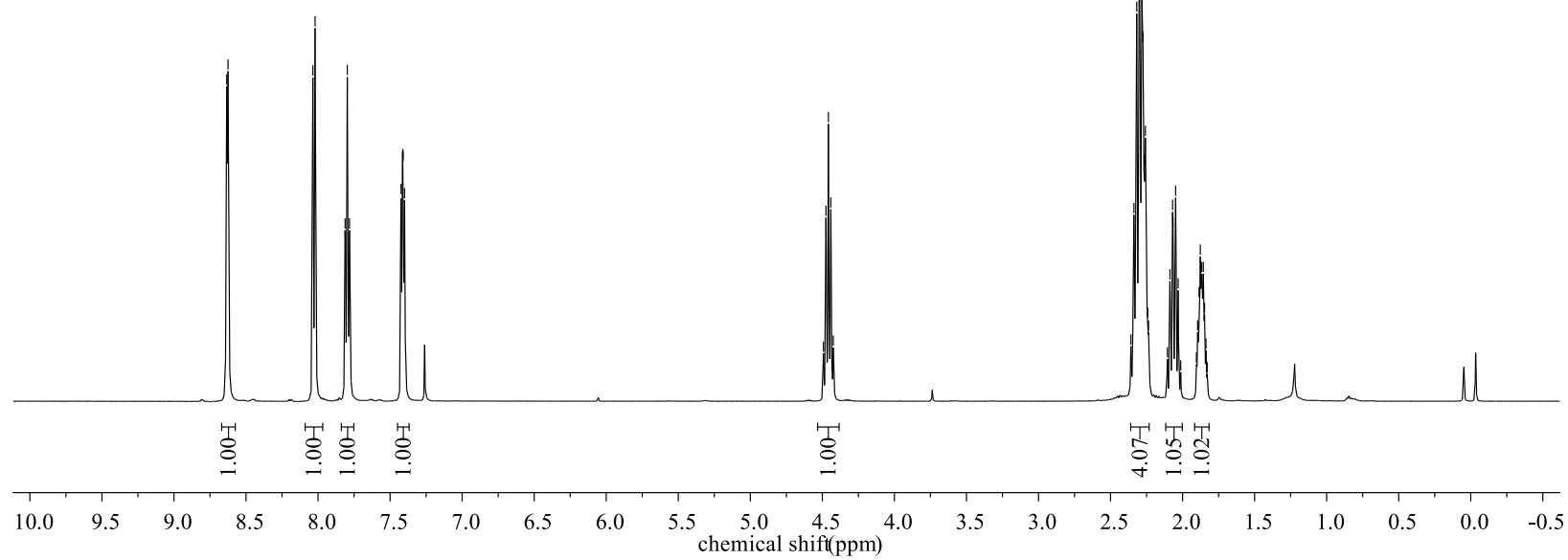

${ }^{13} \mathrm{C}\left\{{ }^{1} \mathrm{H}\right\}$ NMR of compound 3ga (125 MHz, $\left.\mathrm{CDCl}_{3}\right)$

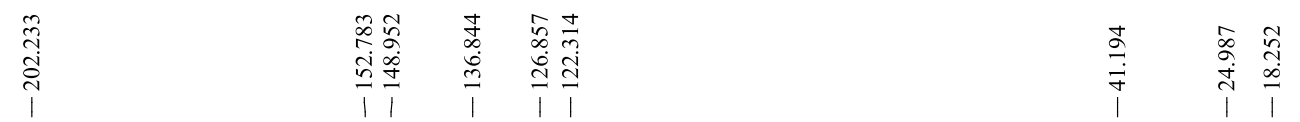<smiles>O=C(c1ccccn1)C1CCC1</smiles>

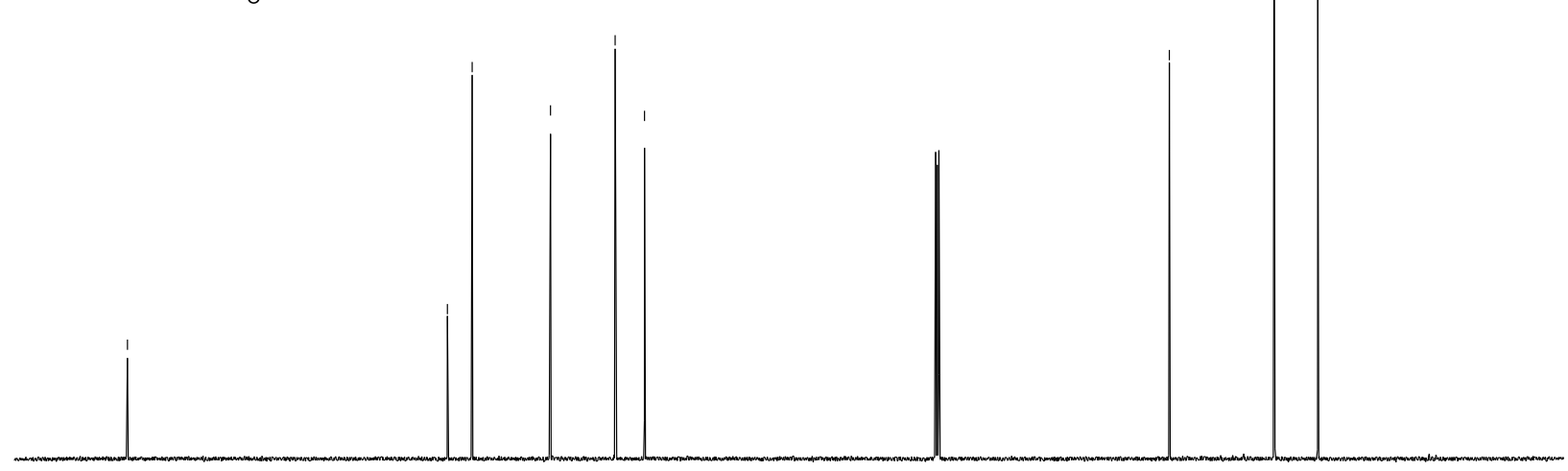

$\begin{array}{lllllllllllllllllllllll}210 & 200 & 190 & 180 & 170 & 160 & 150 & 140 & 130 & 120 & 110 & 100 & 90 & 80 & 70 & 60 & 50 & 40 & 30 & 20 & 10 & 0 & -10\end{array}$ 
${ }^{1} \mathrm{H}$ NMR of compound 3ha $\left(500 \mathrm{MHz}, \mathrm{CDCl}_{3}\right)$
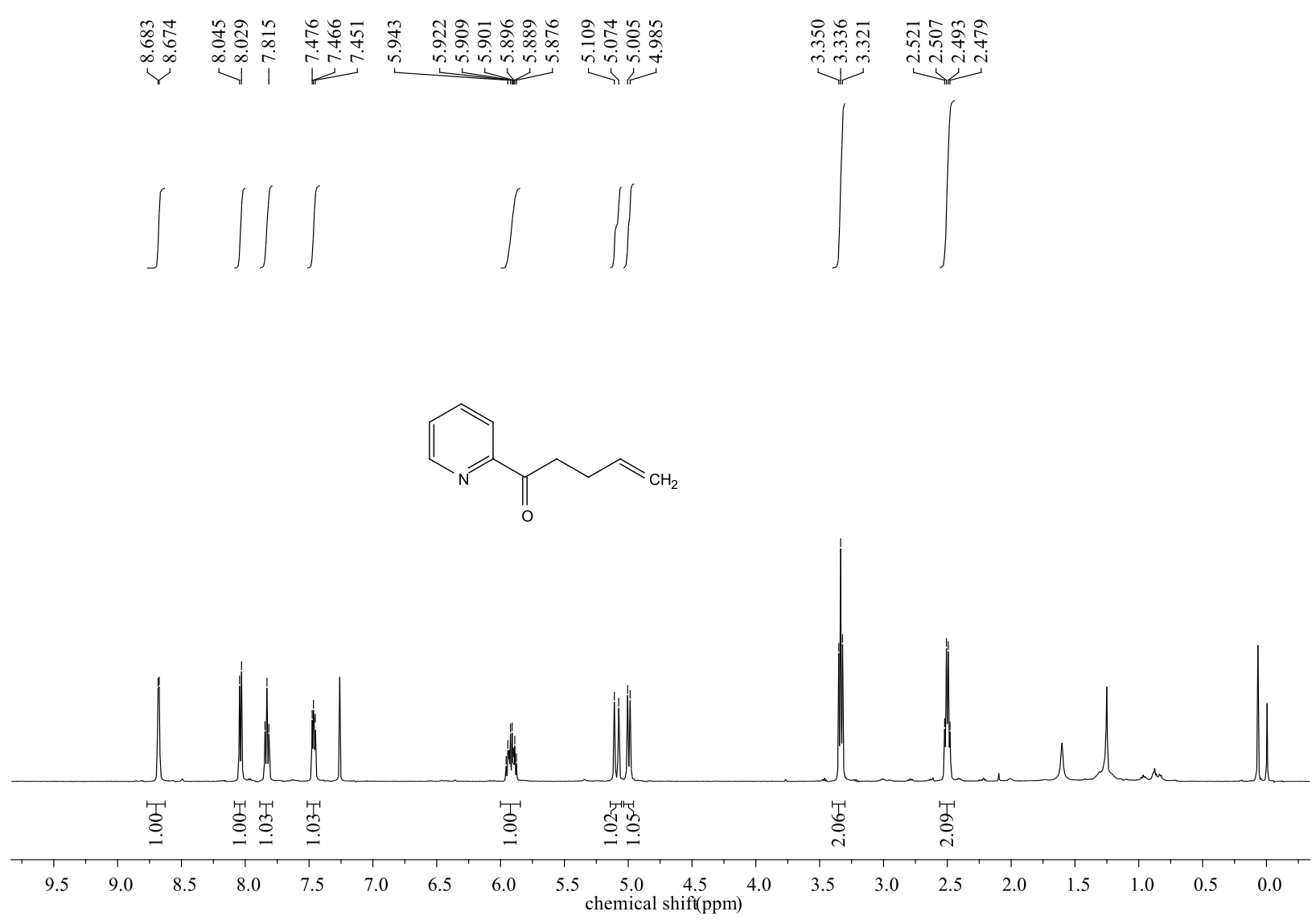

${ }^{13} \mathrm{C}\left\{{ }^{1} \mathrm{H}\right\}$ NMR of compound 3ha $\left(125 \mathrm{MHz}, \mathrm{CDCl}_{3}\right)$

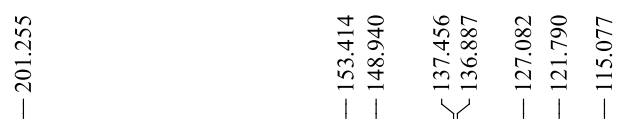

$\begin{array}{ll}0 & \infty \\ \infty & 0 \\ 0 & 0 \\ 0 & i\end{array}$<smiles>C=CCCC(=O)c1ccccn1</smiles>

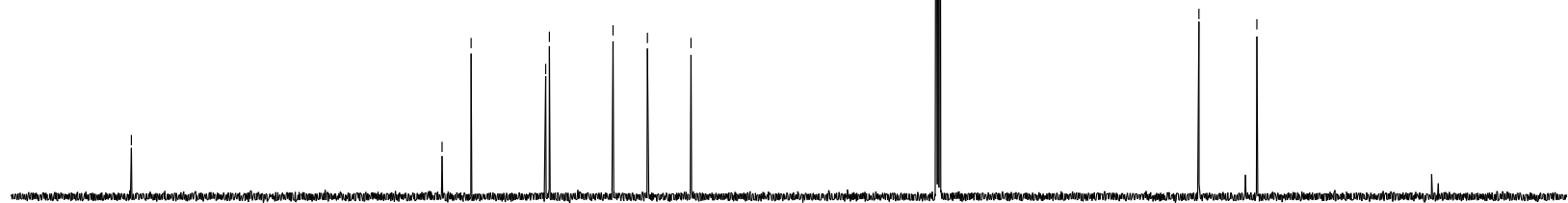

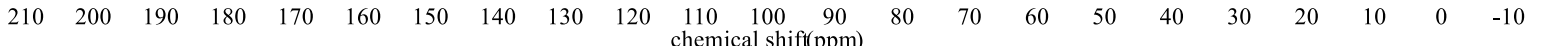


${ }^{1} \mathrm{H}$ NMR of compound 3ia (400 MHz, $\mathrm{CDCl}_{3}$ )
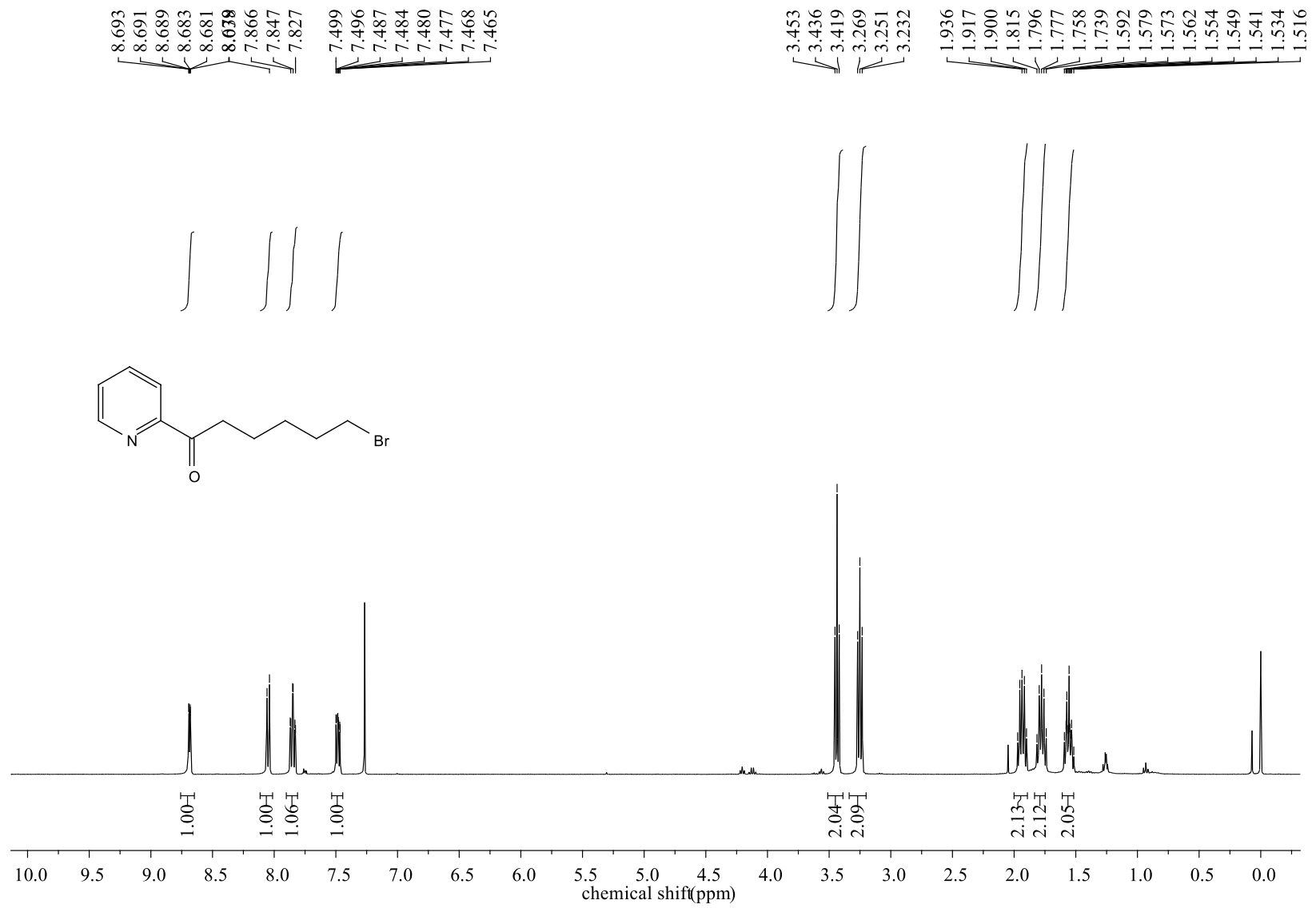

${ }^{13} \mathrm{C}\left\{{ }^{1} \mathrm{H}\right\}$ NMR of compound 3ia $\left(125 \mathrm{MHz}, \mathrm{CDCl}_{3}\right)$
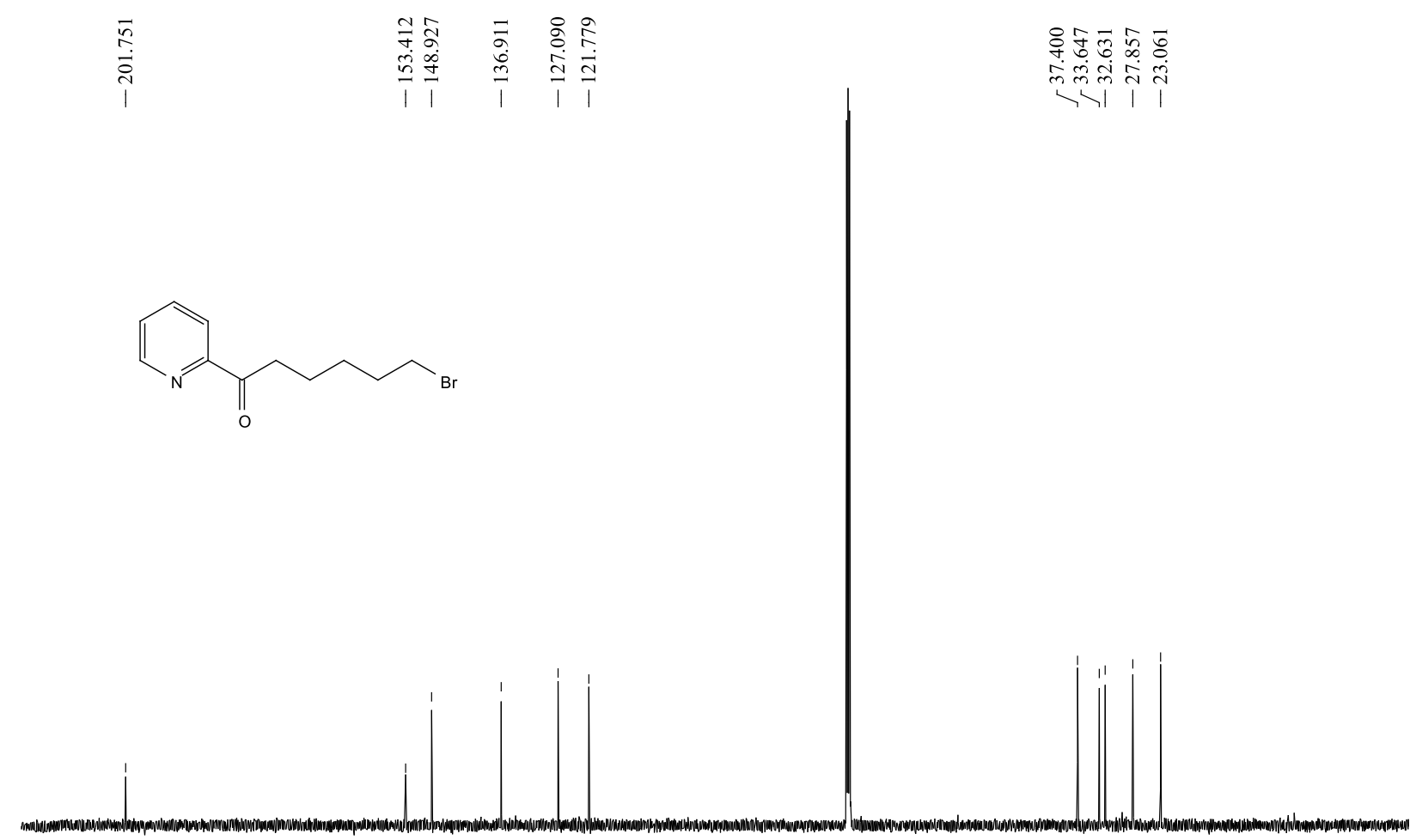

$\begin{array}{lllllllllllllllllllllll}210 & 200 & 190 & 180 & 170 & 160 & 150 & 140 & 130 & 120 & 110 & 100 & 90 & 80 & 70 & 60 & 50 & 40 & 30 & 20 & 10 & 0 & -10\end{array}$ 
${ }^{1} \mathrm{H}$ NMR of compound $\mathbf{3 j a}\left(400 \mathrm{MHz}, \mathrm{CDCl}_{3}\right)$
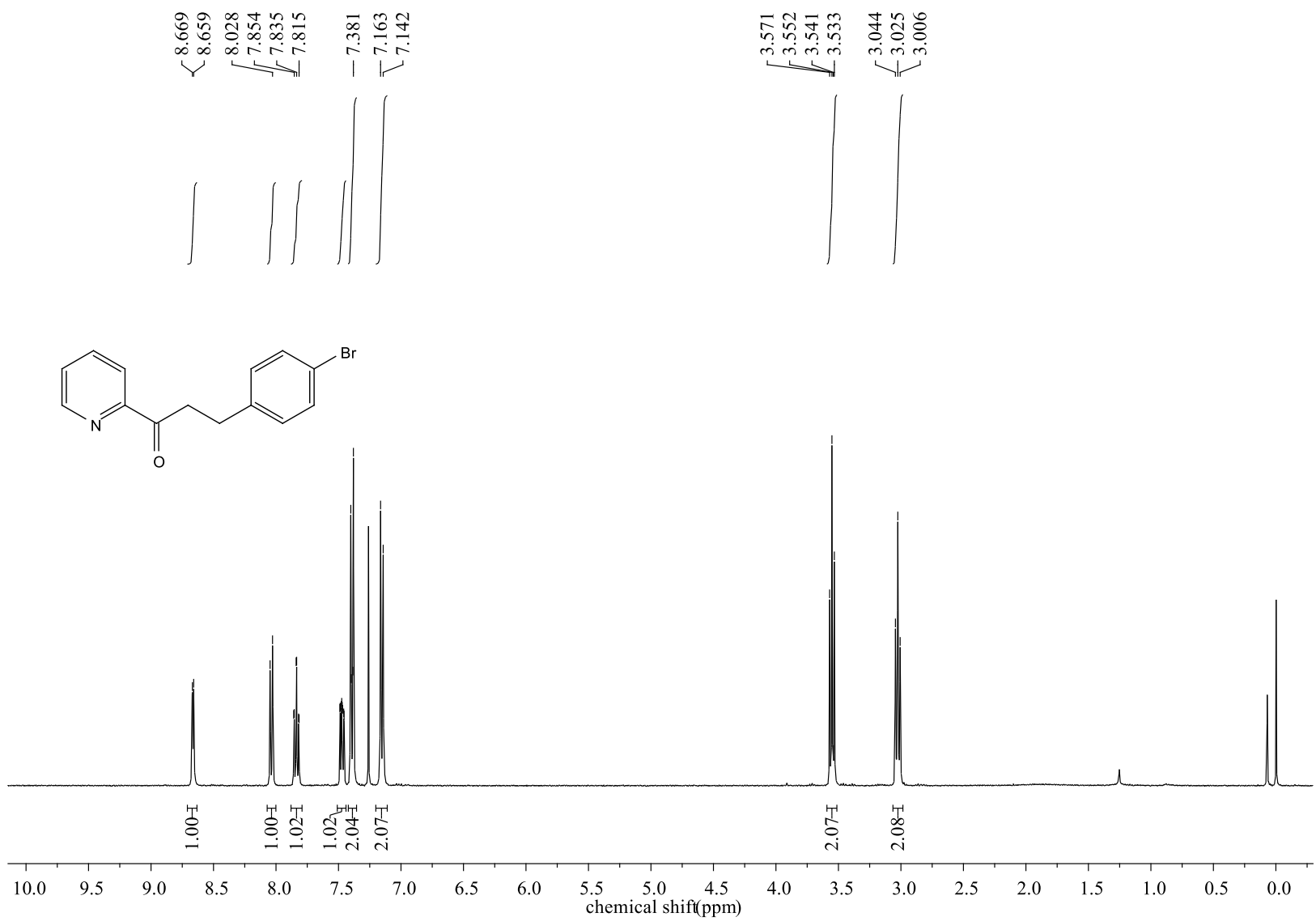

${ }^{13} \mathrm{C}\left\{{ }^{1} \mathrm{H}\right\}$ NMR of compound 3ja (125 MHz, $\left.\mathrm{CDCl}_{3}\right)$

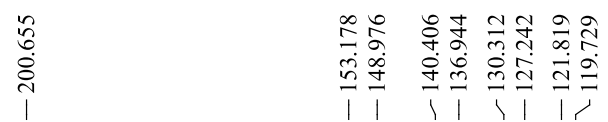

$\prod_{0}^{B r}$

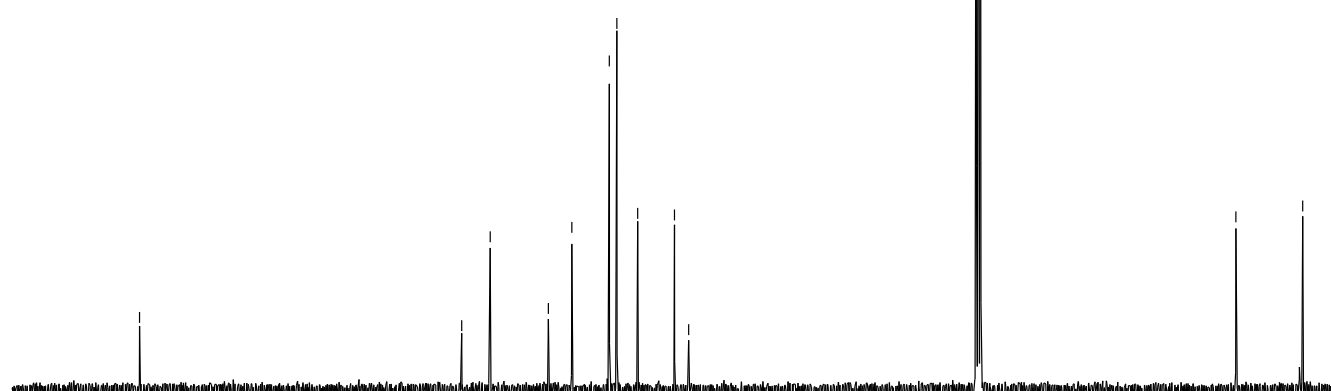

$\begin{array}{lllllllllllllllllllllll}210 & 200 & 190 & 180 & 170 & 160 & 150 & 140 & 130 & 120 & 110 & 100 & 90 & 80 & 70 & 60 & 50 & 40 & 30 & 20 & 10 & 0 & -10\end{array}$ 
${ }^{1} \mathrm{H}$ NMR of compound 3KA (500 MHz, $\left.\mathrm{CDCl}_{3}\right)$
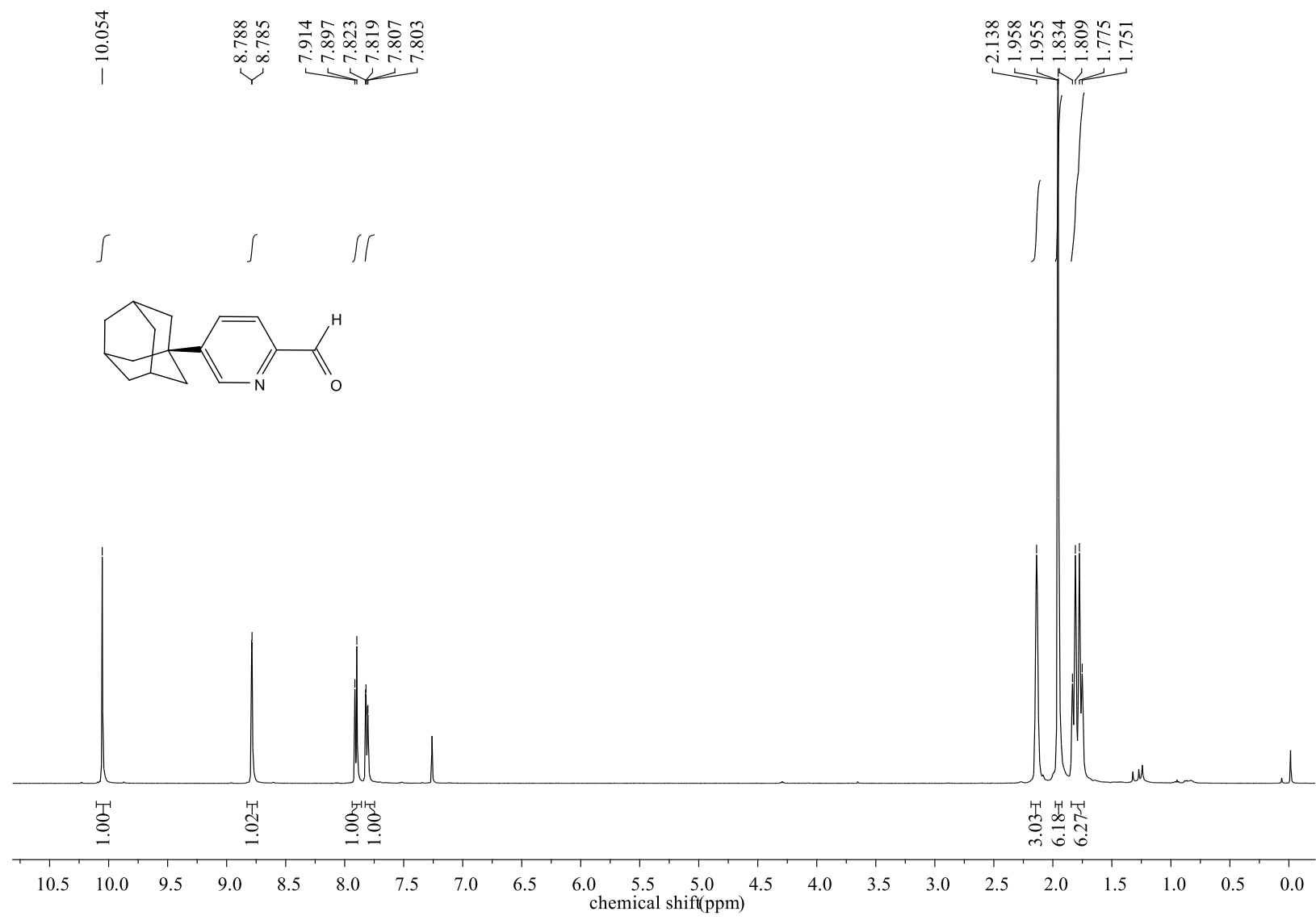

${ }^{13} \mathrm{C}\left\{{ }^{1} \mathrm{H}\right\}$ NMR of compound 3KA $\left(125 \mathrm{MHz}, \mathrm{CDCl}_{3}\right)$

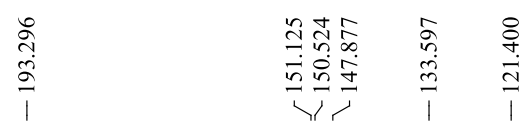
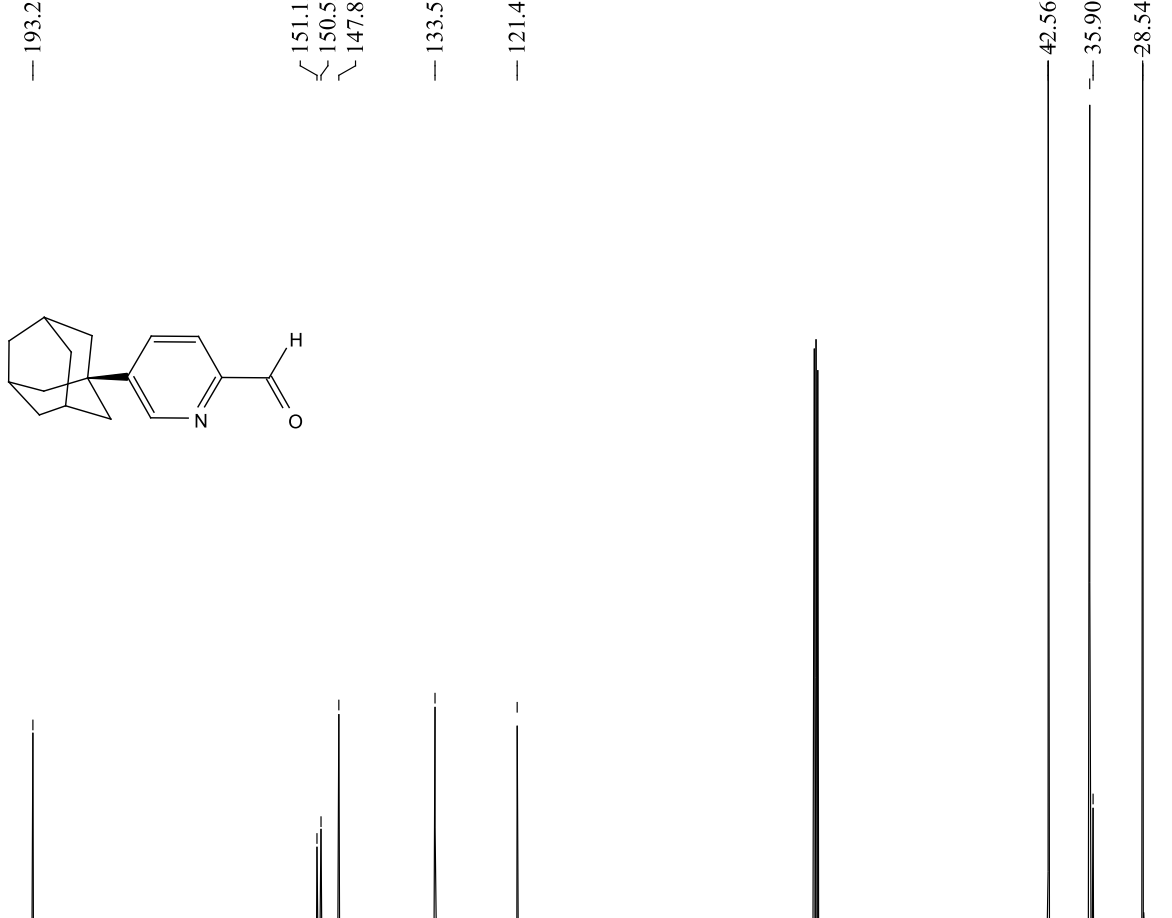

$\begin{array}{llllllllllllllllllllllll}210 & 200 & 190 & 180 & 170 & 160 & 150 & 140 & 130 & 120 & \begin{array}{c}110 \\ \text { chemical shift(ppm) }\end{array}\end{array}$ 
${ }^{1} \mathrm{H}$ NMR of compound 3LA (400 MHz, $\mathrm{CDCl}_{3}$ )

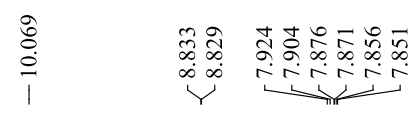<smiles>CC(C)(C)c1ccc(C=O)nc1</smiles>

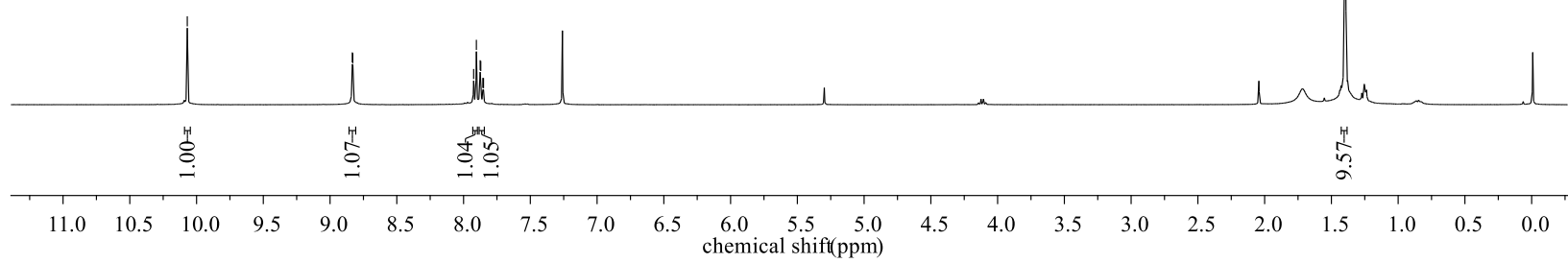

${ }^{13} \mathrm{C}\left\{{ }^{1} \mathrm{H}\right\}$ NMR of compound 3LA $\left(125 \mathrm{MHz}, \mathrm{CDCl}_{3}\right)$

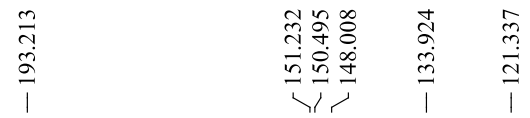<smiles>CC(C)(C)c1ccc(C=O)nc1</smiles>

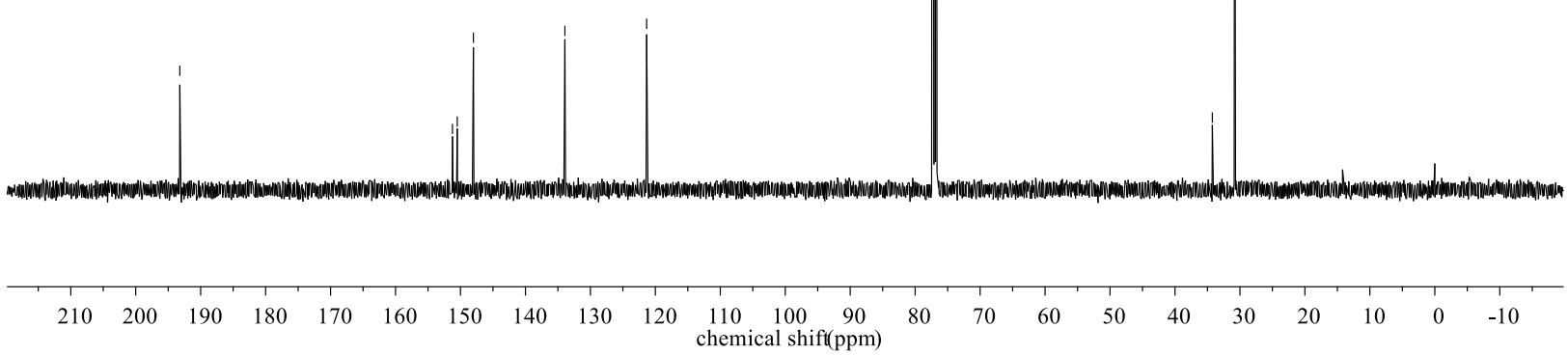


${ }^{1} \mathrm{H}$ NMR of compound $\mathbf{5 a a}\left(500 \mathrm{MHz}, \mathrm{CDCl}_{3}\right)$

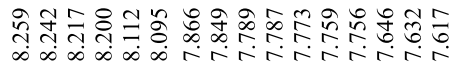

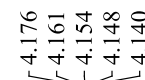

勿

\|\|\|\|
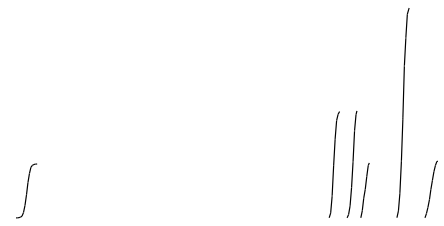

$\overbrace{0}$

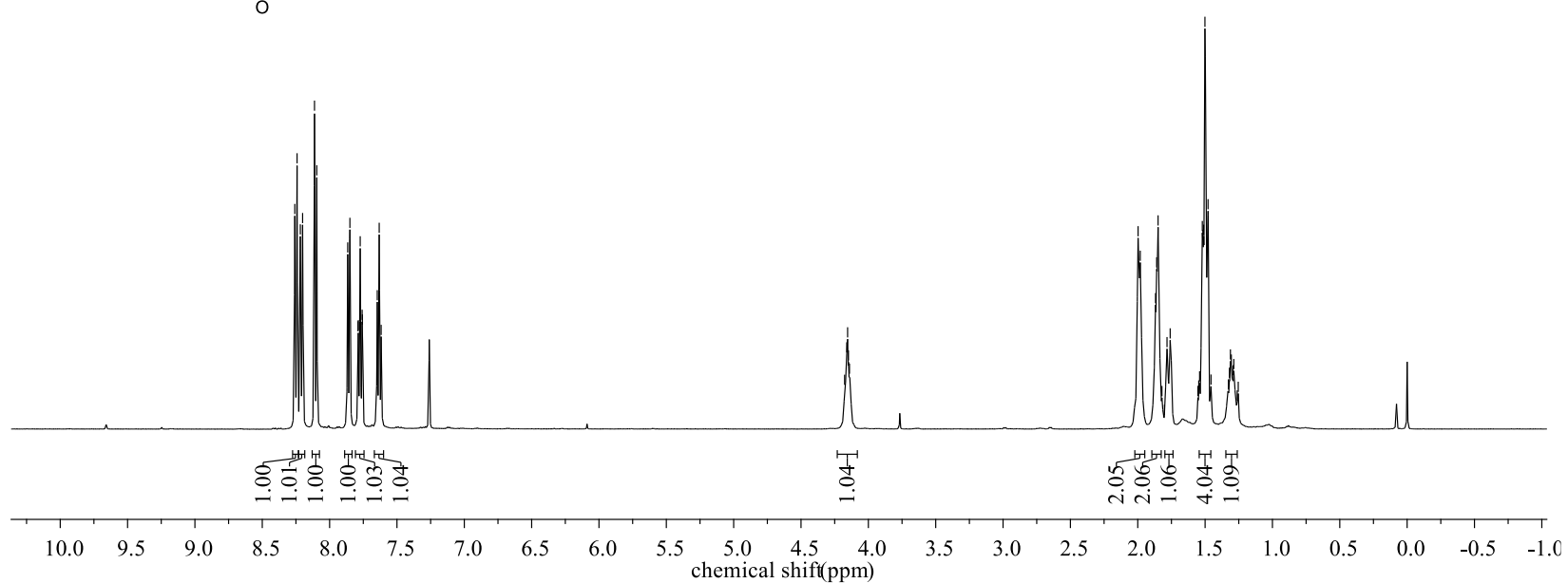

${ }^{13} \mathrm{C}\left\{{ }^{1} \mathrm{H}\right\}$ NMR of compound $\mathbf{5 a a}\left(125 \mathrm{MHz}, \mathrm{CDCl}_{3}\right)$

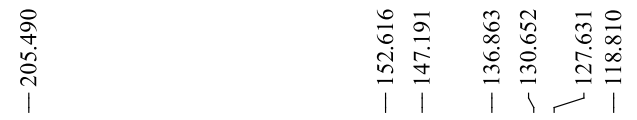<smiles>O=C(c1ccc2ccccc2n1)C1CCCCC1</smiles>

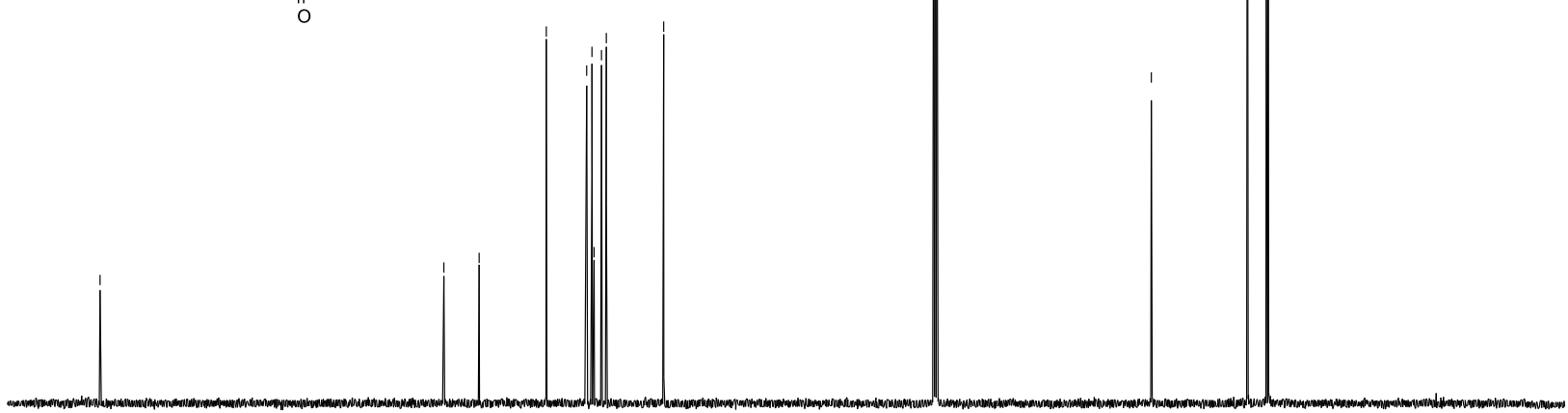

$\begin{array}{llllllllllllllllllllll}210 & 200 & 190 & 180 & 170 & 160 & 150 & 140 & 130 & 120 & \begin{array}{c}110 \\ \text { chemical shift(ppm) }\end{array} & 80 & 70 & 60 & 50 & 40 & 30 & 20 & 10 & 0 & -10\end{array}$ 
${ }^{1} \mathrm{H}$ NMR of compound $\mathbf{5 a b}\left(500 \mathrm{MHz}, \mathrm{CDCl}_{3}\right)$

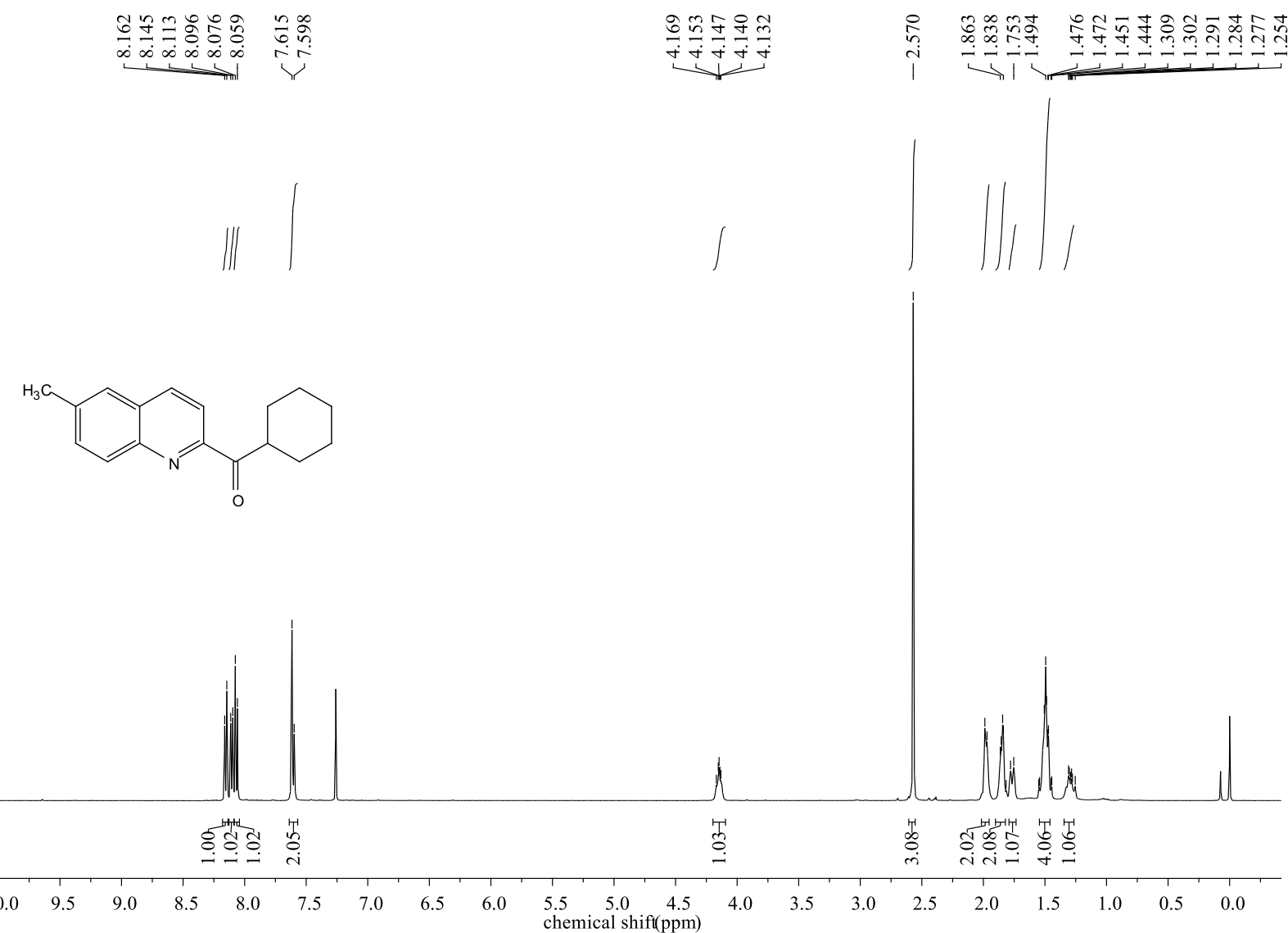

${ }^{13} \mathrm{C}\left\{{ }^{1} \mathrm{H}\right\}$ NMR of compound $\mathbf{5 a b}\left(125 \mathrm{MHz}, \mathrm{CDCl}_{3}\right)$

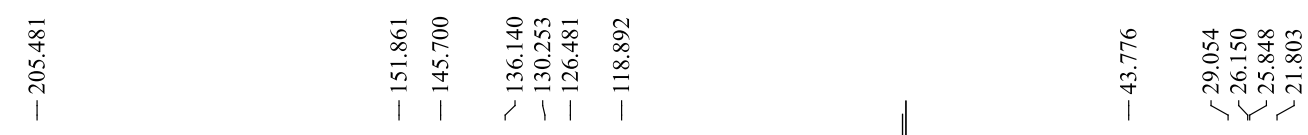

(1)

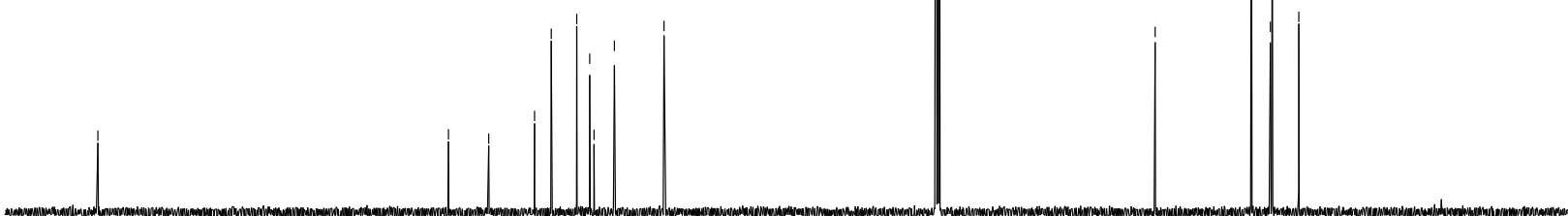

$\begin{array}{lllllllllllllllllllllll}210 & 200 & 190 & 180 & 170 & 160 & 150 & 140 & 130 & 120 & \begin{array}{c}110 \\ \text { chemical shift(ppm) }\end{array} & 80 & 70 & 60 & 50 & 40 & 30 & 20 & 10 & 0 & -10 & \end{array}$ 
${ }^{1} \mathrm{H}$ NMR of compound 5 ac $\left(500 \mathrm{MHz}, \mathrm{CDCl}_{3}\right)$

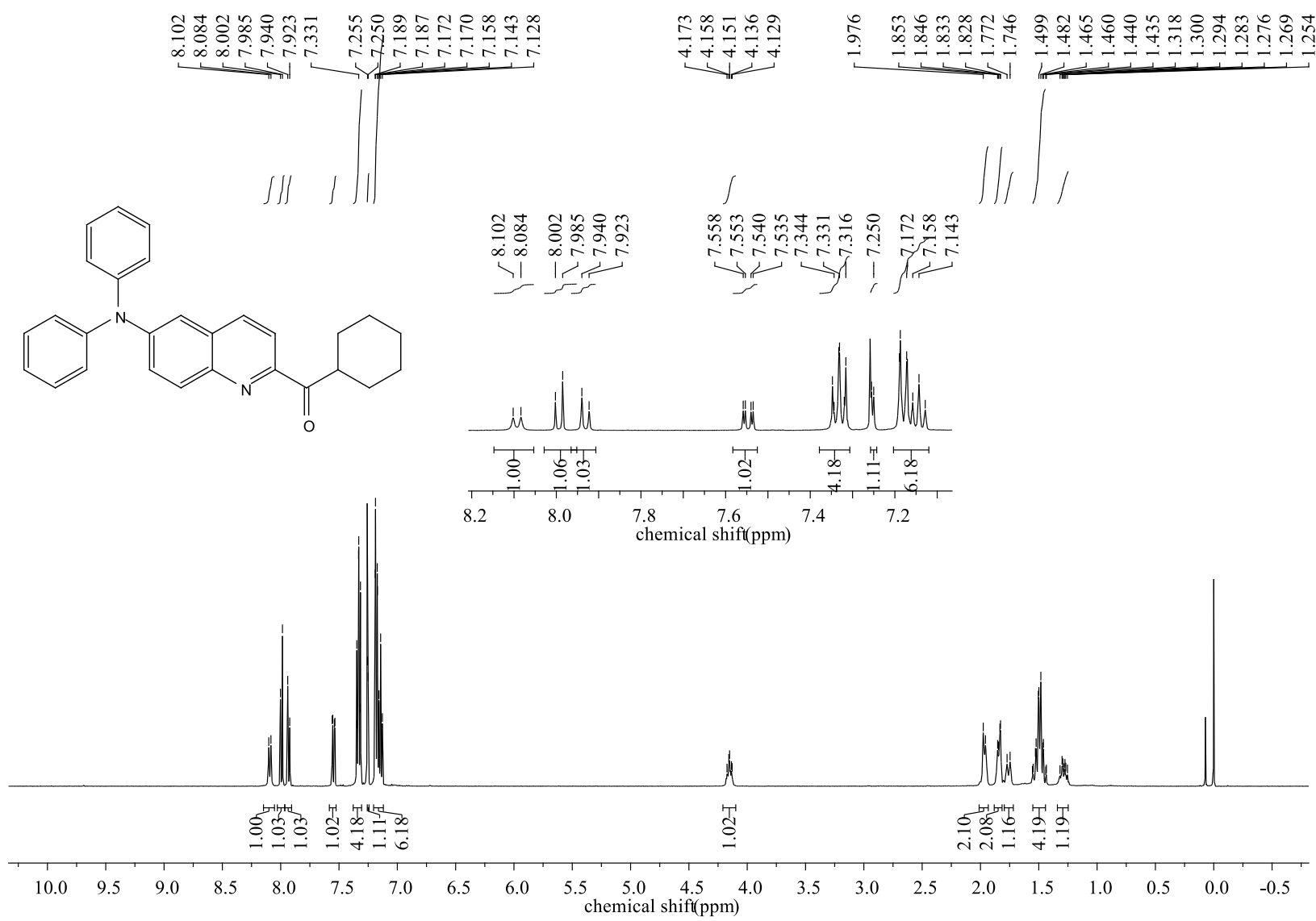

${ }^{13} \mathrm{C}\left\{{ }^{1} \mathrm{H}\right\}$ NMR of compound $\mathbf{5 a c}\left(125 \mathrm{MHz}, \mathrm{CDCl}_{3}\right)$

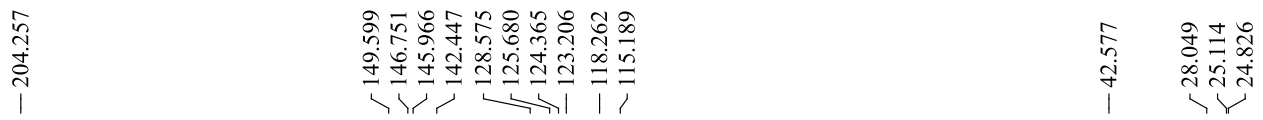

(c)

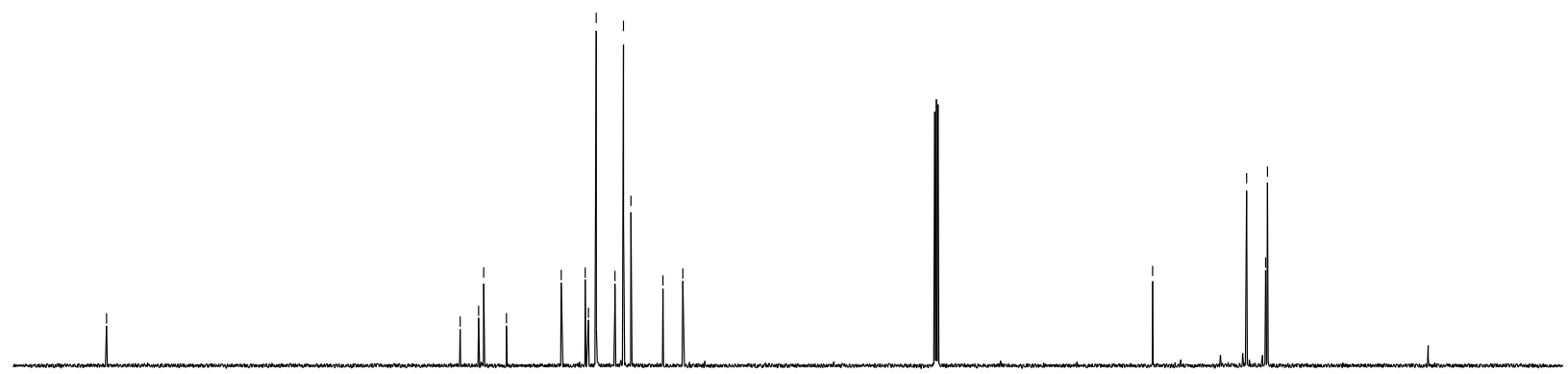

$\begin{array}{llllllllllllllllllllllll}210 & 200 & 190 & 180 & 170 & 160 & 150 & 140 & 130 & 120 & 110 & 100 & 90 & 80 & 70 & 60 & 50 & 40 & 30 & 20 & 10 & 0 & -10 & -20\end{array}$ 
${ }^{1} \mathrm{H}$ NMR of compound $5 \mathbf{a d}\left(500 \mathrm{MHz}, \mathrm{CDCl}_{3}\right)$

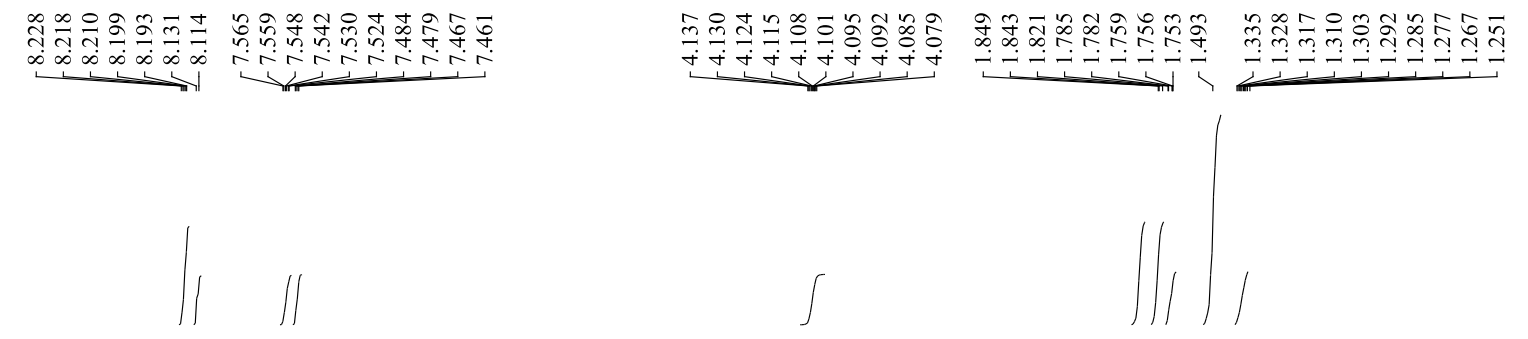<smiles>O=C(c1ccc2cc(F)ccc2n1)C1CCCCC1</smiles>

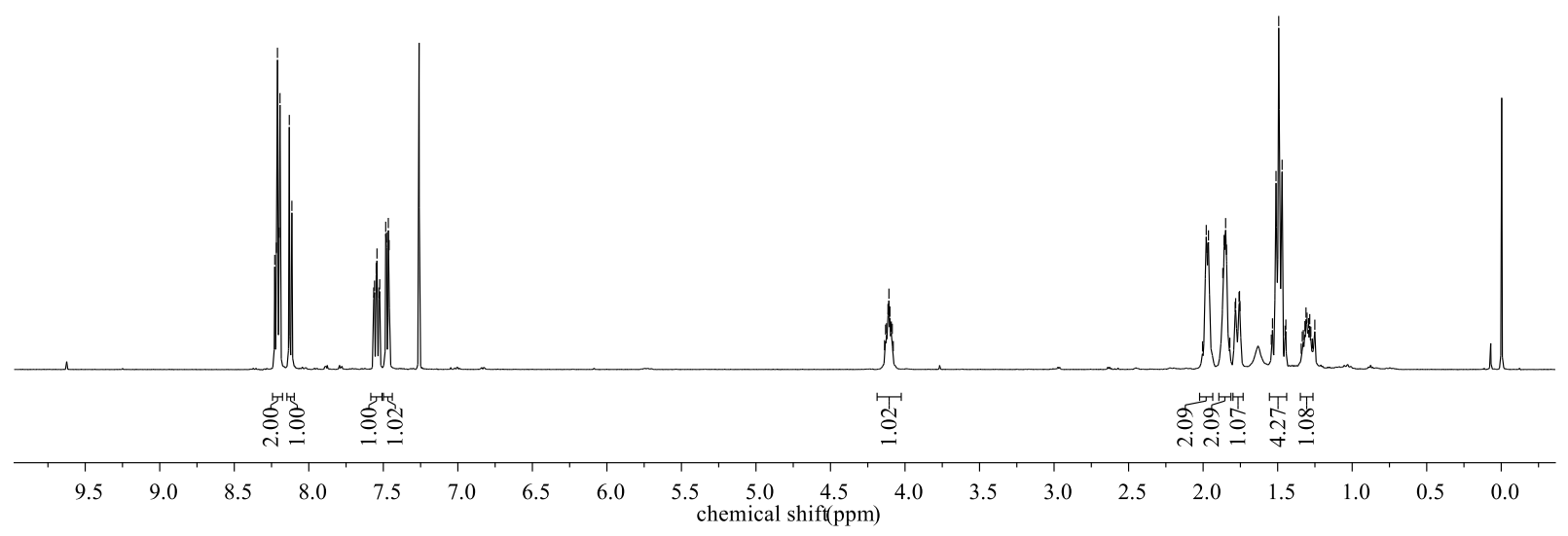

${ }^{13} \mathrm{C}\left\{{ }^{1} \mathrm{H}\right\}$ NMR of compound $\mathbf{5 a d}\left(125 \mathrm{MHz}, \mathrm{CDCl}_{3}\right)$

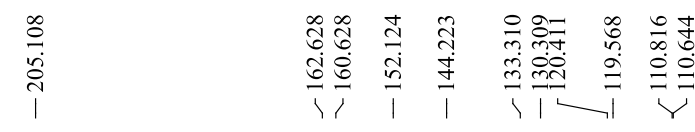<smiles>O=C(c1ccc2cc(F)ccc2n1)C1CCCCC1</smiles>

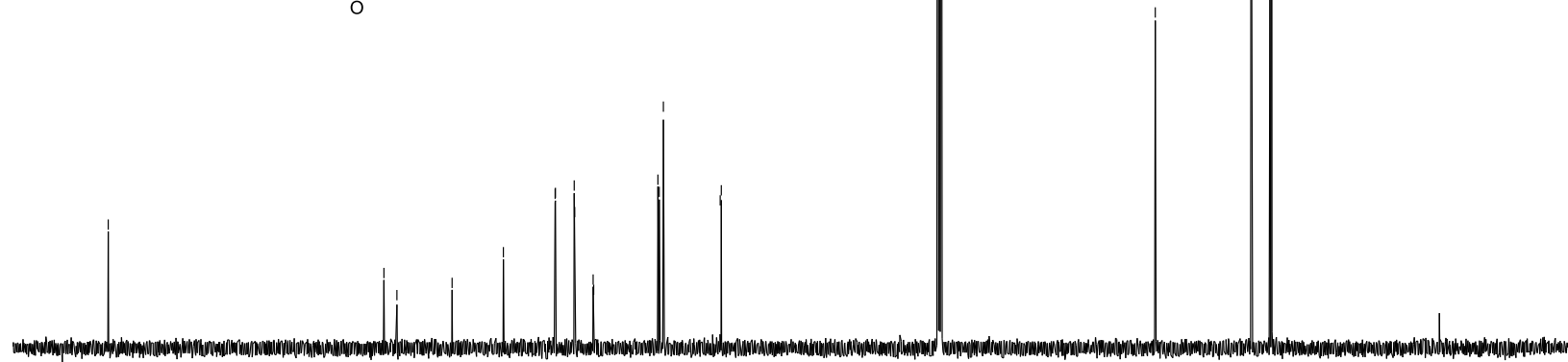

$\begin{array}{llllllllllllllllllllll}210 & 200 & 190 & 180 & 170 & 160 & 150 & 140 & 130 & 120 & \begin{array}{c}110 \\ \text { chemical shift(ppm) }\end{array} & 80 & 70 & 60 & 50 & 40 & 30 & 20 & 10 & 0 & -10 & 90\end{array}$ 
${ }^{19} \mathrm{~F}$ NMR of compound $\mathbf{5 a d}\left(376 \mathrm{MHz}, \mathrm{CDCl}_{3}\right)$

$\stackrel{\substack{8 \\ \hline}}{i}$<smiles>O=C(c1ccc2cc(F)ccc2n1)C1CCCCC1</smiles> 
${ }^{1} \mathrm{H}$ NMR of compound $5 \mathbf{b a}\left(500 \mathrm{MHz}, \mathrm{CDCl}_{3}\right)$

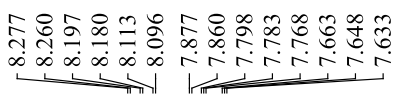

$\iiint \iint$

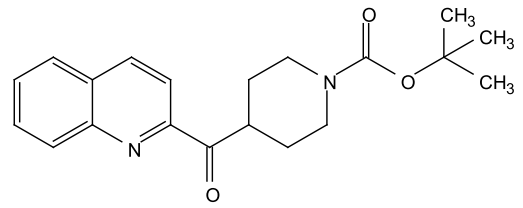

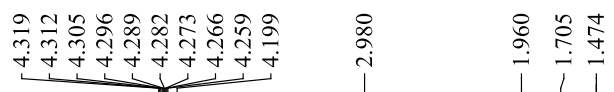

$\int$

${ }^{13} \mathrm{C}\left\{{ }^{1} \mathrm{H}\right\}$ NMR of compound $\mathbf{5 b a}\left(125 \mathrm{MHz}, \mathrm{CDCl}_{3}\right)$

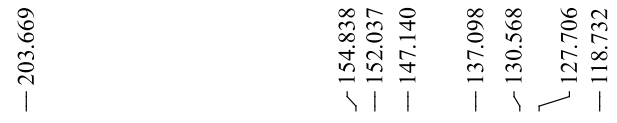<smiles>CC(C)(C)OC(=O)N1CCC(C(=O)c2ccc3ccccc3n2)CC1</smiles> 
${ }^{1} \mathrm{H}$ NMR of compound $\mathbf{5} \mathbf{c a}\left(400 \mathrm{MHz}, \mathrm{CDCl}_{3}\right)$

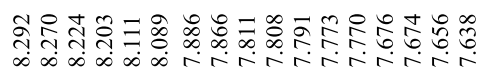

$\int / \int / / /$
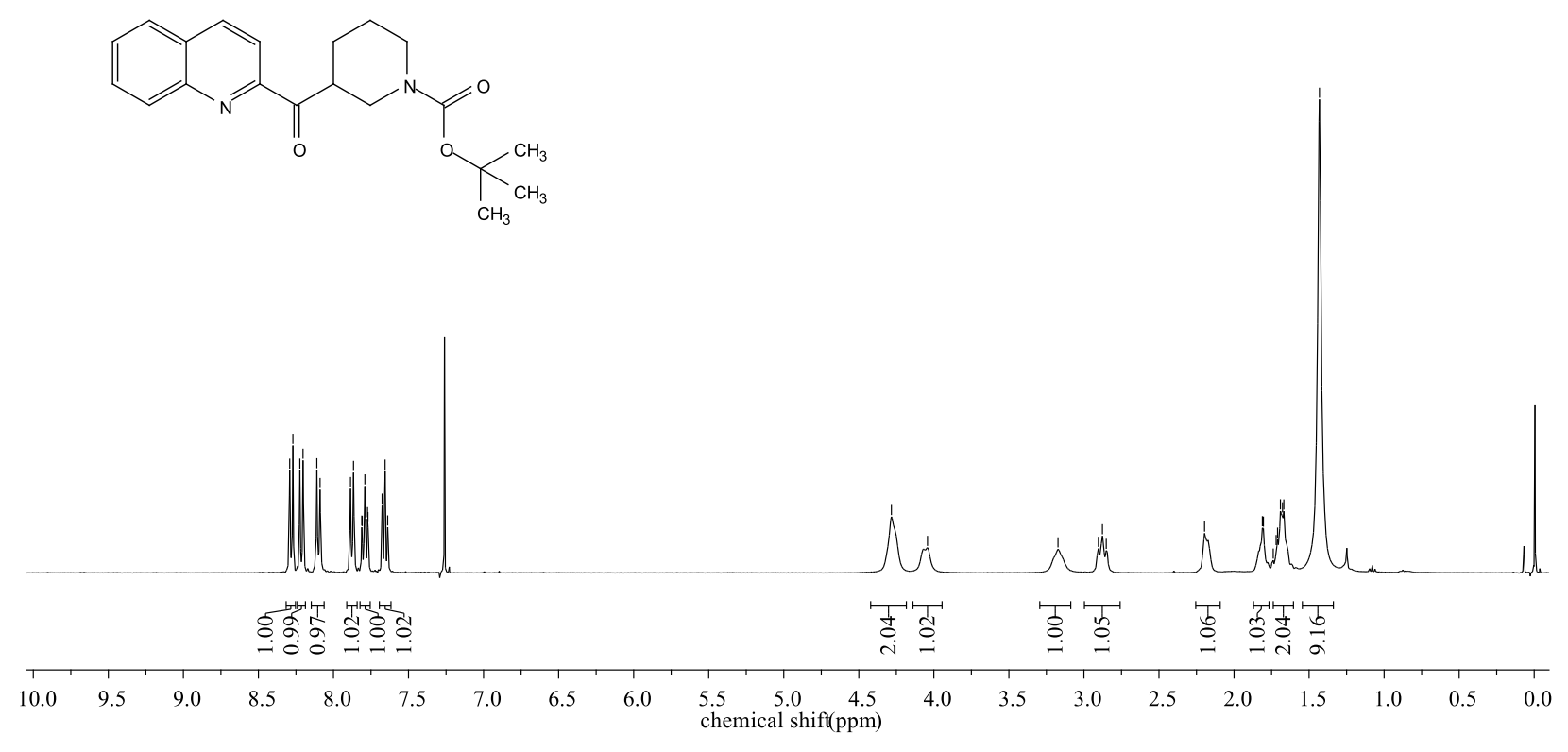

${ }^{13} \mathrm{C}\left\{{ }^{1} \mathrm{H}\right\}$ NMR of compound $5 \mathbf{c a}\left(125 \mathrm{MHz}, \mathrm{CDCl}_{3}\right)$

in
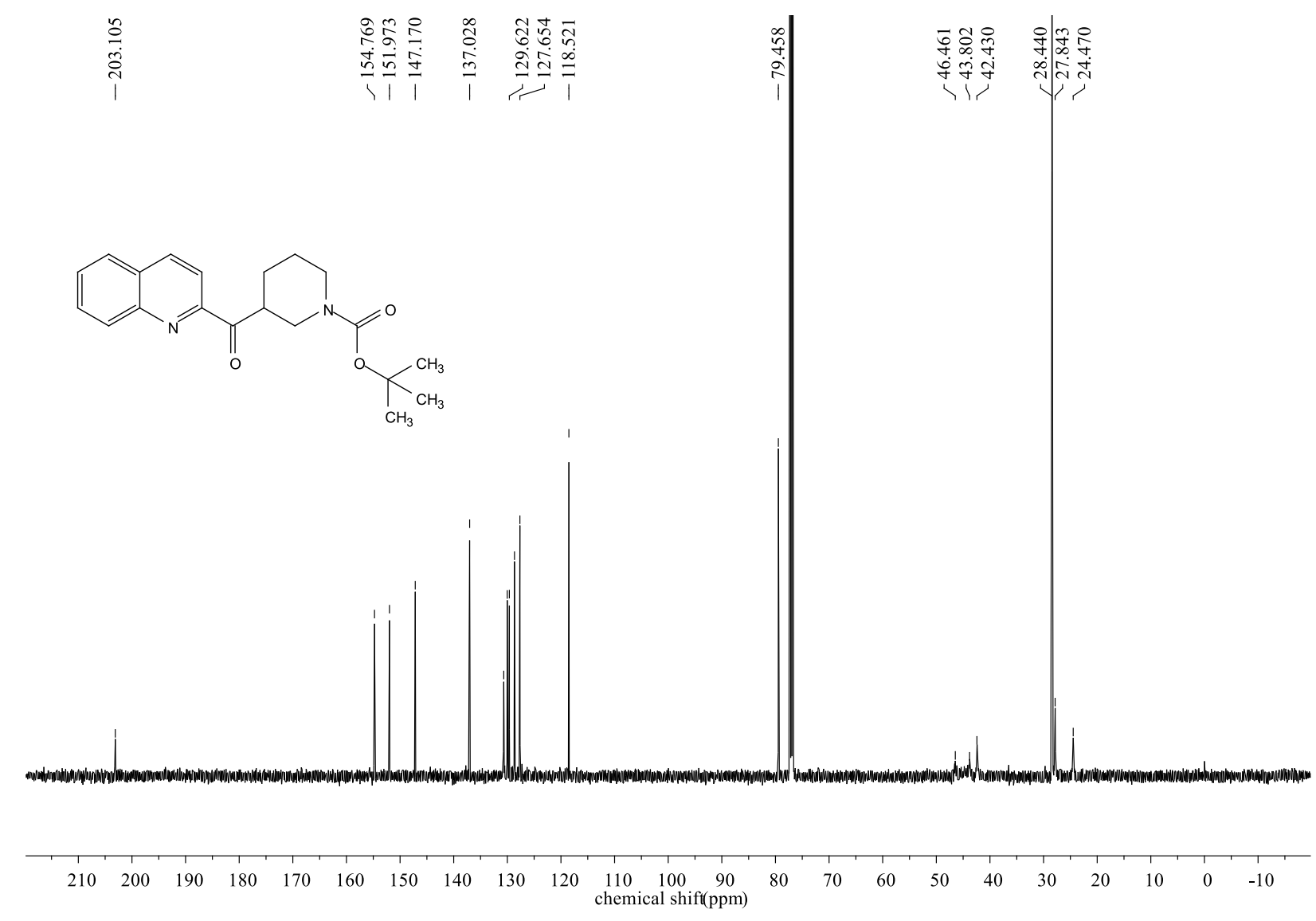

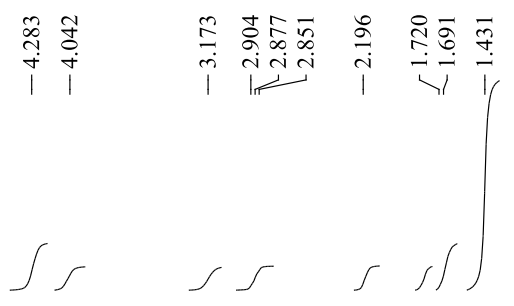

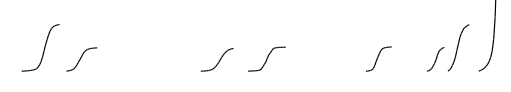

S28 
${ }^{1} \mathrm{H}$ NMR of compound $5 \mathbf{d a}\left(500 \mathrm{MHz}, \mathrm{CDCl}_{3}\right)$

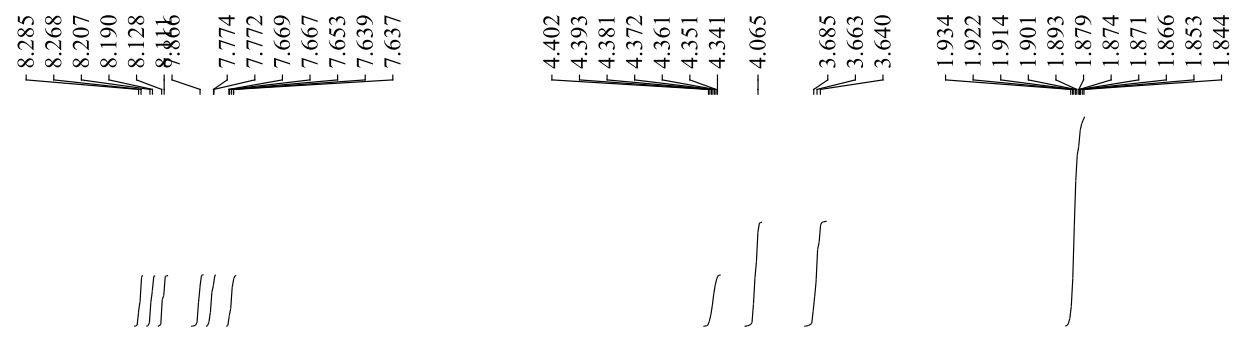<smiles>O=C(c1ccc2ccccc2n1)C1CCOCC1</smiles>

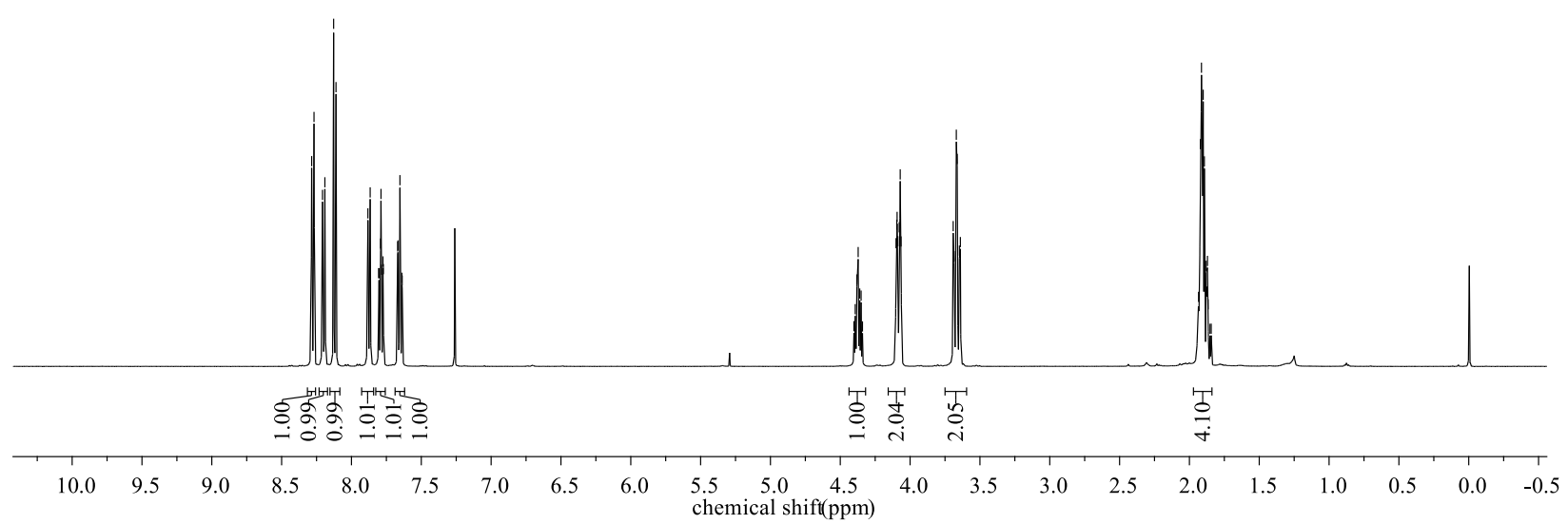

${ }^{13} \mathrm{C}\left\{{ }^{1} \mathrm{H}\right\}$ NMR of compound $5 \mathbf{d a}\left(125 \mathrm{MHz}, \mathrm{CDCl}_{3}\right) \backslash$

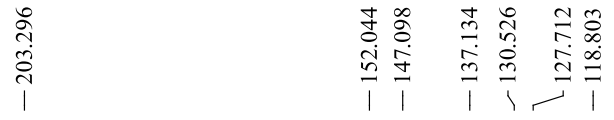<smiles>O=C(c1ccc2ccccc2n1)C1CCOCC1</smiles>

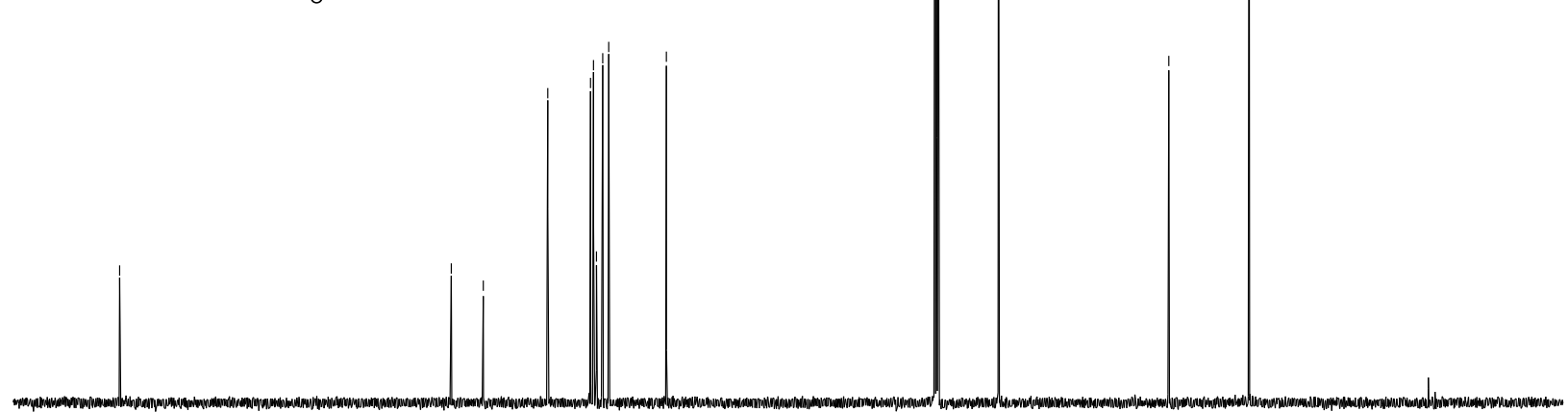

$\begin{array}{lllllllllllllllllllllll}210 & 200 & 190 & 180 & 170 & 160 & 150 & 140 & 130 & 120 & 110 & 100 & 90 & 80 & 70 & 60 & 50 & 40 & 30 & 20 & 10 & 0 & -10\end{array}$ 
${ }^{1} \mathrm{H}$ NMR of compound $5 \mathbf{e a}\left(500 \mathrm{MHz}, \mathrm{CDCl}_{3}\right)$
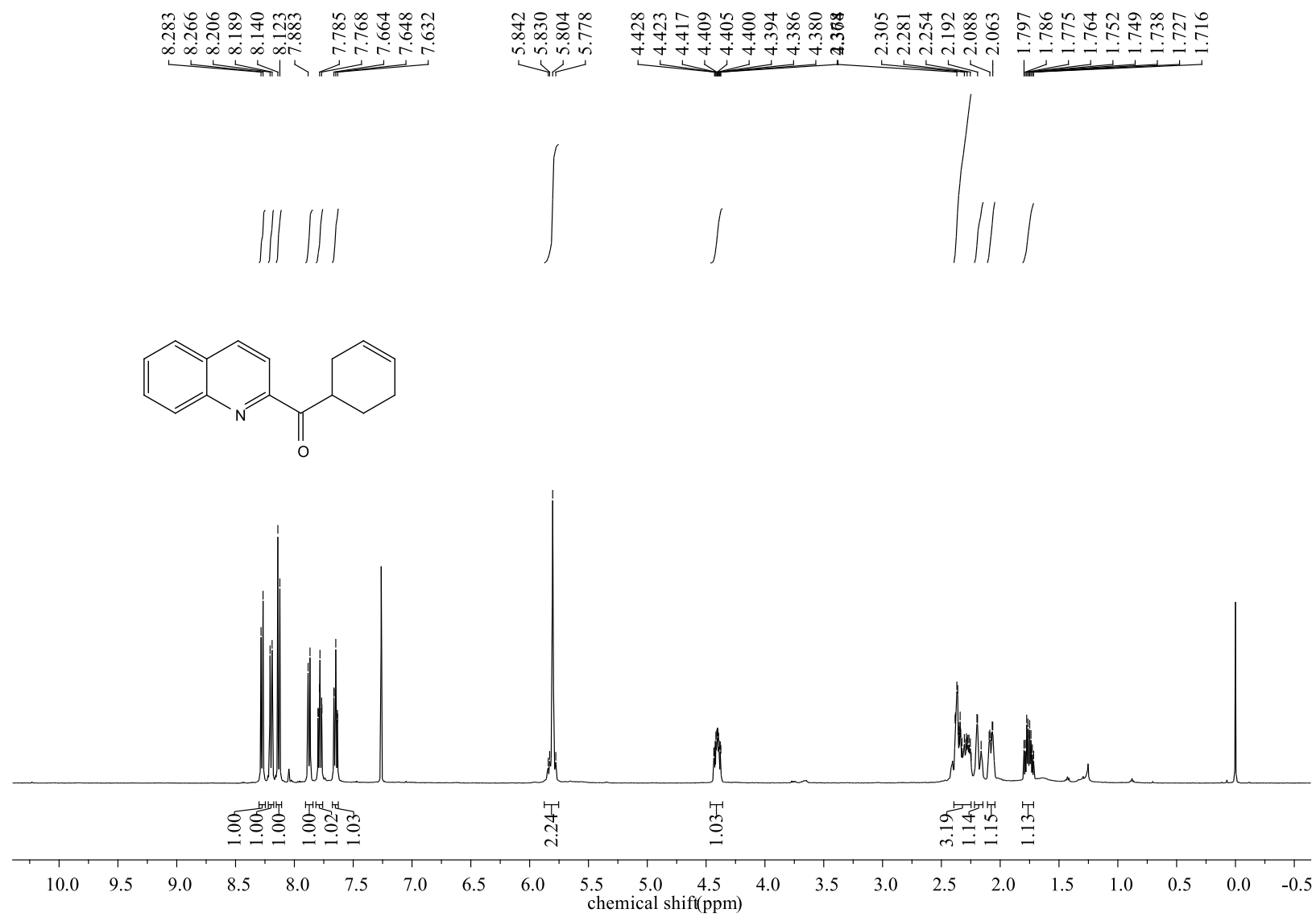

${ }^{13} \mathrm{C}\left\{{ }^{1} \mathrm{H}\right\}$ NMR of compound 5 ea $\left(125 \mathrm{MHz}, \mathrm{CDCl}_{3}\right)$

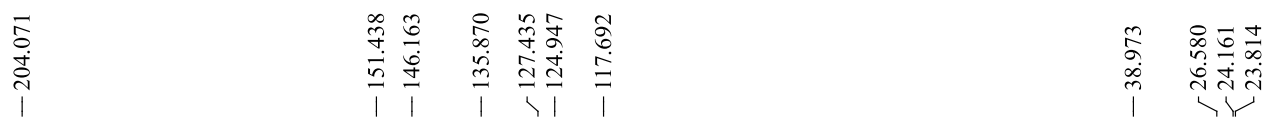

$\overbrace{0}$

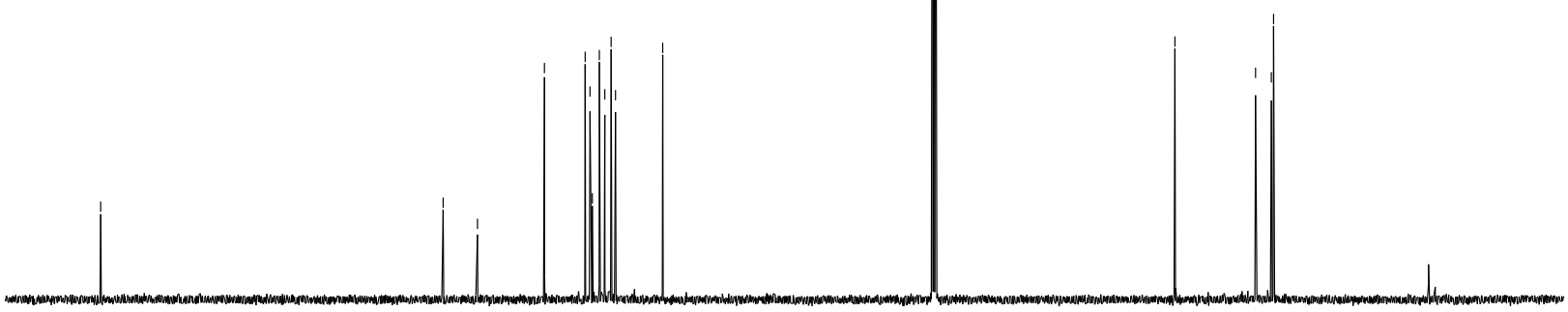

$\begin{array}{llllllllllllllllllllllll}210 & 200 & 190 & 180 & 170 & 160 & 150 & 140 & 130 & 120 & 110 & 100 & 90 & 80 & 70 & 60 & 50 & 40 & 30 & 20 & 10 & 0 & -10 & -20\end{array}$ 
${ }^{1} \mathrm{H}$ NMR of compound $\mathbf{5 f a}\left(500 \mathrm{MHz}, \mathrm{CDCl}_{3}\right)$

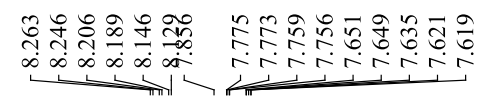<smiles>C#CC1CCCC1C(=O)c1ccc2ccccc2n1</smiles>

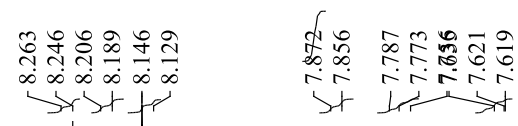

ji jising
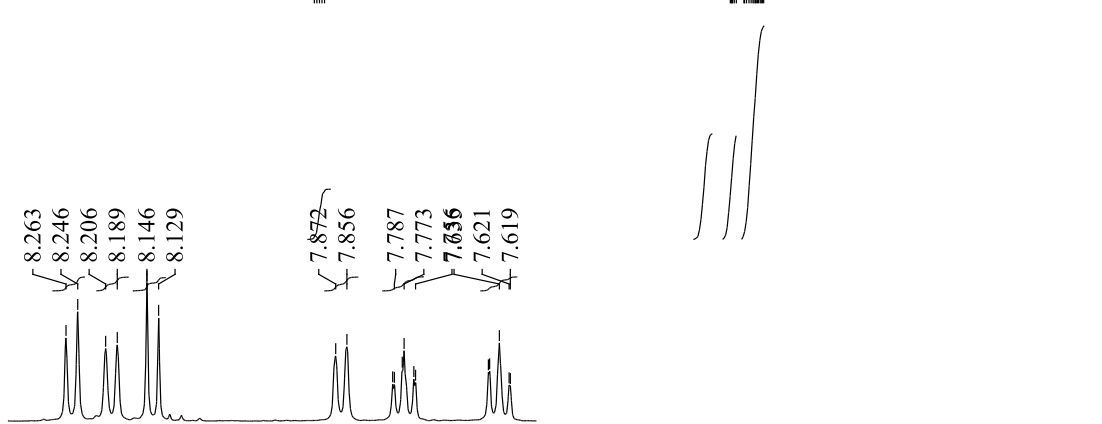

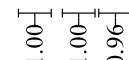
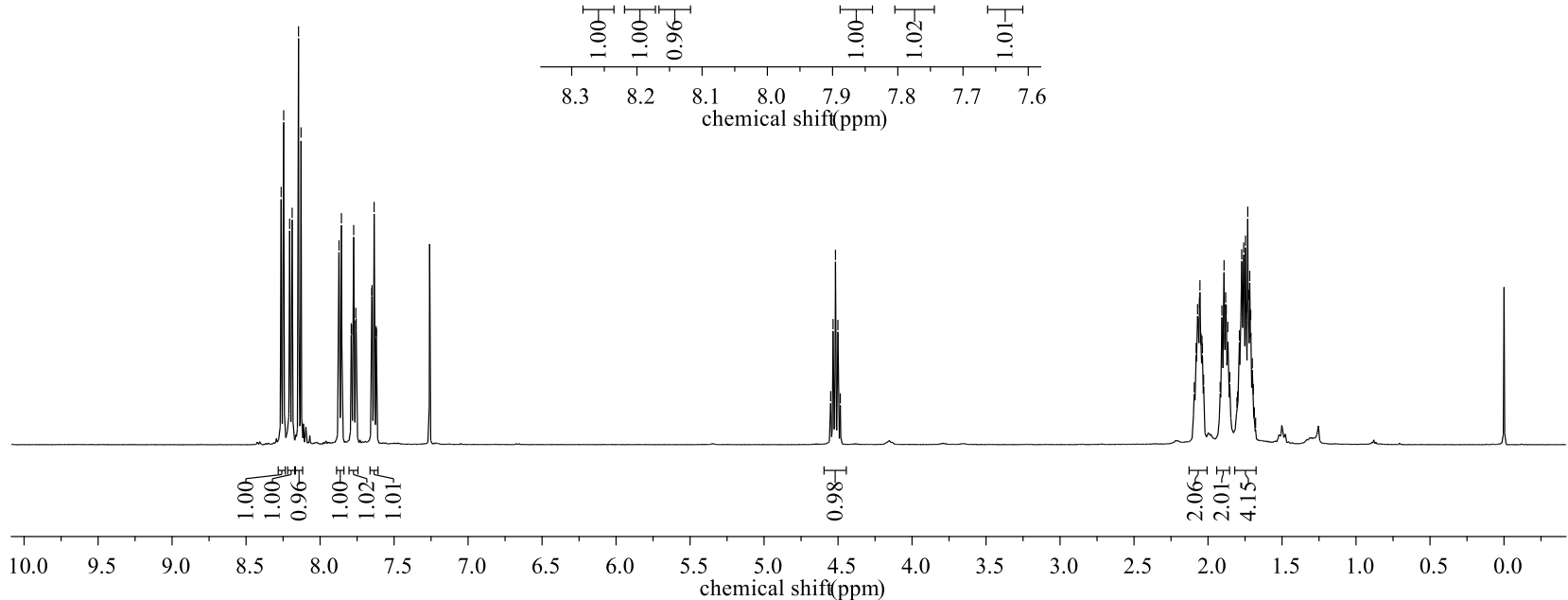

${ }^{13} \mathrm{C}\left\{{ }^{1} \mathrm{H}\right\}$ NMR of compound $\mathbf{5 f a}\left(125 \mathrm{MHz}, \mathrm{CDCl}_{3}\right)$

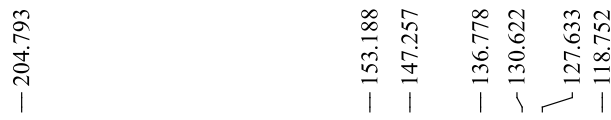<smiles>O=C(c1ccc2ccccc2n1)C1CCCC1</smiles>

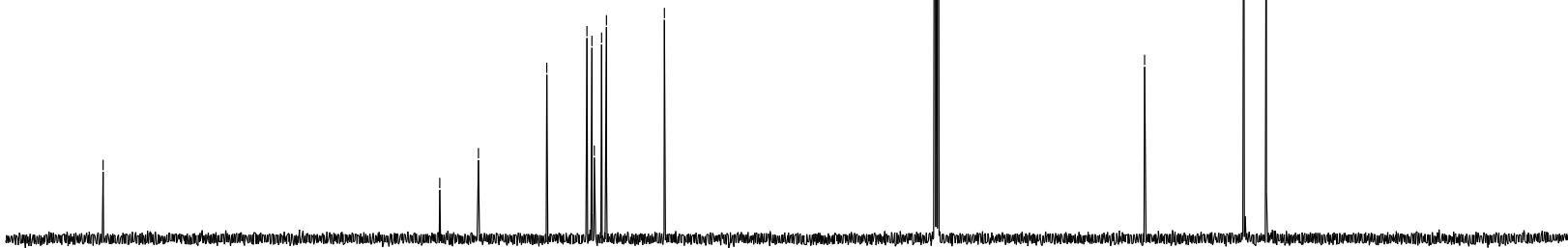

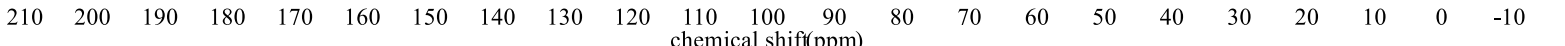


${ }^{1} \mathrm{H}$ NMR of compound 5 ga $\left(500 \mathrm{MHz}, \mathrm{CDCl}_{3}\right)$

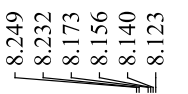<smiles>C#CC=CC</smiles>
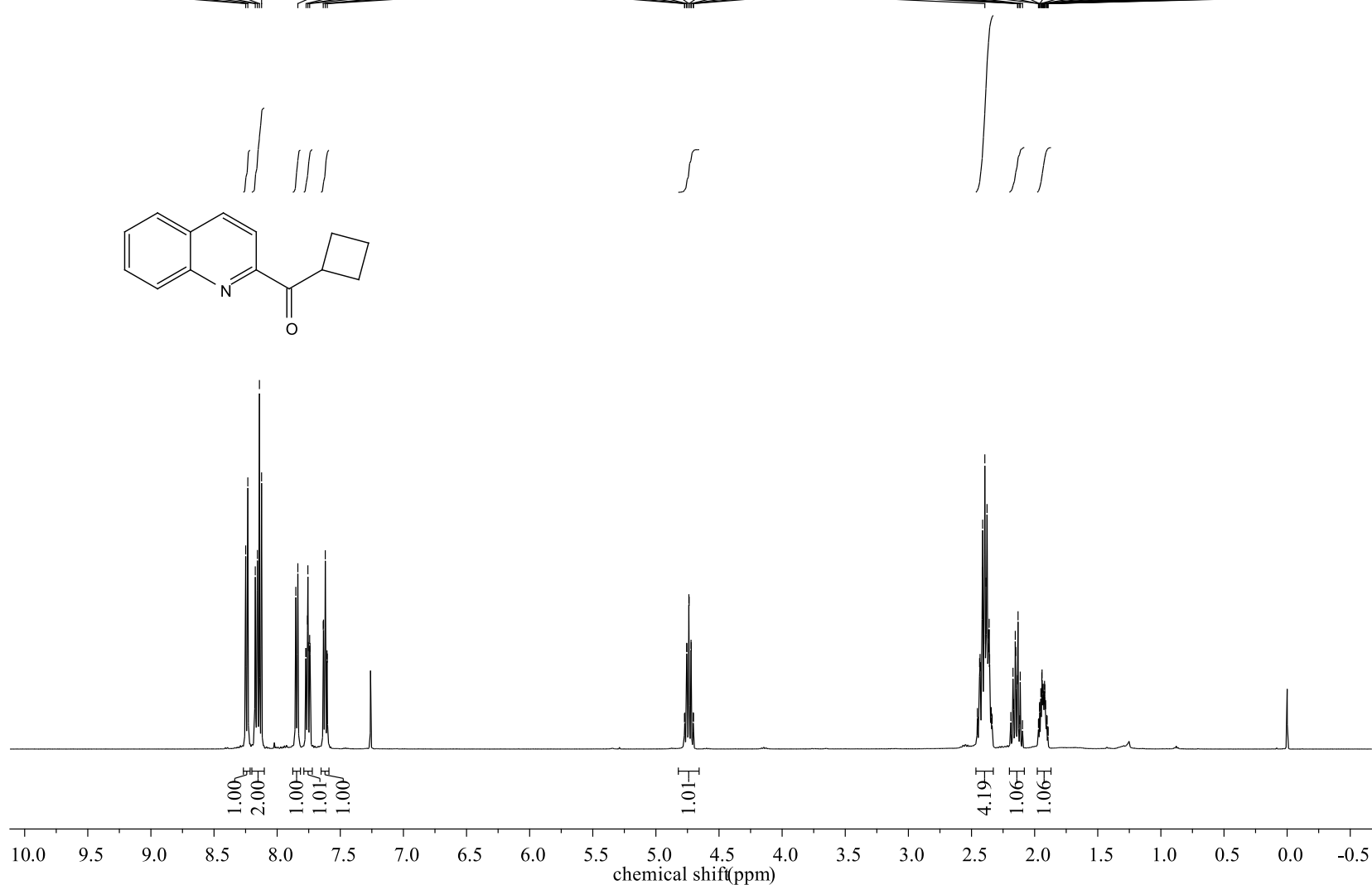

${ }^{13} \mathrm{C}\left\{{ }^{1} \mathrm{H}\right\}$ NMR of compound 5 ga $\left(500 \mathrm{MHz}, \mathrm{CDCl}_{3}\right)$

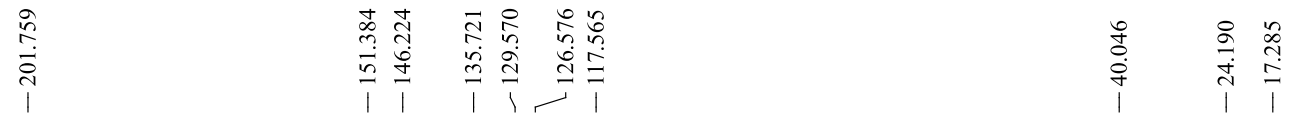<smiles>O=C(c1ccc2ccccc2n1)C1CCC1</smiles>

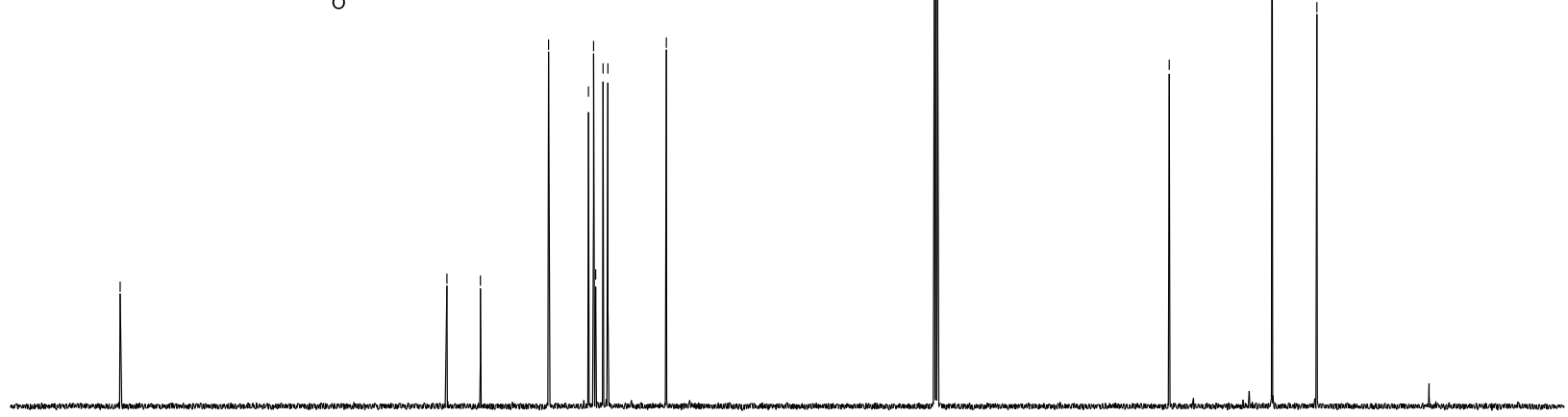

$\begin{array}{llllllllllllllllllllllll}210 & 200 & 190 & 180 & 170 & 160 & 150 & 140 & 130 & 120 & 110 & 100 & 90 & 80 & 70 & 60 & 50 & 40 & 30 & 20 & 10 & 0 & -10 & -20\end{array}$ 
${ }^{1} \mathrm{H}$ NMR of compound $\mathbf{5 j a}\left(500 \mathrm{MHz}, \mathrm{CDCl}_{3}\right)$

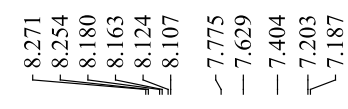<smiles>C#CCCCC1C#CC1</smiles>

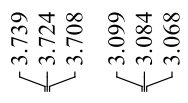

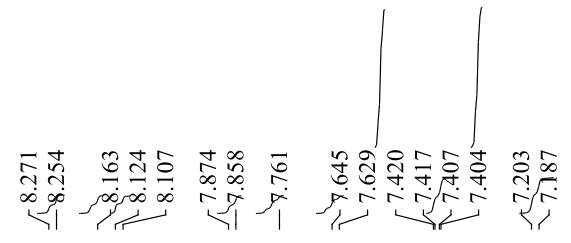

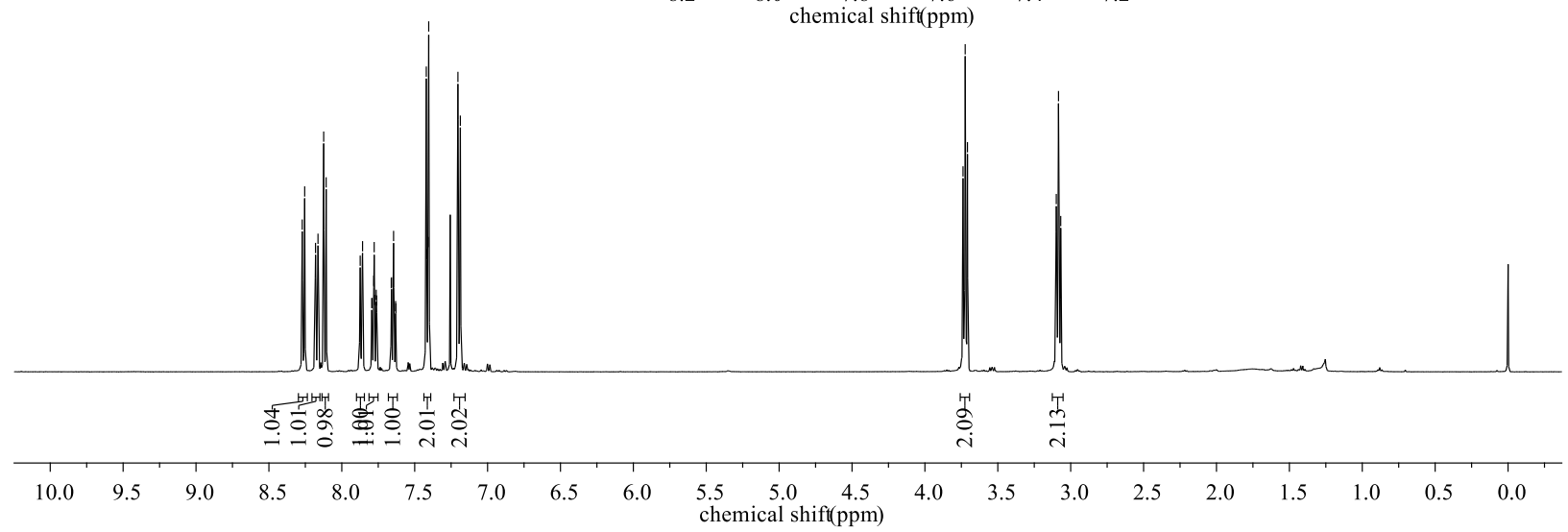

${ }^{13} \mathrm{C}\left\{{ }^{1} \mathrm{H}\right\}$ NMR of compound $\mathbf{5 j a}\left(500 \mathrm{MHz}, \mathrm{CDCl}_{3}\right)$

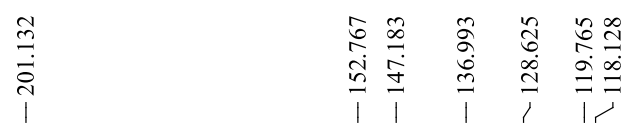<smiles>O=C(CCc1ccc(Br)cc1)c1ccc2ccccc2n1</smiles>

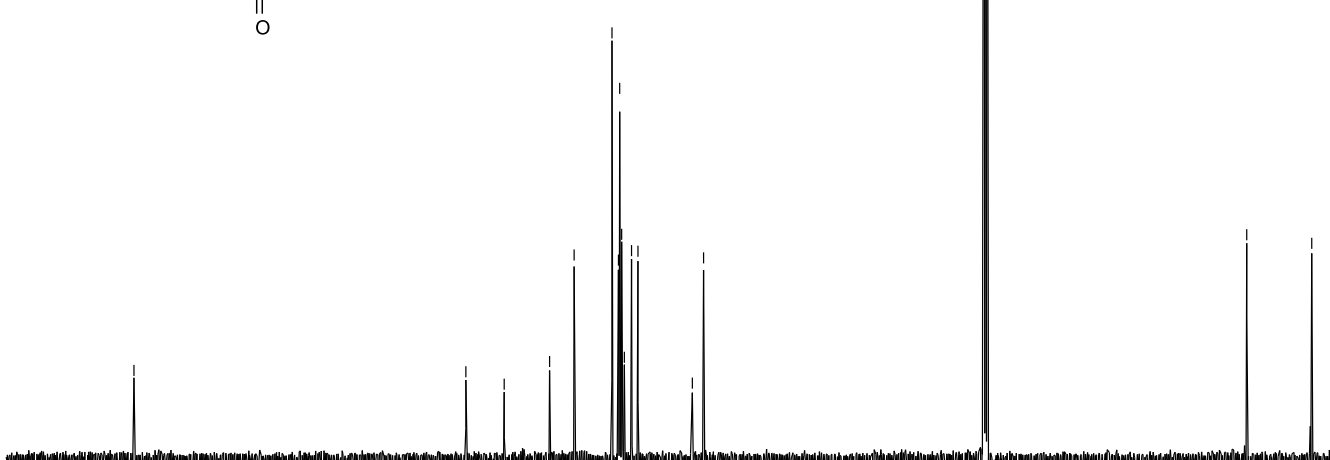

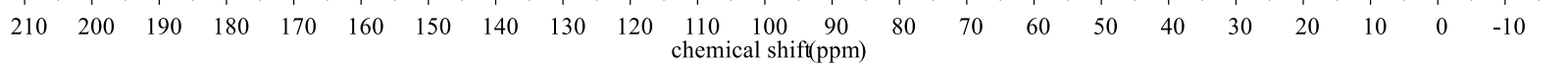


${ }^{1} \mathrm{H}$ NMR of compound $9 \mathrm{a}\left(500 \mathrm{MHz}, \mathrm{CDCl}_{3}\right)$
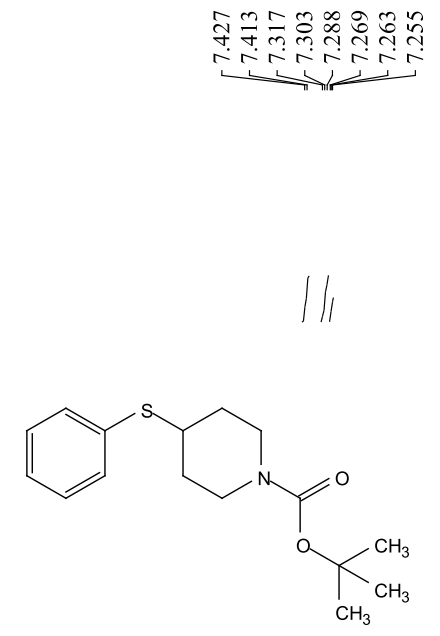
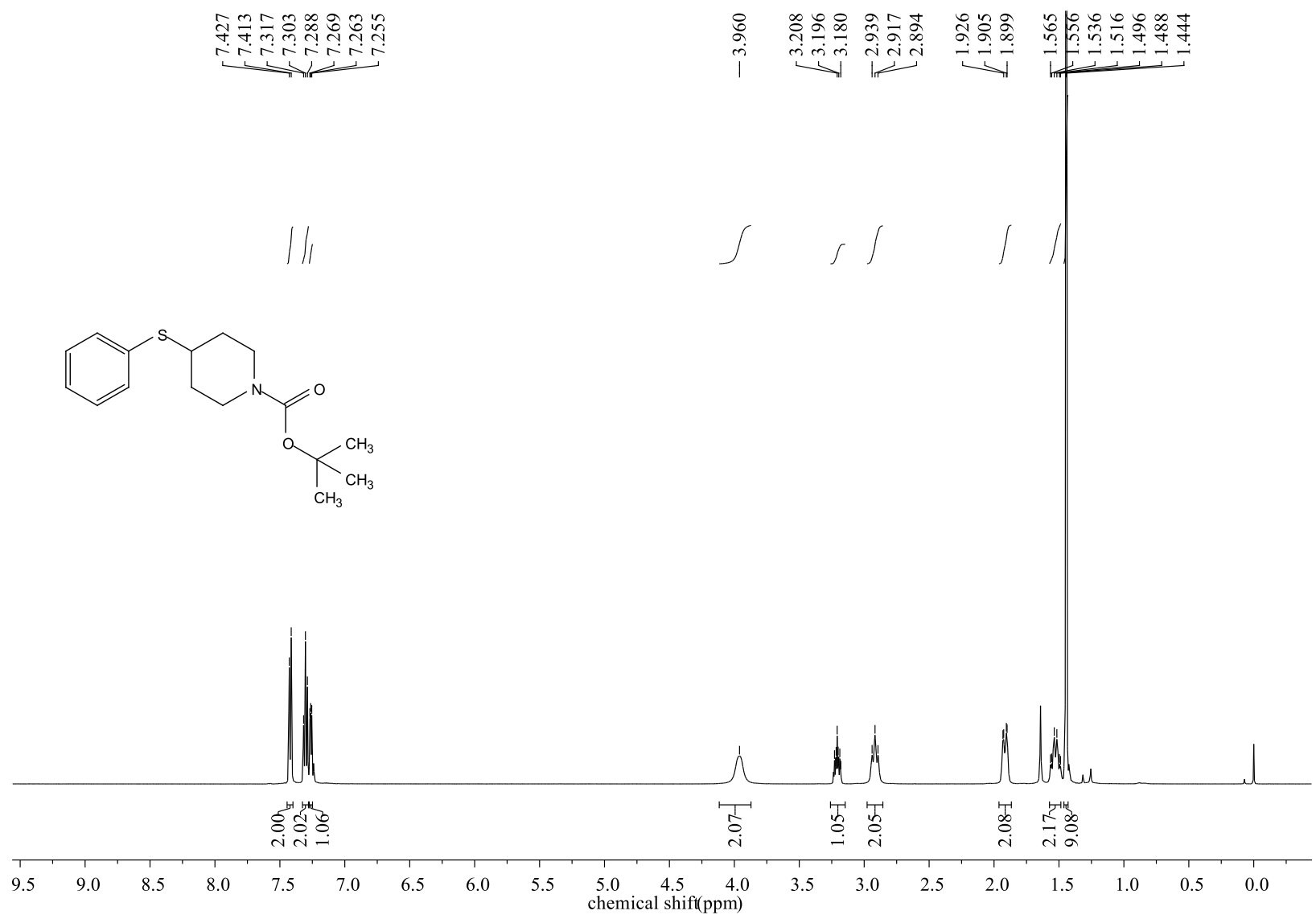

${ }^{13} \mathrm{C}\left\{{ }^{1} \mathrm{H}\right\}$ NMR of compound $9 \mathrm{a}\left(500 \mathrm{MHz}, \mathrm{CDCl}_{3}\right)$
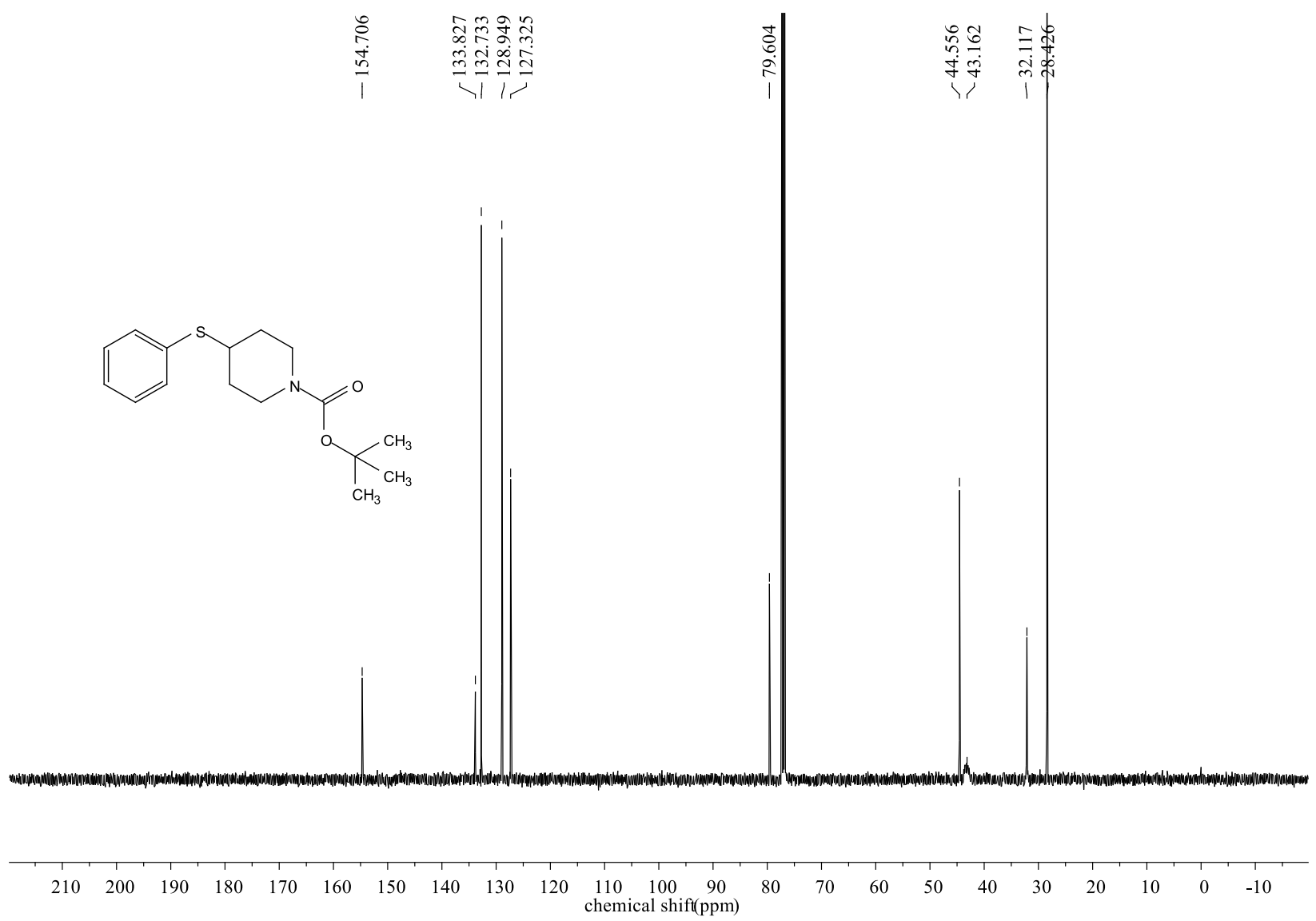

S34 
${ }^{1} \mathrm{H}$ NMR of compound $9 \mathbf{b}\left(500 \mathrm{MHz}, \mathrm{CDCl}_{3}\right)$
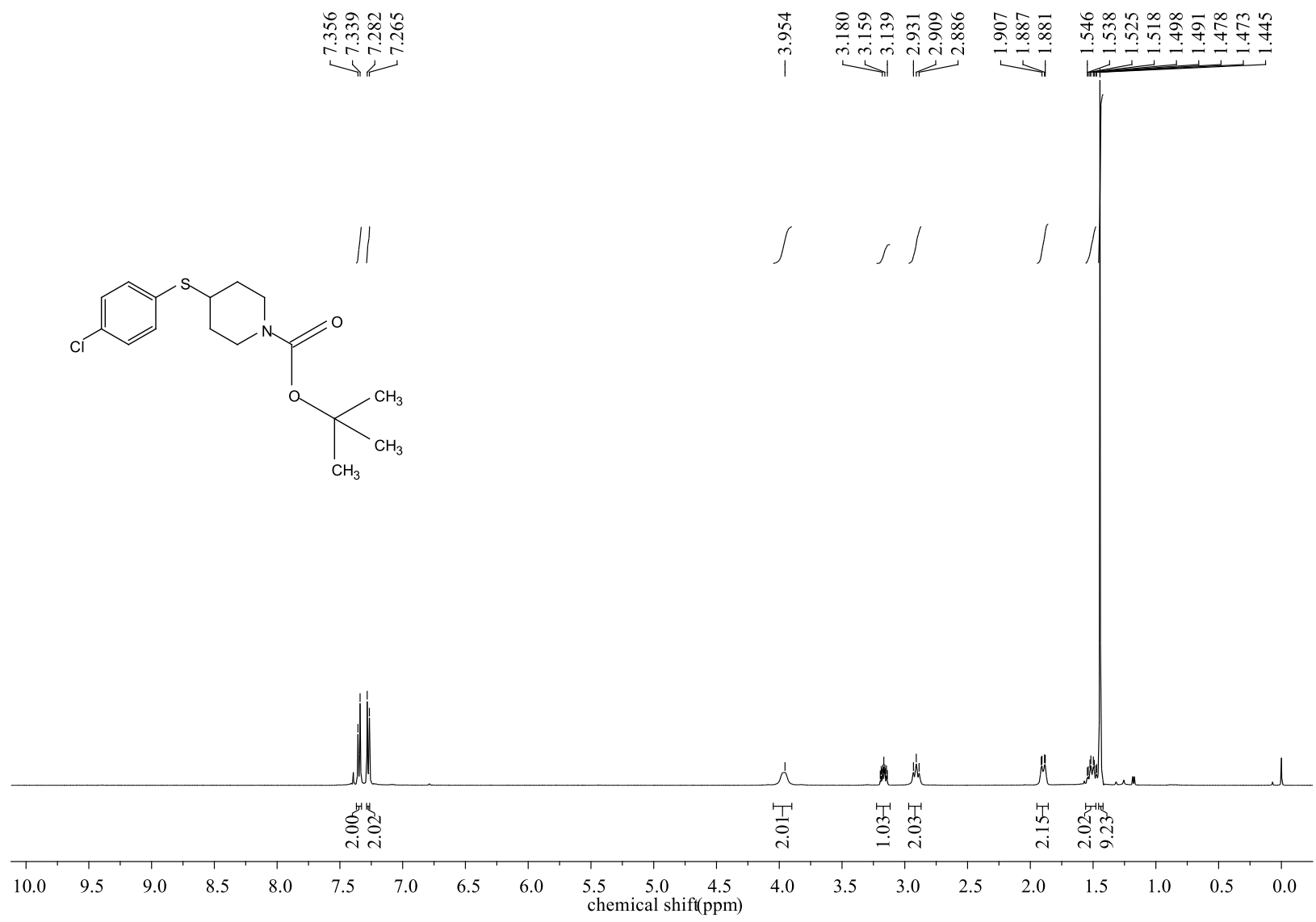

${ }^{13} \mathrm{C}\left\{{ }^{1} \mathrm{H}\right\}$ of compound $9 \mathbf{b}\left(500 \mathrm{MHz}, \mathrm{CDCl}_{3}\right)$

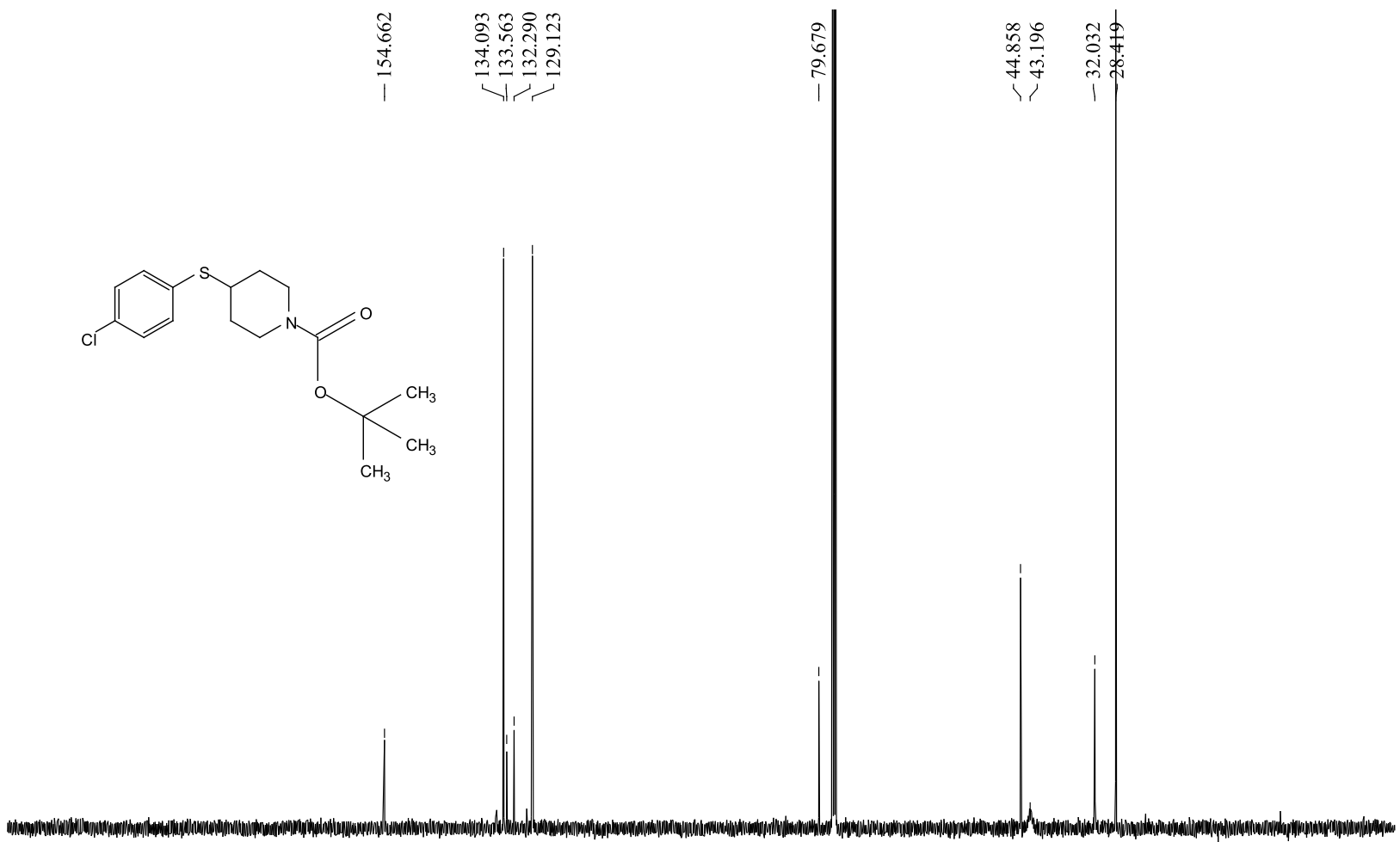

$\begin{array}{lllllllllllllllllllllllll}210 & 200 & 190 & 180 & 170 & 160 & 150 & 140 & 130 & 120 & 110 & 100 & 90 & 80 & 70 & 60 & 50 & 40 & 30 & 20 & 10 & 0 & -10\end{array}$ 
${ }^{1} \mathrm{H}$ NMR of compound $9 \mathrm{c}\left(500 \mathrm{MHz}, \mathrm{CDCl}_{3}\right)$

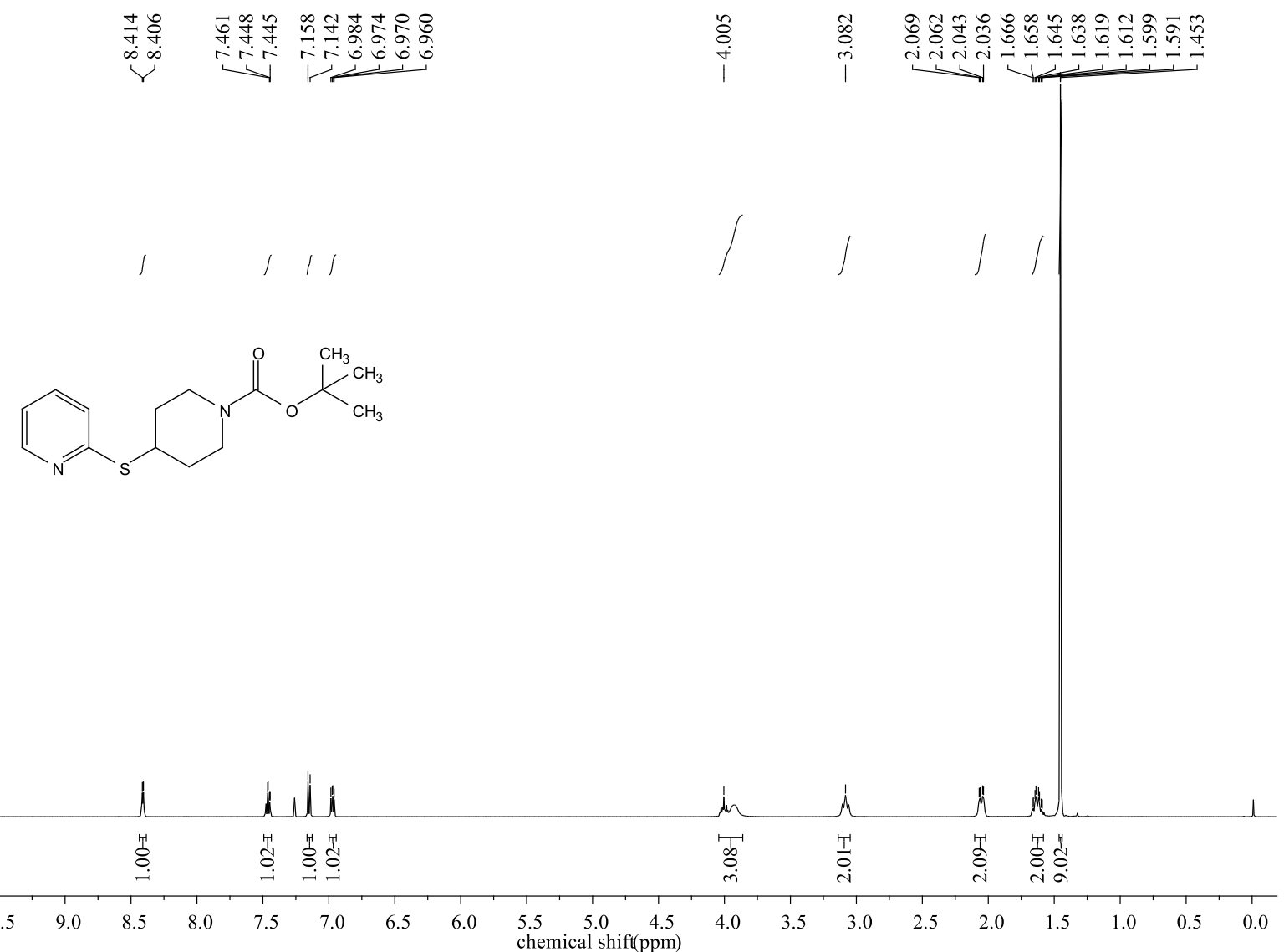

${ }^{13} \mathrm{C}\left\{{ }^{1} \mathrm{H}\right\}$ NMR of compound $9 \mathrm{c}\left(500 \mathrm{MHz}, \mathrm{CDCl}_{3}\right)$

$\begin{array}{llll}1 & 1 \\ 1 & 1 & 1\end{array}$<smiles>CC(C)(C)OC(=O)N1CCC(Sc2ccccn2)CC1</smiles>

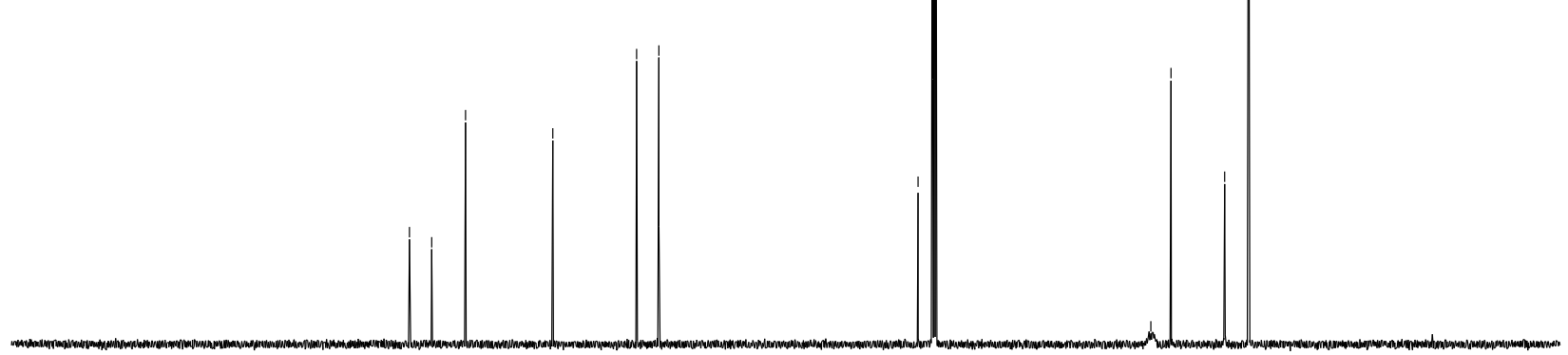

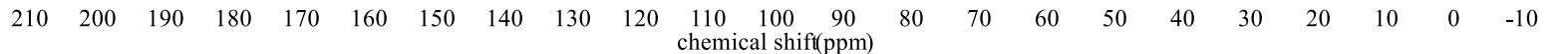


${ }^{1} \mathrm{H}$ NMR of compound $9 d\left(500 \mathrm{MHz}, \mathrm{CDCl}_{3}\right)$

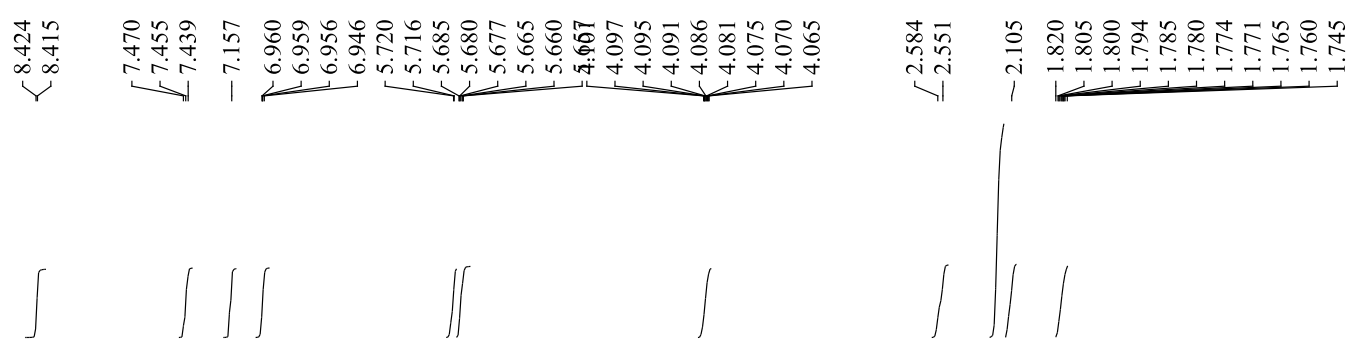<smiles>C1=CCC(Sc2ccccn2)CC1</smiles>

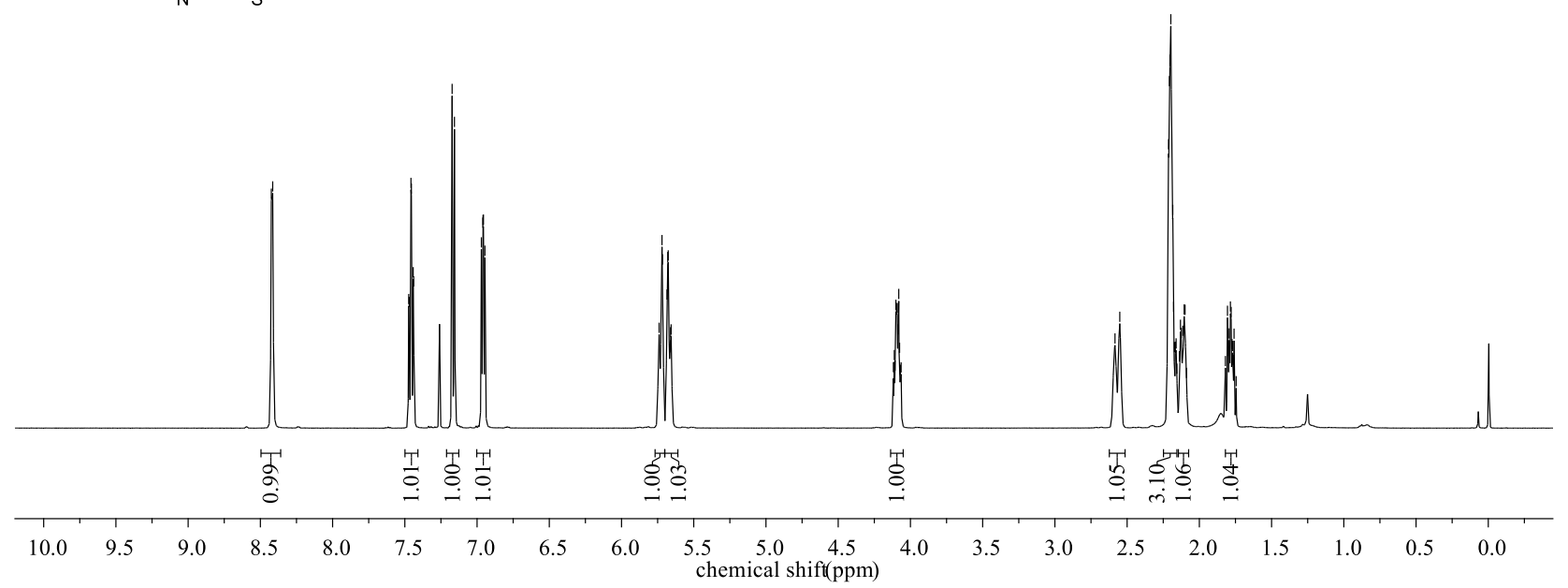

${ }^{13} \mathrm{C}\left\{{ }^{1} \mathrm{H}\right\}$ NMR of compound $9 d\left(500 \mathrm{MHz}, \mathrm{CDCl}_{3}\right)$

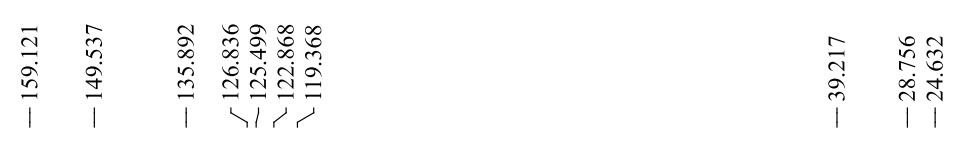

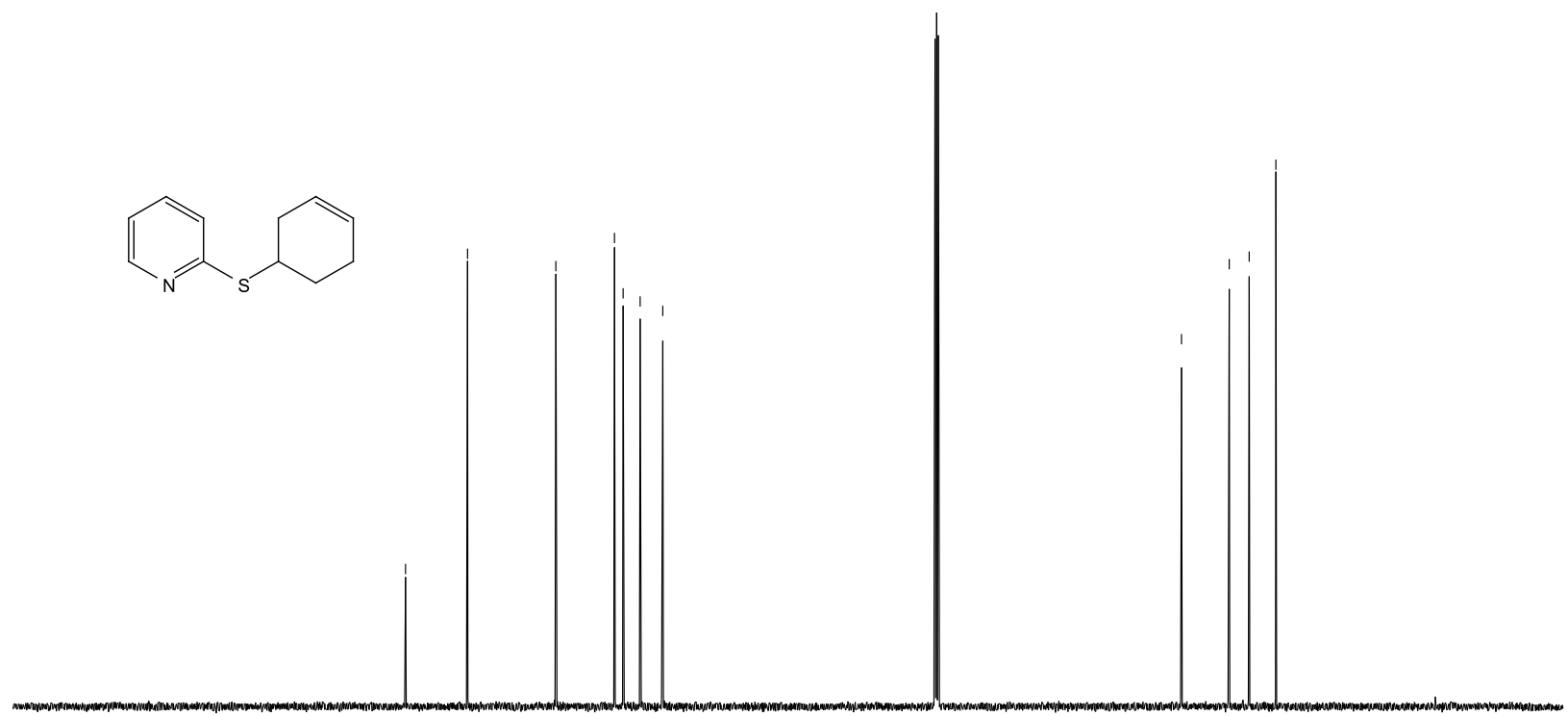

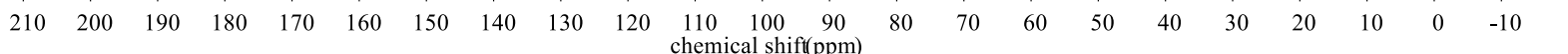


${ }^{1} \mathrm{H}$ NMR of compound $9 \mathbf{e}\left(500 \mathrm{MHz}, \mathrm{CDCl}_{3}\right)$
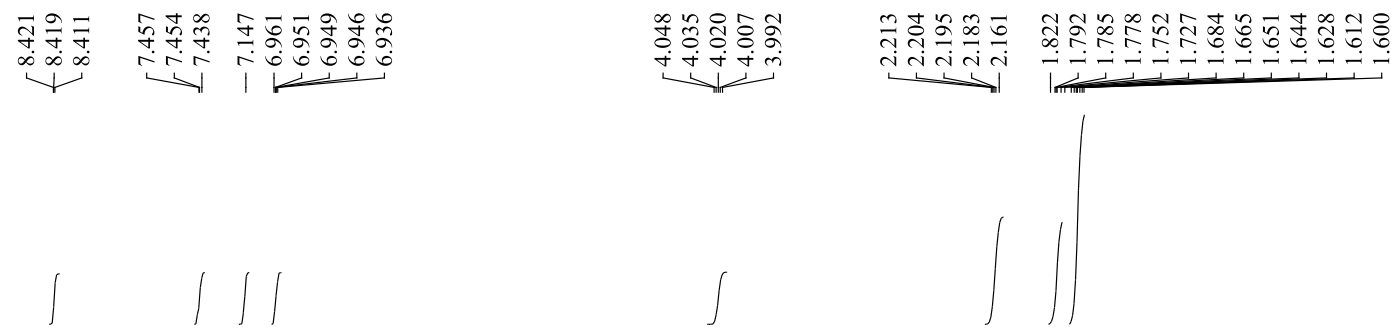<smiles>c1ccc(SC2CCCC2)nc1</smiles>

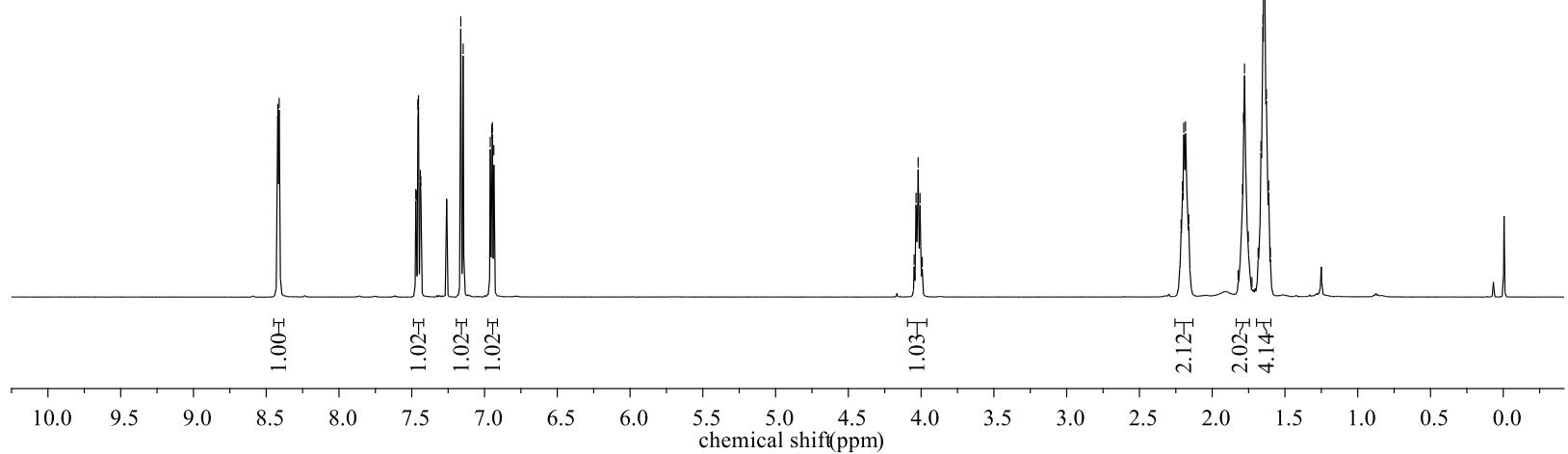

${ }^{13} \mathrm{C}\left\{{ }^{1} \mathrm{H}\right\}$ NMR of compound $9 \mathrm{e}\left(500 \mathrm{MHz}, \mathrm{CDCl}_{3}\right)$

$$
\begin{array}{lllll}
1 & 1 & 1 & 1
\end{array}
$$<smiles>c1ccc(SC2CCCC2)nc1</smiles>

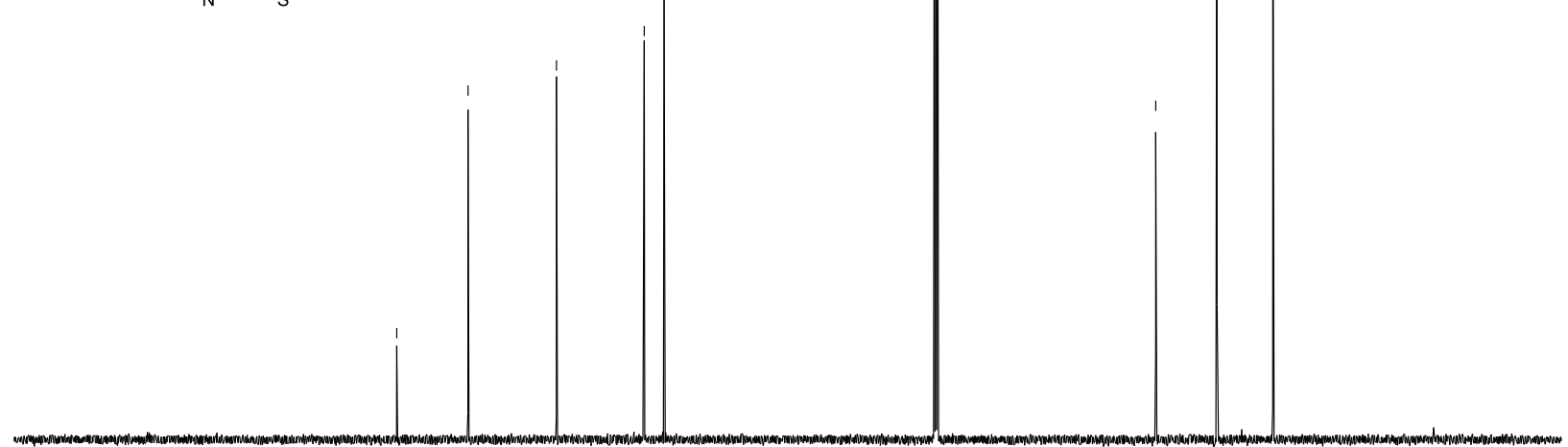

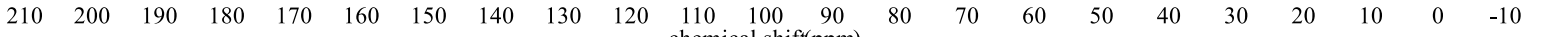


${ }^{1} \mathrm{H}$ NMR of compound $9 \mathrm{f}\left(500 \mathrm{MHz}, \mathrm{CDCl}_{3}\right)$

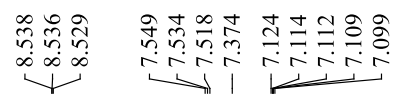
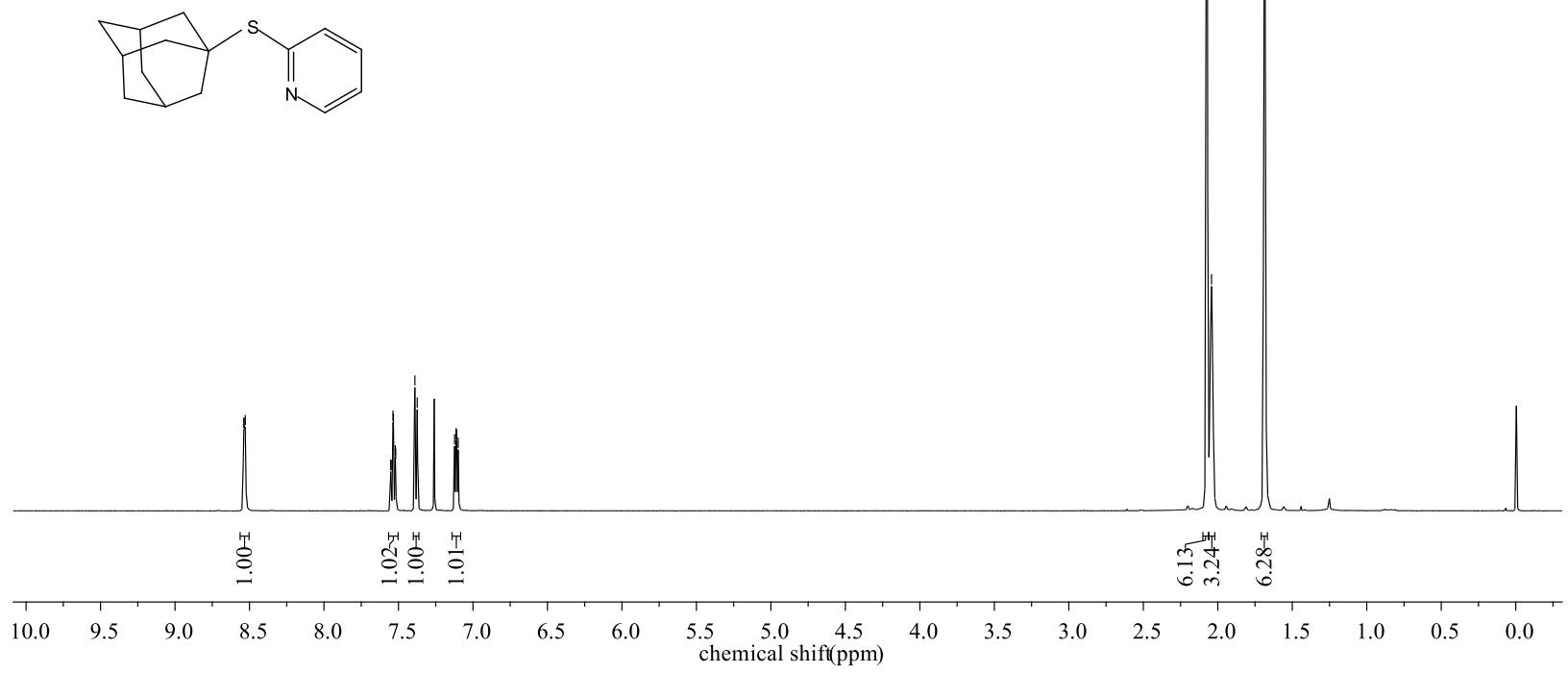

${ }^{13} \mathrm{C}\left\{{ }^{1} \mathrm{H}\right\}$ NMR of compound $9 f\left(500 \mathrm{MHz}, \mathrm{CDCl}_{3}\right)$
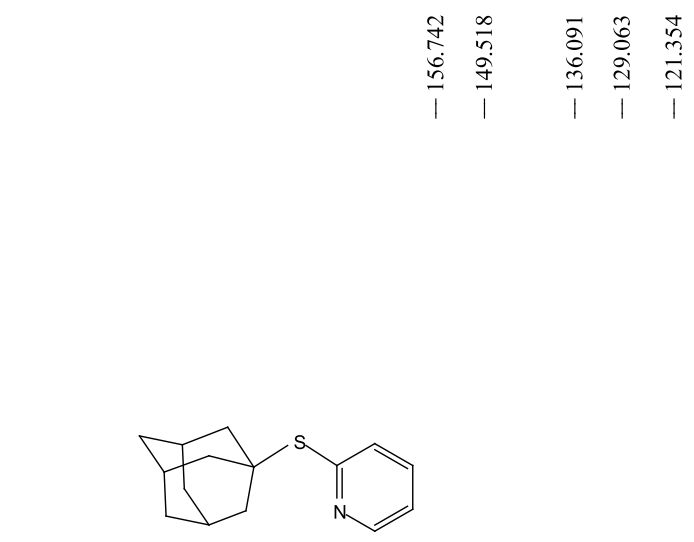

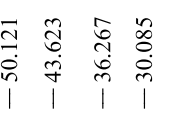

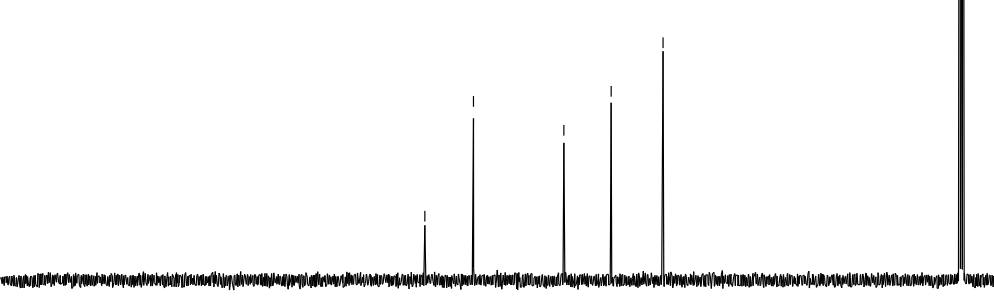

$\overbrace{}^{5}$ 
${ }^{1} \mathrm{H}$ NMR of compound $9 \mathrm{~g}\left(400 \mathrm{MHz}, \mathrm{CDCl}_{3}\right)$

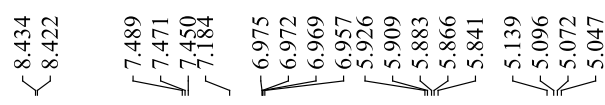

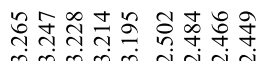

mimm nivin
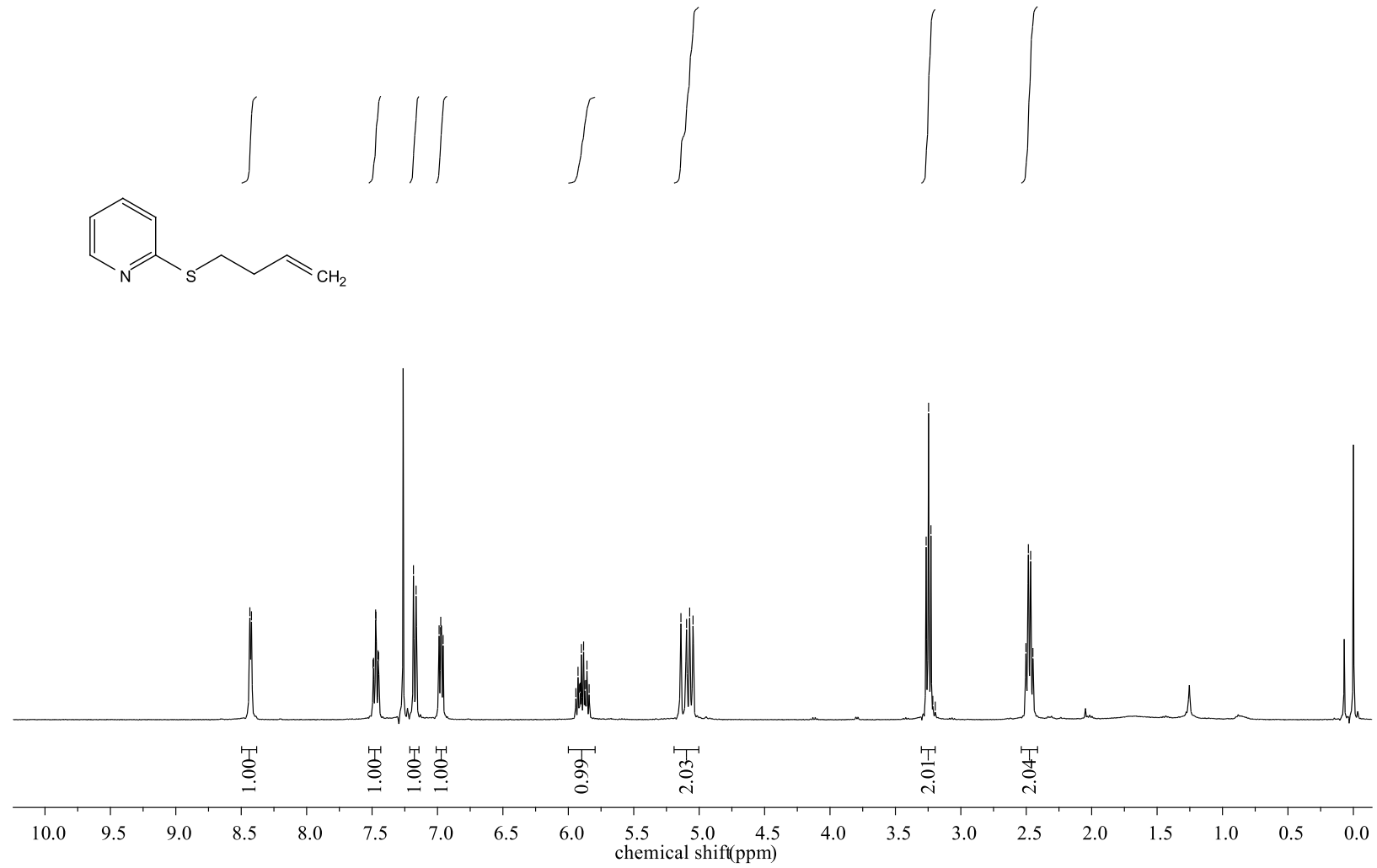

${ }^{13} \mathrm{C}\left\{{ }^{1} \mathrm{H}\right\}$ NMR of compound $9 \mathrm{~g}\left(500 \mathrm{MHz}, \mathrm{CDCl}_{3}\right)$

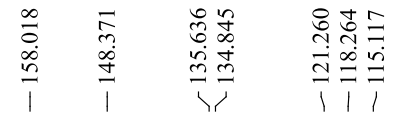<smiles>C=CCCSc1ccccn1</smiles>

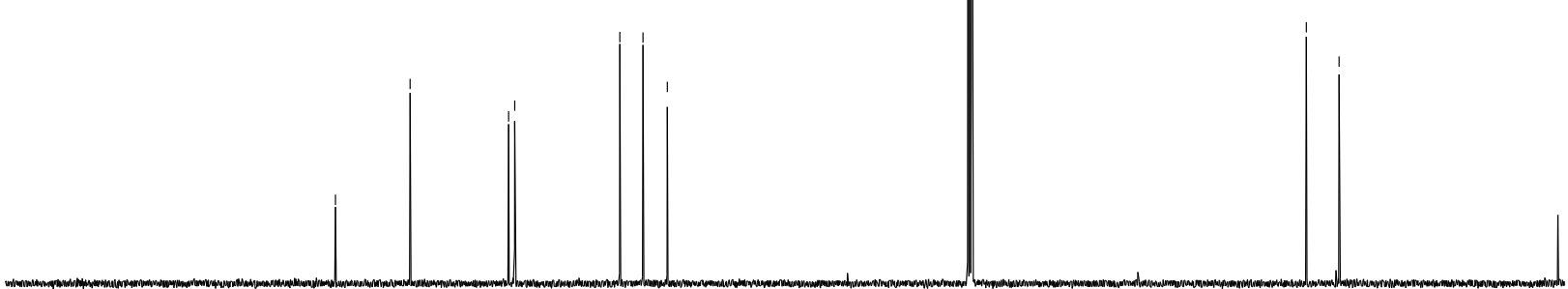


${ }^{1} \mathrm{H}$ NMR of compound $9 \mathbf{h}\left(400 \mathrm{MHz}, \mathrm{CDCl}_{3}\right)$
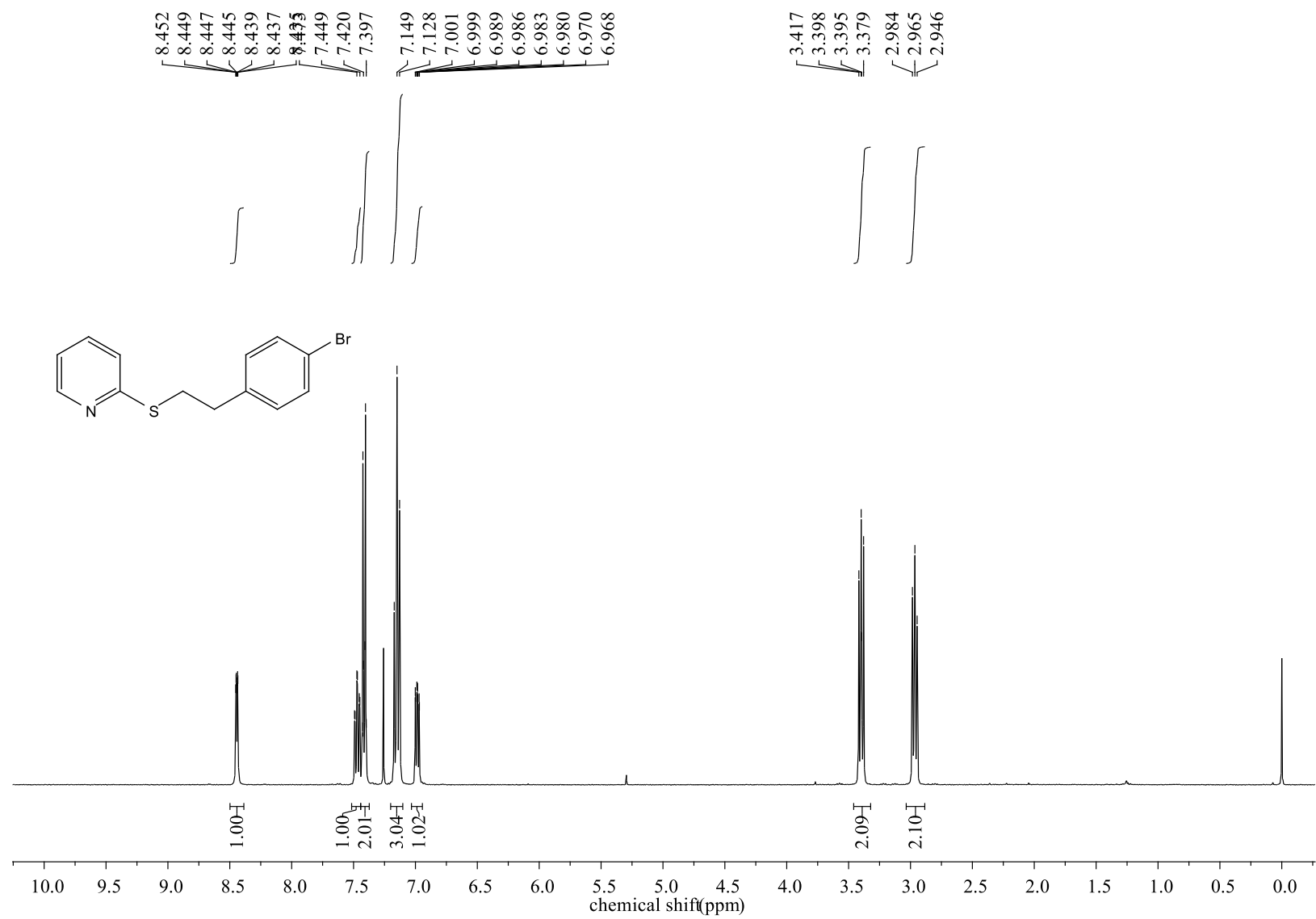

${ }^{13} \mathrm{C}\left\{{ }^{1} \mathrm{H}\right\}$ NMR of compound $\mathbf{9 h}\left(500 \mathrm{MHz}, \mathrm{CDCl}_{3}\right)$

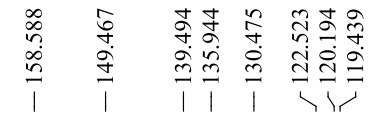

ĩ<smiles>Brc1ccc(CCSc2ccccn2)cc1</smiles>
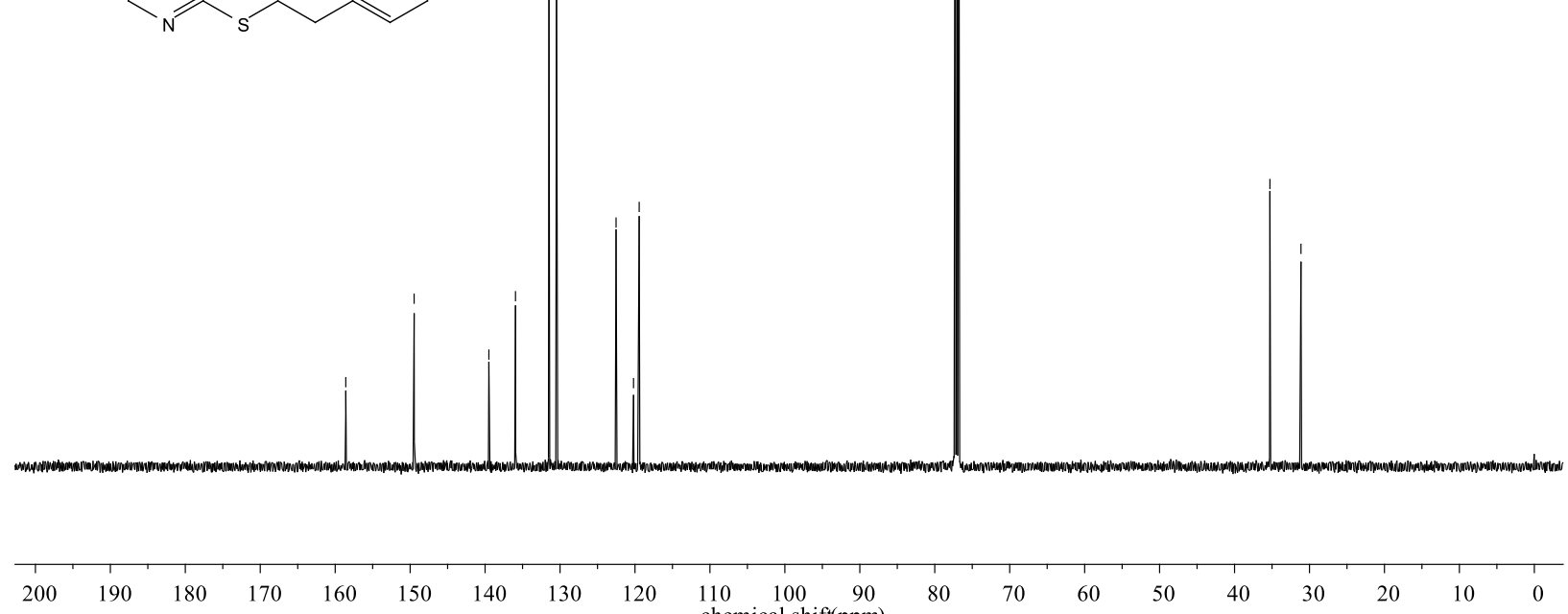
${ }^{1} \mathrm{H}$ NMR of compound $10\left(500 \mathrm{MHz}, \mathrm{CDCl}_{3}\right)$

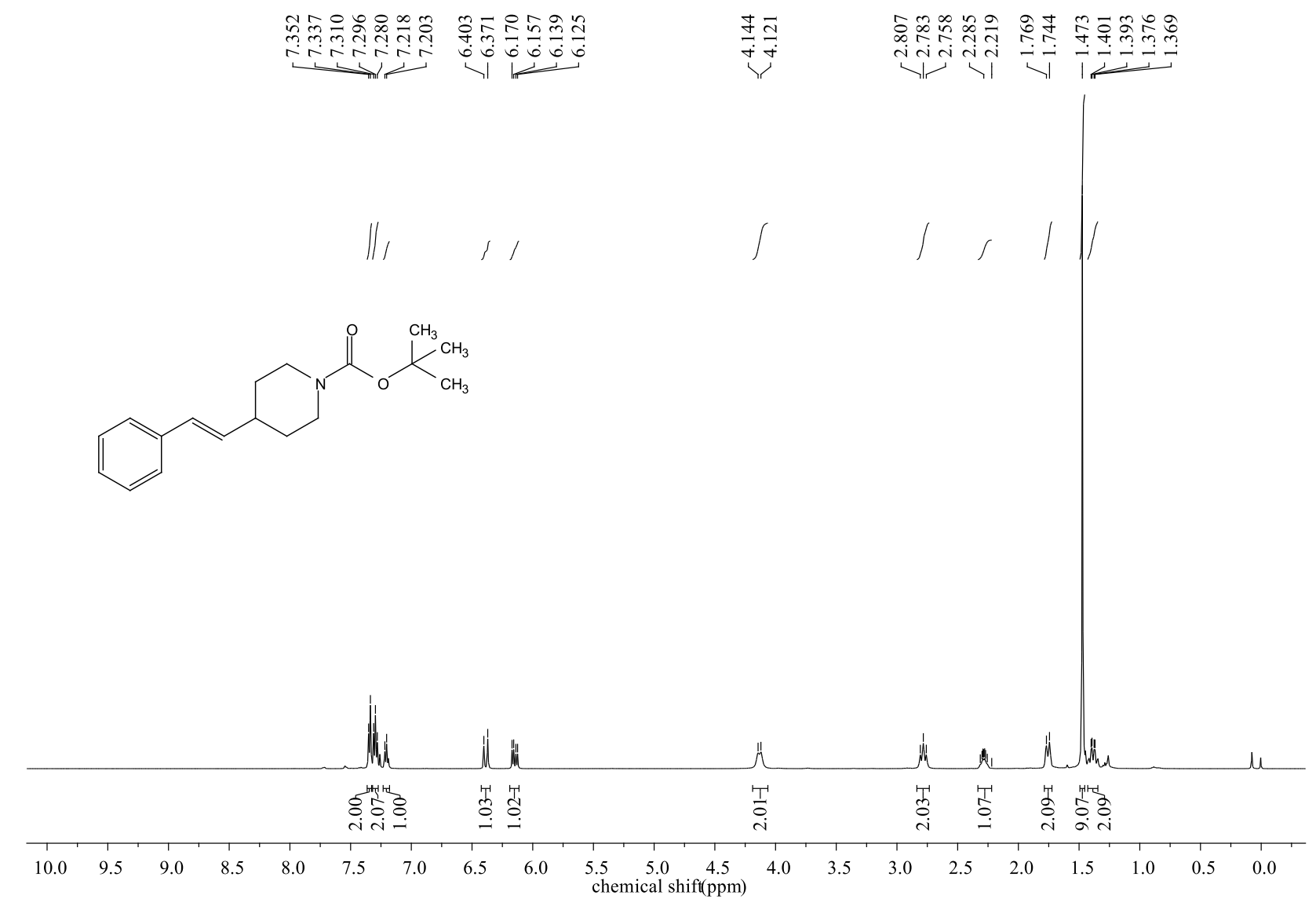

${ }^{13} \mathrm{C}\left\{{ }^{1} \mathrm{H}\right\}$ NMR of compound $\mathbf{1 0}\left(500 \mathrm{MHz}, \mathrm{CDCl}_{3}\right)$

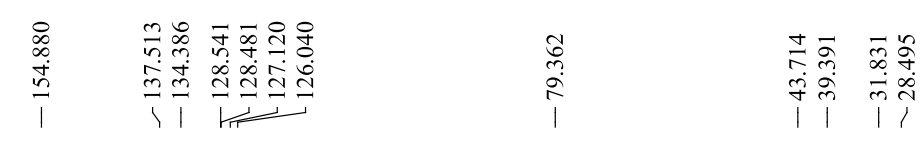

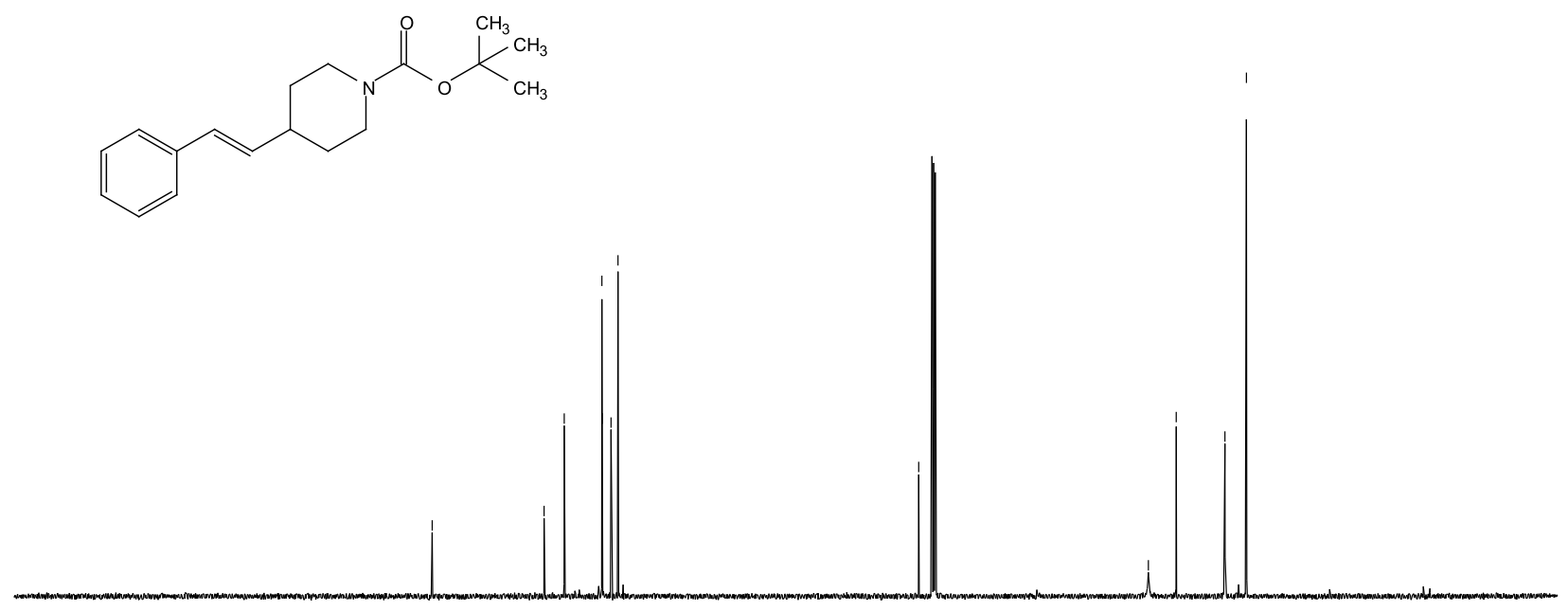

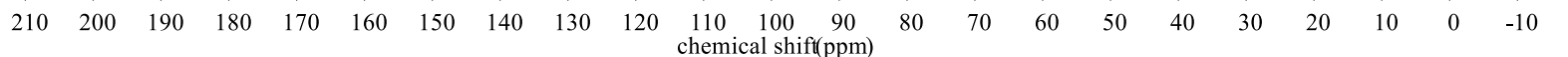

